\title{
The Problem of Formulating Design Problems A Typology of Design Briefs
}

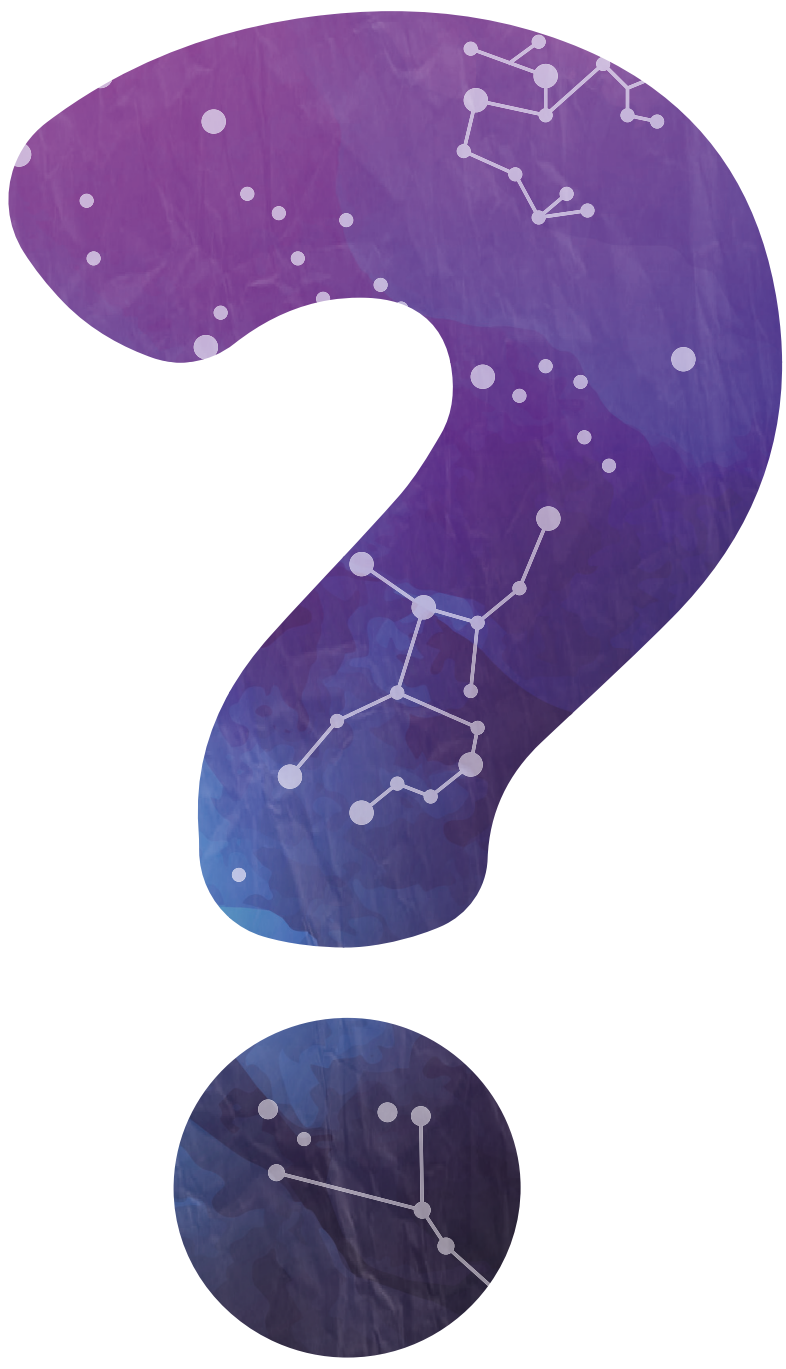



Linköping Studies in Science and Technology Licentiate Thesis No. 1895

\section{The Problem of Formulating Design Problems}

A Typology of Design Briefs

Juan Felipe Ruiz Muñoz

Division of Product Realization

Department of Management and Engineering Linköping University, SE-581 83 Linköping, Sweden

Linköping 2020 
Licentiate Thesis:

The Problem Of Formulating Design Problems A Typology Of Design Briefs

(C) Juan Felipe Ruiz Muñoz, 2020

Licentiate Thesis no. 1895

ISSN 0280-7971

Distributed by:

Division of Product Realization

Department of Management and Engineering

Linköping University

SE-581 83 Linköping, Sweden

Printed in Sweden by LiU-Tryck, Linköping, 2020 
A mi amada familia

"The second component of intelligence involves the elegance of interpretations of the experiences of life."

James G. March 


\section{Abstract}

It is common for a design team to be handed a problem to solve for others. The handing over is normally referred to as a 'briefing' process, and the documentation of the starting point and what is to be done is known as a 'brief'. It is known that the way we frame and understand a problem influences what paths we see to potential solutions. The aim of this thesis is to understand what makes a good design brief and to do so in order to create an empirically informed, and theoretically underpinned, typology of design briefs and the kind of search processes they are disposed to induce.

Different bodies of literature have tried to grasp how design solves problems in order to understand designer's behavior and ultimately facilitate or improve it. Distinctions can, and have been made, between different kinds of problem formulations, as well as different problem-solving approaches. This thesis aims to integrate two previously distinct literatures, search process from the organizational perspective developed by James G. March, Herbert A. Simon, Richard Cyert and others and Design and the Design Process from the perspectives of authors such as Donald Schön, Kees Dorst and Nigel Cross among others, to propose a typology of design briefs in order to ultimately facilitate problem formulation and subsequently facilitate the design process.

The simple and immediate answer to the question of what makes a good design brief is: 'that depends'. It depends on the design process to be followed (if there is one), it depends on the kind of goals that should be achieved, the time available, and it also depends on how much and what is known about the problem and potential solutions. Based on this, four ideal types of design briefs are articulated, including the expected associated search behavior and challenges of design teams. 


\section{Sammanfattning}

Det är vanligt att ett designteam får ett problem att lösa åt andra. Överlämnandet kallas normalt en "briefing" -process och dokumentationen av utgångspunkten och vad som ska göras kallas ett "design brief". Det är känt att det sätt vi ramar in och förstår ett problem påverkar vilka vägar vi ser till potentiella lösningar. Syftet med denna avhandling är att förstå vad som gör ett bra "design brief" och att göra det för att skapa en empiriskt informerad och teoretiskt underbyggd typologi av design brief och vilken typ av sökprocesser de uppmuntrar.

Olika litteratur har försökt förstå hur design löser problem för att förstå designerns beteende och i slutändan underlätta eller förbättra det. Skillnader kan och har gjorts mellan olika typer av problemformuleringar och olika problemlösningsmetoder. Denna avhandling syftar till att integrera två tidigare distinkta litteraturområden, sökprocess ur det organisatoriska perspektivet som utvecklats av James G. March, Herbert A. Simon, Richard Cyert och andra samt Design och designprocessen ur perspektiv av författare som Donald Schön, Kees Dorst och Nigel Cross bland andra för att föreslå en typologi av design brief för att underlätta problemformulering och därmed också underlätta designprocessen.

Det enkla och omedelbara svaret på frågan om vad som gör ett bra design brief är: "det beror på". Det beror på designprocessen som ska följas (om det finns en), det beror på vilken typ av mål som ska uppnås, den tillgängliga tiden, och det beror också på hur mycket och vad som är känt om problemet och potentiella lösningar. Baserat på detta artikuleras fyra idealtyper av design brief, inklusive det förväntade associerade sökbeteendet och utmaningar för designteam. 


\section{Acknowledgment}

It is often said that it takes a village to raise a child. I wouldn't know anything about that given that I don't have children, nor do I live in a village. However, I can for sure tell you that it takes a small army of loving and helpful people to raise a Ph.D. student... even if it's only to the point of a licentiate. That being said some special thanks are in order.

First and foremost, I must thank the people who made me the person that I am, and for that I must turn to Spanish... don't worry I will be back in English. A toda mi amada familia, el logro que este libro representa no seria posible sin el apoyo y amor incondicional que siempre me han dado. Papá y Mamá, gracias por todo el amor, los sacrificios y el continuo apoyo durante toda mi vida. Sin importar cual fuera mi nueva meta o aventura, siempre estuvieron detrás mío respaldándome y acompañándome con todo el amor del mundo. Hermanita, Víctor, Valeria y Valentina, el apoyo y el amor que siempre me han dado es gran parte del motor que me traído hasta acá.

To my beautiful wife Maju, thanks for the love and the patience. Thanks for not only understanding but also supporting me every single day through the long hours, the weekends at work and the lost vacations. Without you by my side, it would have been impossible.

To my advisors, I will forever be thankful. Renee, thank you for taking a huge chance on me, supporting me every step of the way, and for your everpositive outlook on every piece of text that I create. Marie, I will never be able to thank you enough for everything that you have done for me. From pushing me to be the best that I could be (even if I didn't believe in myself at times) to hosting my family in your home as if they were your own. 
To my officemates Philip, Wanjun, Malin, Fredrik, Ludwig, thank you for making everyday fun (maybe a little too fun) it has been a pleasure working everyday side by side with you. I will also like to extend this to all of my fellow Ph.D. students from both Machine Design and Business Administration every fika, AW, and other random activities have been a source of good and happy moments that help to always keep the spirits up.

I will also like to thank all of my multiple academic homes. To the people at Javeriana University in Cali for helping me get started in both the design and the academic life. To Maria Fernanda, thanks for taking a chance on me as a student, that is where it all began. To Juan Pablo for bringing me in as part of the Teaching Team and then giving me away to the Swedes. To every single person in Machine Design, Business Administration, the SMIO program and the SUGAR Network, it is my pleasure to work and learn from all of you.

To the people at the Stanford ME310 program, specially to George Toye and Larry Leifer, for everything I have learned about design and teaching from you, but also for allowing me to use the course as an inspiration for this thesis.

Finally, there has been so many people that have helped me, given me advice, loved me and even lent a shoulder when I was tired of reading and writing. If your name was not listed, believe me that I am greatful for every single one of you and for helping me to get to this point.

Gracias... totales. 


\section{Contents}

1. A Brief Introduction 11

1.1 Design Process as a Creative Search 14

1.2 Research Question and Aim 15

1.3 The Data and the Methodology 17

1.4 Thesis Outline $\quad 18$

2. A Brief Theoretical Background 21

2.1 Problem Formulation 21

2.1.1 Design Problems 21

2.1.2 Problem Formulation $\quad 23$

2.1.3 The Design Brief 26

2.2 Design Field 28

2.3 Design Paradigms 32

2.3.1 Paradigm of Rational Problem-Solving 32

2.3.2 Paradigm of Reflection-in-Action 34

2.3.3 Bridging between paradigms $\quad 35$

2.4 Design Process as a Search Process 39

2.5 Stages of a Search Process 44

2.5.1 Pre-Search Stage 44

2.5.2 Search Stage $\quad 48$

2.5.3 Selection and Adoption Stage $\quad 50$

3. A Brief Explanation of the Method 53

3.1 Introduction 53

3.2 Science and Research 54

3.3 Inspiration $\quad 56$

3.4 The Data Set $\quad 58$

3.4.1 Design Projects 58

3.4.2 The ME310 Intended Design Process 61

$\begin{array}{ll}\text { 3.4.3 The Briefs } & 67\end{array}$ 
3.5 Building the Codex 68

3.5.1 Typology vs Taxonomy 69

3.5.2 Characteristics of a Brief 70

3.5.2.1 First Codex Prototype 71

3.5.2.2 Second Codex Prototype 75

3.5.2.3 Final Codex Prototype $\quad 81$

4. A Brief Explanation of the Use of the Codex 87

4.1 Applying the Codex to the Briefs 87

4.2 Information Obtained From the Design Briefs 89

4.3 Grouping and Clustering 93

5. A Brief Typology 103

5.1 Grand Theoretical Assertion 103

5.2 Typology 107

Design Brief Type I: Directed Search 107

Design Brief Type II: Problem Oriented Search 112

Design Brief Type III: Solution Oriented Search 118

Design Brief Type IV: Discovery Oriented Search 124

6. A Brief Discussion of Outcomes and Future Possibilities 131

6.1 Thinking/Talking Tool 131

6.2 An Example of How This Can Be Used 137

6.2.1 The Typology In A Known Search Process 137

6.2.2 The Typology in a Setting With Multiple Goals and

Differing Levels of Expertise $\quad 142$

6.3 Future Work 143

7. A Not So Brief List of References 147 
A Brief

Introduction

01 


\section{Chapter 1}

\section{A Brief Introduction}

The practice of design is one that is associated with the making of things (Lawson, 2006; Nadler, 1980). However, the discipline and the professional practice of design goes beyond only the making, and it also involves the process used in the invention of things (Gregory, 1966) and the transformation of needs and requirements to solutions that generate value (Archer, 1979; Cross, 1982). This means that the creation of something that is new and innovative that deviates from what currently exists is something very familiar for designers of all fields. In order to be able to create new solutions to a problem, designers embark on the process of discovery and mapping of the problem (Hatchuel \& Weil, 2009) while searching for possible solutions that could yield the preferred results.

In the professional practice of design, it is quite common that the process of search, design and development of projects is not executed by the same people who identified the need for such projects and who commission them, creating a client-designer partnership (Wever et al., 2019). In these cases, the client identifies a dissatisfaction or desire for better performance that then is translated into action to solve it (Chen, 2008; Nadler, 1980). The identification of the dissatisfaction normally does not appear in a single moment or in a vacuum, but 
rather it happens in a progression of time and in the context of the clients' organization (Nadler, 1980).

Once the client has identified a desire for a novel solution, there is a need to transfer the information that leads to the design project to happen. One of the main reasons for this transfer of information between the client and the designers is to provide an orientation of the task (Sosa et al., 2018). The transfer is normally handled with the production of an explicit agreement where the parties involved, specify the "what?" and the "how?" of the project. The process of making explicit these questions culminates in an agreement that can be as informal and short as a single sentence, or it can be as formal and detailed as a legal contract. Irrespective of its form, this agreement is normally referred to as a design brief, and the overall process of transfer is called the briefing (Blyth \& Worthington, 2010; Ryd, 2004).

However, the design brief serves as more than merely the transfer of information. The brief as a starting point document for a design project can also serve the purpose of directing the design efforts (Koronis et al, 2019). It can serve as a point of reference that can be used to evaluate the outcome of the project (Bogers et al., 2008). And it has also been noted that it serves as a starting point for the framing and reframing of the problems as more knowledge is gained by the designers during the process (Paton \& Dorst, 2011).

The design brief is often where we find the first attempt at representing the problem and/or the solution that is desired as an outcome, and even though the starting point does not necessarily dictate the outcome, it plays a key role during the development of the project (Koronis et al., 
2019; Sosa et al., 2018). In design and problem-solving literature, we can find consensus of its importance, given how problem formulation determines the problem to be solved and consecutively its solution (Hayes \& Simon, 1977; Simon, 1973; Volkema, 1983).

Based on the current efforts in design research to understand the process of design briefing we can note its importance and influence in determining the later stages in the creative search for solutions of designers (Baer et al., 2013; Blyth \& Worthington, 2010; Bogers et al., 2008; Lawson, 2006; Nadler, 1980; Paton \& Dorst, 2011; Sosa et al., 2018; Volkema, 1983). However, in practice it remains a hard task.

One reason for this difficulty is that design problems are largely illdefined or ill-structured (Buchanan, 1992; Cross, 1982; Simon, 1973). Which means the problem is not fully known making it harder to describe and synthetize it in a single document. Another difficulty is that no design process is exactly the same and so design briefs are also not standardizable. Each type of creative search will contain different types of variables which should be included in the brief. However, in a study conducted by Bogers, Van Meel and van der Voordt, (2008) they found discontent among 80 percent of the respondents with design briefs that were not tailormade to the "unique nature of the project".

The creation of the design brief, as previously mentioned, begins with the client's identification of the need to search for a new design outcome. However, many times the clients are inexperienced in the creation of briefs and struggle to communicate properly with the designers involved (Dell'Era et al., 2011; Koronis et al., 2019). In the same study as previously mentioned half the respondents answered that they would like to be involve in the briefing process which can 
also show the frustration and desired for a more participative role in the transfer of information between client and designer.

\subsection{Design Process as a Creative Search}

In order to better understand the role that the design brief plays in the design process, we must then look at the whole process. One of the main paradigms that has been used in order to understand the process in which designers look for new solution is the one in which design is regarded as a search process (Cross, 1999; Dorst, 2003; Newell \& Simon, 1972; Simon, 1969). In order to be able to create new solutions for a given problem, they have to embark on the process of searching and exploring possible ideas that could yield the desired results.

The search can be understood as the exploration of unknown, rugged landscapes full of peaks that maps the desired attributes. In this rugged map, each peak represents a combination of possible outcomes, and the searchers' job is to locate a peak that represents a desired solution (Billinger et al., 2014; Gavetti \& Levinthal, 2000; Levinthal, 1997). From the perspective of design, we can add that the exploration is been made simultaneously in two landscapes or spaces, one being the problem space and the other the solution space. The problem space can be understood as the area that contains the attributes that describe the problem that is being solved and the solution space the area that contains the attributes that make up the desired solution (Remington \& Pollack, 2016). The implications of defining both the problem and the solution into spaces mean that a search within those areas can be conducted to find a desirable combination of attributes that can make up problem and solution that better satisfies the desired outcome. 
This theoretical model of search forms part of the perspective on organizational studies developed by Herbert Simon, James G. March and Richard Cyert. From here on a school of thought has then expanded through many researchers in what has come to be known as the Carnegie School of organizational theory. From this school of thought and with the inclusion of others such as John Dewey we can discern three stages of the exploratory search.

First there is an initial pre-search stage, in which the desire to look for new goals and how-to best attempt at looking for said goals is established. The second stage refers to the process of searching for actual ways to reaching said goal. And finally, a stage in which a solution is selected and adopted as the new desired behavior. Each of these stages are of great importance to obtain a satisfactory goal. However, one could argue that the pre-search stage is rather important as it would set the stage for the proceeding search process. A better understanding of the task at hand will in the end produce a more intelligent identification of the alternatives to sample (Nelson, 1982).

\subsection{Research Question and Aim}

Given that the design search process is in the province of exploring the unknown (Campbell, 1960) and the invention of things that do not yet exist (Gregory, 1966) it becomes impossible to standardize how a problem is formulated in the design brief. No search is exactly the same and so briefs are also not the same. However, based on the design and search literature and the study done in this thesis, we can find that design briefs share common traits and characteristics. By clustering briefs based on these shared traits we can then identify 
types of briefs, that can help us understand better the consequences that they can have in the rest of the design search process.

Purpose: Based on this, the purpose of this study is not to create a fillin-the-blanks template to draft the perfect brief. Rather, this thesis aims to understand what makes good design briefs.

Also, an important goal for me as author is to provide practitioners a tool that helps to think, and later discuss with the different stakeholders, the elements that are known about the problem and the desired goals for a search and reduce the mismatch in communication between clients and designers. By providing a thinking/talking tool and a typology of briefs, a discussion between the parties can be facilitated around the desired outcomes and desired processes with ideal types as a common point of understanding.

In order to make a contribution towards this ultimate objective, the following question has been formulated for the current study:

Question 1: Based on the existing literature on search, design and problem formulation what are different characteristics or dimensions that can be used to describe design briefs?

Question 2: Based on the characteristics of problem formulations found in different design briefs what are different types of design briefs?

Question 3: Based on the existing literature on search and design process what are the different characteristics or dimensions of a search process that could be influenced by the different types of formulations? 
Question 4: Based on the different types of problem formulations in design briefs and the literature on search and design process what are possible consequences of each type to the search process?

\subsection{The Data and the Methodology}

For this thesis a set of data coming from university student projects from the ME310 Design Innovation and product development course at Stanford University will be used. Despite the projects being set in a university setting, the problems that each design team received is unique and came from a real company, which has made a substantial financial commitment to the project. The data obtained from these projects contains the initial briefs of 118 design projects across 14 years. Each design brief is the initial problem formulation as presented from a client (company) and received by the design team (students $\&$ teaching team) as their first point of contact with the problem. In this sample, the briefs span across multiple industries, and each formulation is unique and not repeated. The briefs are also diverse in their format, length and content.

The methodology that was used in this study can be describe as an abductive approach. A set of characteristics from the theoretical perspective of problem solving and problem formulation and from empirical observations were identified and then each brief was classified based on these characteristics. Initially, a first round of theoretical definition of problem formulation was used to identify the anatomy of a brief and the most important characteristics that make up a description of a problem or a problem area. Consecutively, these characteristics where used as a codex to classify each brief. However, after a first round of classification and based on the information found 
in the data, some characteristics were identified as missing from the initial codex. This then led to a second round of theoretical definition of the missing characteristics on the initial codex. Moreover, other empirical characteristics that where observed in the data were also added to the codex. Then, the last version of the codex was then used to classify each design brief. With the information obtained from the classification of the briefs, clusters were formed based on the characteristics shared by multiple briefs. And subsequently a typology was created based on these characteristics. The next step on the process followed a similar pattern of theoretical and empirical identification of characteristics of search processes that can be influenced by the type of formulation. Finally, these characteristics where used to create the types in in the typology that is the result of this thesis.

\subsection{Thesis Outline}

This thesis is divided into 6 chapters. And they are as follow:

\section{Chapter 2. A Brief Theoretical Background}

This chapter will introduce the theoretical foundation that was used in this thesis. The literature that would be introduced in this chapter will be in the fields of search, organizational studies and design. More specifically this chapter will examine search as a design paradigm, which includes the stages of a search process, search as a landscape exploration and different aspects of search as a problem-solving mechanism. This chapter will also examine the literature on problem formulation and design briefs from the perspective of search and design. 
Chapter 3. A Brief Explanation of the Method

This chapter will introduce the research approach that was taken in order to create this thesis. This will include the approach and design of the research, the data that was used, the abductive creation and use of a classifying codex and the coding of the data.

\section{Chapter 4. A Brief explanation of the Use of the Codex}

This chapter will contain the data that was analyzed with the used of the classification codex and the group and clustering of the data according to the characteristics found in them and the foundation of the typology.

\section{Chapter 5. A Brief Typology}

This chapter will present the typologies created and will serve as the results and findings of this thesis.

\section{Chapter 6. A Brief Discussion of Outcomes and Future Possibilities}

The last chapter will be used to present the final discussions and to indication of future studies that have been identified as the next step in expansion of the research created by this thesis. 


$$
\text { A Brief }
$$

\section{Theoretical}

Background 
Chapter 2

\section{A Brief Theoretical Background}

\subsection{Problem Formulation}

\subsubsection{Design Problems}

Throughout this thesis the topics that will be discussed relate to the design process, behaviors of designers and the situations or problems in which designers work. However, of these topics the one that is most important for the work here portrait, relates to the kind of problems that the design practice addresses from the perspective of researchers such as Simon, Archer, Cross, Buchanan among others. They propose that design problems, that require creativity for their solution (Reitman, 1964), are characterized by being ill-define, illstructured and some might be even 'wicked'.

In an attempt to better understand what this means we can examine what are the different attributes that make these problems ill-defined or ill-structured. To start off, we may need to clarify that in the literature both terms, 'ill-define' and 'ill-structure', have been used and may even be used interchangeable (Oxford Reference n.d.). However, in this thesis I would like to present the definition that both terms have been given by different authors. Not with the intention of discussing them as separate terms but rather to provide better understanding of what can be well or ill defined. 
First, Ill-defined problems have been identified in the design literature as problems in which the elements of the problem that have been given do not have sufficient information to allow the designer to arrive at a solution by those elements alone (Archer, 1979). The information provided might even be confusing and conflicting given the many views and values of several stakeholders (Buchanan, 1992 quoting Rittel, 1967). Even more, all information regarding the problem might never become available to the designer, which limits the possibility to fully comprehend the problem to produce the one optimal solution (Cross, 1983).

Secondly, Ill-structured problems have been identified as problem in which the structure of the problem lacks definition (Simon, 1973). Ones in which the problems are not perfectly stated by which solvers need to investigate the problem space in order to fence it appropriately (Simon, 1973; Voss, 2005). This is strongly connected with what has been said before in the definition of ill-defined problem, however, the interesting thing that this second term provides is the notion of problem structure. Simon proposes that it is "impossible to construct a formal definition" (Simon, 1973, p. 182) for what a well-structured and, subsequently, an ill-structured problem is. He rather proposes that we can identify them based on a criterion of characteristics that the problem poses and how well or ill-defined they are. These characteristics are goal definition, knowledge of problem domain, a criterion for solution, possible solution paths, and limitations or constrains (Simon, 1973; Goel and Pirolli, 1992; Smy, Cahillane and MacLean, 2016).

With the specification of this characteristics and their definition we can better envision what makes a problem well-defined or ill-defined, it is important to also note that problems are not binarily spread in 
these two extremes. They rather inhabit in the spectrum in between well-defined and ill-defined (Fernandes and Simon, 1999; Smy et al, 2016) as different characteristics of the structure have more or less definition.

Furthermore, designers continuously define and redefine the problem in order to provide themselves with structure and boundaries to perform the search for solutions. This has important implications for the definition of the structure of problem in the design process given that "structure is not a stable problem characteristic" (Smy et al, 2016, p. 187). As the design process progresses the structure of the problem also changes. Goals are established, criteria for a satisfactory solution are set and more information of both the problem and the solution spaces becomes available.

Before the process of problem formulation is explained it should be added that the following sections would be divided into two parts. The first is concerned with how a problem is identified and formulated (problem formulation) from a general design perspective. The second one is concerned with the problem formulation process in the design practice context and the document that contains the formulation along with elements of the ensuing process (design brief).

\subsubsection{Problem Formulation}

In the previous subsection, the theoretical perspective of the type of problems designers tackle in regard to the problem structure and its characteristics, was presented. However, it has not yet been discussed how and by who do these characteristics get definition before the design process starts. 
Before any design project starts there is the detection of a need for action that motivates the kickstart of the process. This detection might come in many different ways. It can either be a discovery of a problem or a need that it is not being met or just the identification of the existence of an opportunity (Volkema, 1983). In other cases, where organizations search for design solutions, the motivation might come from a dissatisfaction or poor performance based on a mismatch between current performance and the aspirational performance (Nadler, 1981; Chen, 2008). Or in some other cases it might come from a slack in resources that prompts an aimless search (Cyert and March 1963). Any of these motivations then is translated into a specification of 'what?', 'Why?' or even 'how?' that becomes the problem formulation.

\section{Difficulties in the formulation}

It is quite common, in the professional practice of design, that design projects are not executed by the same people who identified the need for such projects and who commission them (Wever et al., 2019). The identification of the dissatisfaction normally does not appear in single moment or in a vacuum, but rather it happens in a progression of time and in the context of clients' organization (Nadler, 1981). However, the discovery of any of the motivations previously mentioned and the establishment of a formulation of the problem is always subjected to interpretations of the individual or individuals involved in the process. The different limitations of human bounded rationality, the level of expertise in problem formulation, and the experiences that each one of us has play a significant role in how a problem is perceived and then formulated (Volkema, 1983). 
Furthermore, in the same way that design problems are ill-defined and information about the nature of the problem is confusing and conflicting and might never become available to the designer, the problems that need to be formulated also share these traits. Simon (1977) explains that problems that are found in the real world are always changing by the new information acquired by the actions of the practitioners. Additionally, more complex problems might contain a higher quantity of, sometimes conflicting, variables (Volkema, 1982). Given these characteristics of ill-define information, nonstatic problems, and large number of variables make the task of formulating the problem into a single optimal formulation an almost an impossible task.

\section{Importance of problem formulation}

Previously, we have discussed the important role that discovery and definition of the problem plays in the design process. Cross (1982) asserts that this capability to deal with ill-defined problems by changing the problem though redefinition is key to the 'designerly way' in which practitioners of design work. That being said, redefining a problem is a difficult task even for experienced designers. Cross (1982, p. 224) himself quotes Jones as saying that "changing the problem in order to find solutions is the most challenging and difficult part of designing". It is quite common to find in the design and problem-solving literature comments in regard to this. Joseph (1996, p. 238) affirms that "it is not so much finding the answers as finding the questions that is difficult". Moreover, Volkema (1983, p. 640) proposes that a "reformulation of the problem becomes less likely once a particular formulation is selected and pursued". 
If we bring together the difficulties that one could encounter in the process of identifying and formulating a problem, such as the ones discussed above, with the difficulty of the task of redefining a problem, we encounter that problem formulation is definitely not an easy task. Additionally, Volkema (1983) through Mintzber et al. (1976) makes us very aware of the importance of formulation given the formulation happens early in the process and that it might even be the first contact that the practitioner might have with problem, it has the potential to influence and set the direction in which the process goes. This does not mean that the formulation will dictate what the process or the solution might be, however it can create a disposition or even fixation to follow a certain path or procedure.

\subsubsection{The Design Brief}

In the design context the process of capturing the formulation of the detected problem is the briefing process, and the document that encapsulates what has been captured is the design brief. This document can contain a number of different elements that in the end describe what is known about the situation in which the design project will occur. In it, it might be expressed several questions like what? who? how? why? (Koronis et al., 2019; Wever et al., 2019). This in the end provides information related to the problem and its structure such as what might be the end-state, goals, scope of the project, resources and constrains that provides definition to the designer (Hey et al., 2007; Paton \& Dorst, 2011; Sosa et al., 2018).

Furthermore, in the design literature we can encounter that the design brief is defined to have multiple purposes beyond presenting the identified problem. Firstly, it can have the additional purpose of 
being point of communication in between the client and the designer, where both parties converge in an agreement of a common view of both the problem and the ensuing design project (Bogers et al., 2008; Ekströmer et al., 2017; Paton \& Dorst, 2011). Lastly, the brief serves the purpose of a reference point for the requirements and desired outcomes that both the designer or the client can refer back for validation or confirmation during the process (Bogers et al., 2008)

The briefing process and the construction of the design brief is another element that has received attention on the literature of design given the collaborative and communicative aspect that it holds in between the client and the designer. The briefing process, in the design context, commonly happens in the early stages of the design process. From an initial identification of a dissatisfaction or undesirable situation a first expression of the problem and an intention to solve it is stated (Nadler, 1980; Sosa et al., 2018). This is then typically further developed in interactions between the designer and the client in order to articulate the brief in a manner that expresses the mutual understanding of the problem and to orientate the project (Koronis et al., 2019; Paton \& Dorst, 2011; Sosa et al., 2018). However, in practice, is not always a smooth and clear process of communication which can be hindered by the inexperience in the identification or proper statement of the problem structure by the parties involved (Dell'Era et al., 2011; Koronis et al., 2019).

Beyond the identified importance of the design brief as a communicative tool that serves to present the known information of a problem and to create a common agreement in between the involved parties, the design brief is also a central piece for the design process that follows. The design brief represent a first point of contact for the 
designer with the problem and would have an effect on the later stages of the process (Baer et al., 2013; Blyth \& Worthington, 2010; Bogers et al., 2008; Lawson, 2006; Nadler, 1980; Paton \& Dorst, 2011; Sosa et al., 2018; Volkema, 1983). In connection to what has been stated in the previous section of problem formulation, it has the potential to influence, or even generate fixation, and set the stage to what is consider and what is not (Mintzberg et al., 1976; Volkema, 1983).

\subsection{Design Field}

Design has been amply studied from many different perspectives such as engineering, economy, management, cognitive sciences, among others. However, it is often that we find in literature that authors seem to agree of the dispersion or lack of development in certain areas, or even on the role and importance that design has beyond simply aesthetics (Dorst \& Dijkhuis, 1995; Hatchuel, 2001; Hobday et al., 2011). Beyond this agreement and desire for more research into design field a lot has already been built in what is referred as theory of design from the works of researchers such as Archer, Nadler and Cross or paradigms of design from Simon and Schön. But before we go into these theories and paradigms it is important to understand what we understand design to be.

Design as most fields has a great number of definitions and that has also changed with time and exploration of the field (Buchanan, 1992; Hobday et al., 2011). In his 'Think piece' on design Tether (2006) observes the different definitions of design from a practical perspective. There, Tether provides an example of not only the number of definitions of design but also the difference between them. 
The conclusion he draws is that "design refers to both processes and outcomes" that can be abstract or not in the process and tangible or intangible in the outcome (Tether, 2006, p. 3).

One of the struggles that the field faces from the practical perspective relates to the disperse and inadequate understanding of what design is and the trivialization of the role it plays in organizations (Tether, 2006). Moreover, these misunderstandings and trivializations may be a reflection on the common use of the word design in the everyday vocabulary (Lawson, 2006). It is not unlikely to hear the word design being used to refer to changing something's appearance to make it look "pretty". The other most common use of design, and the one used in this thesis, is to refer to the creation of a things such as products, buildings, experiences among others, which would then refer more to the professional practice of design.

The academic world has then attempted to provide guidance to better understand design and its purpose. From the literature we can draw other key elements that can give us a better picture of what makes up design. Simon (Simon, 1969) serves a basis to understand design as a transformation of existing conditions to new preferred ones. Cox (Cox, 2005), provides us with similar elements of the transforming power of design to "shap[e] ideas" and give value to user or costumers. from Hobday (2011) we can draw design as a "technical activity" that is central to the innovation process. Finally, Hatchuel and Weil (Hatchuel \& Weil, 2009, p. 183) provide the distinction that design goes beyond selecting from existing solution, it rather involves a "mapping between specifications and design solutions" and the creation of things discovered during this process. 
Despite the multiple definitions of design here presented and the many more that can be found in literature, a definite and satisfactory definition of design would be hard to find and would greatly vary depending on the observer's background (Lawson, 2006). What most seem to agree in the design literature is that, regardless of the specific definition, design separates itself based on the kind of problems that it aims to solve and the process that designers use to do so.

Design problems are of the kind that are ill-defined where all information about the problem is or might never be completely available which in turn means that a single-optimal solution might never be found (Archer, 1979; Buchanan, 1992; Cross, 1982). These types of problems have been described as ill-defined (Archer, 1979; Buchanan, 1992; Cross, 1982) or as ill-structured (Newell \& Simon, 1972). Given that this thesis deals with how the problems are formulated in the design brief, design problems play an important role and so further exploration will be done in a later section.

The process of designing then is heavily influenced by the lack of definition and structure of the problems that designers must deal with. However, the act of designing separates itself from scientific process by the search and production of solutions rather than a complete and exhaustive exploration of the problem (Cross, 1982). Given that there is a lack of a simple definition of the problem, designers need to continuously define and redefine the problem in order to provide themselves with structure and boundaries to perform the search for solutions while at the same time they establish what may constitute an acceptable outcome. The way in which designers explore the problem also involves the use of temporary solutions that help with the constant redefinition of the problem while at the same time 
experimenting with possible solutions. This means that the process of design involves balancing both exploring the problem and developing provisional solutions at the same time and not as separate steps on a sequential process (Archer, 1979; Cross, 1982; Lawson, 2006).

These elements that we were able to observe above, can give us a better picture of what is design and gives a better understanding of its basic dynamics. This then leads us to two different classic paradigms of design (Dorst, 1997; Dorst \& Dijkhuis, 1995; Ralph, 2010) that differ on these fundamental elements of design and how we study the field.

\section{Two design paradigms}

On one side we find the paradigm of design as a rational problemsolving process. This paradigm was one of the initial theories of design that served as a basis for the understanding and study of design process and still holds an important place on today's views of design (Dorst \& Dijkhuis, 1995; Hatchuel, 2001). On the other side we find a completely different paradigm that questions and criticizes the problem-solving paradigm. This opposing paradigm proposed by Schön (Schön, 1983) proposes that the process of design is a process of "reflection-in-action". These two paradigms differ vastly on their views of design problems, the design task and the role of the practitioner in the process which we will see in the following sections.

To very briefly introduce both paradigms in the light of design, Dorst (1997) uses three key components that help differentiate these two views of design. These three components are design process, design task and the designers. 


\subsection{Design Paradigms}

\subsubsection{Paradigm of Rational Problem-Solving}

On the side of the problem-solving paradigm the design process is viewed as one that involves a search for solutions within a problem space that needs to be surveyed. This paradigm proposes that design deals with ill-structure problems. This search involves the breaking down of said ill-structured problem into smaller and more manageable subproblems and then combining them to complete a solution. Finally, this paradigm views the designer as a 'goal seeking' problem solver that inhabits an objective reality.

The paradigm of design developed by Herbert Simon, is rooted in the organizational field but more specifically in Simon's intensive and extensive exploration of decision making and bounded rationality (Hatchuel, 2001). Simon regarded design as creative thinking that is unconventional and produces novelty and deals with poorly defined problem where an important part of the process is to formulate it (Simon, 1980). Simon observed the design process from the positivistic perspective based on natural science and empiric evidence to create a model of the science of design (Dorst \& Dijkhuis, 1995). This came as a response to the classical belief in optimal choice (Dorst, 1997; Hatchuel, 2001). The concept of bounded rationality was introduced based on the idea that when confronted with decision making humans are limited by access and capacity to store and recall information (Simon, 1955) changing optimal choice to choices that are able to satisfy a number of requirements. 
The problem-solving paradigm can be better understood through Simons description of the process to find solutions to a given problem as a "search through a vast maze of possibilities, a maze that describes the environment", an environment that he often referred as a 'problem space'. But in order to be able to manage that vast maze "successful problem solving involves searching the maze selectively and reducing it to manageable solutions" (Simon, 1969, p. 54). From these two sentences we can then gather three vital elements that form an important part of the problem-solving paradigm, 1) problems lay within a vast problem space 2 ) In turn that vast problem space offers a vast number of possible places that need to be searched to find possible solutions 3 ) In order for it to be manageable it needs to be divided or reduced into smaller/simpler problems (Simon, 1973).

\section{Problem-Solving Paradigm}

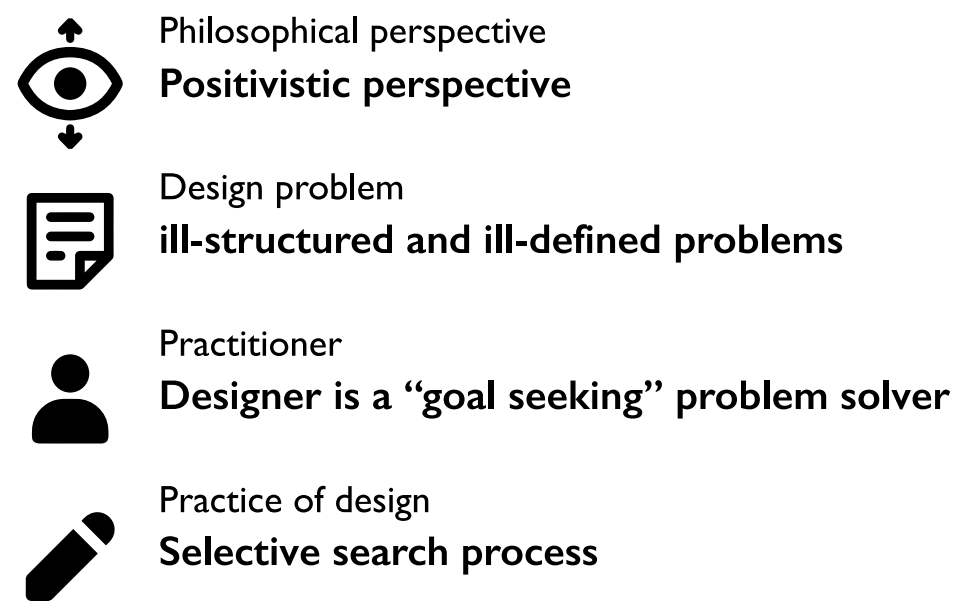

Figure 1. Characteristics of the rational problem-solving paradigm. Based on Dorst \& Dijkhuis, 1995 


\subsubsection{Paradigm of Reflection-in-Action}

On the other side we find the 'reflective-practitioner' paradigm proposed by Donald Schön in 1983. The proposal of a new paradigm came from Schön's belief that the "nature of human design activity is misunderstood" (Dorst, 1997, p. 66) and came as a response to Simon's paradigm for the design process. In this paradigm Schön proposes that each design task is unique, and designers cannot use standard theories to deal with it (Dorst \& Dijkhuis, 1995; Schön, 1983). Given this, Schön postulates that the exercise of design is one of 'reflective conversation' (Schön, 1992) between the practitioner and the 'design situation. This reflective conversation in between the designer and the design means that the former reshapes his way of seeing the problem and his thinking as he searches and produces solutions (Schön, 1987).

Schön's reflection in action paradigm like Simon's paradigm has its roots in the organizational field. However, Schön's paradigm sits more closely to architecture, organizational learning and education of professionals. In the late 70's and early 80's a there was growing discontent with the problem-solving paradigm, especially from architecture which was mainly voiced by Jones and Alexander. The discontent came from their view on the action of designing which they consider to be constructed from their own experience and nongeneralizable (Dorst, 1997). This discontent also found voice with Schön in his book The Reflective Practitioner, where he challenges the view of the professional practitioners as acting solely as processing on technical knowledge but as capable of reflecting in the midst of action (Schön, 1983) in the form of an 'artistry' of professional development and practice. 
This combination of unique and 'universe of one' types of problems with the 'artistry' of professional practice, to Schön, means that the problems of design are 'framed' by the practitioner as they go along the process, by making 'moves' in the form of trials-and-errors to improve the situation framed (Dorst \& Dijkhuis, 1995).

\section{Reflection in Action Paradigm}

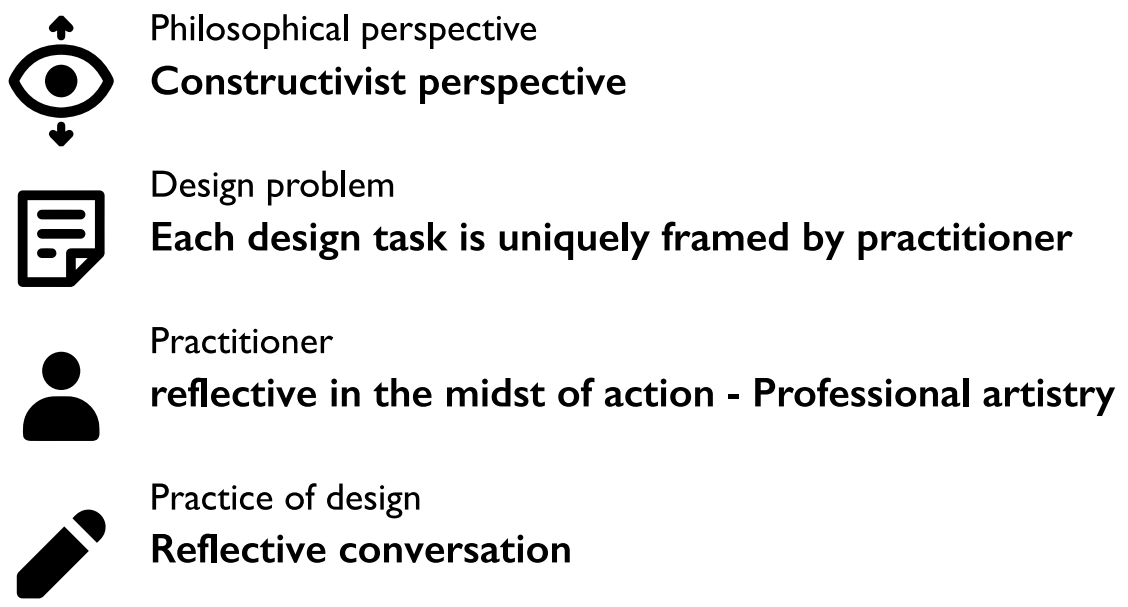

Figure 2. Characteristics of the reflection in action paradigm. Based on Dorst \& Dijkhuis, 1995

\subsubsection{Bridging between paradigms}

Both, problem-solving and reflection in action paradigms here presented have been pillars for the design field and design research. Through the years since they were presented these two paradigms have found acceptance and opposition in the design research community. 
In the case of the problem-solving paradigm we have already discussed some of the critics and opposition that the paradigm has drawn from its view of the role and behavior of the practitioner in the action of design. Among more recent critics of this view we find Conklin (2006) as presented by Hobday (2011). They discuss that design teams do not 'rationally plan in advance' and choose among solutions, as Simon presented, but rather they engage in rough definitions and re-definitions moving back and forth in between the problem and solutions.

On the other hand, even though reflection in action was seen as 'interesting' because of its difference with problem-solving, it has also been criticized because of its vagueness in its key concepts and its difficulty to be used in practice (Dorst, 1997). Part of Schön's criticism to Simon's paradigm is that, in his eyes, Simon's paradigm can only "be applied to well-formed problems extracted from situations of practice". Schön made especial emphasis in the role that the designer plays in the design process by giving structure to both task and solutions in what he referred as 'framing', which is seen as one of his most important contributions. However, he makes no attempt at addressing the possibility that design tasks may come with prior structuring or definitions that may come from a commissioning party such as a client (Dorst, 2003).

Given the polarity in which these two paradigms find themselves, many have attempted to create bridges to reconcile or connect them, for the purpose of this thesis three of these 'bridges' will be considered and further explored. 
The first bridge is an attempt to connect the possibility that in the process of design, a designer can both act as a reflective practitioner in conversation with the problem and a methods-and-rules following practitioner. Since the two paradigms stand on opposite extremes in their epistemology, Dorst (2003) makes an attempt at connecting a proposed hermeneutics 'bridge' created by Gadamer (Gadamer et al., 1988) to the design situation in order to better reconcile the possibility that the two can coexisting in the design practice. The 'bridge' created by Gadamer proposes that the 'operation of acquiring knowledge' can be viewed as a dualistic interpretation (Dorst, 2003). This entails the possibility of an objective interpretation "where an outside element impresses its meaning upon the observer" or subjective interpretation "where the subject, in act of will, impresses meaning upon something" (Dorst, 2003, p. 140). Dorst places this possibility of dual interpretation in the design context by pointing out that it rests in the hands of the designer working in a particular problem to decide "whether a part of the design activity will involve objective or subjective interpretation" (Dorst, 2003, p. 141).

The second bridge can be viewed as a way to connect different levels of professional expertise to the kind of process followed based on the two paradigms. In the same article from 2003, Dorst points to Dreyfus (2003) and his development of levels of expertise as a way of differentiating the way in which design problems are interpreted, structured and subsequently solved. Dreyfus proposes five different levels of design expertise: novice, beginner, competent, proficient and expert. To which Dorst adds that an important element of this levels of expertise is the shift in interpretation of problems, moving from a "detached view of an 'objective' reality" (Dorst, 2003, p. $145)$ in the less experienced levels to an "active interpretation of a 
situation" in the more experience ones. This in terms of the paradigms comes to mean, for Dorst, that problem-solving could better describe the behavior of lower levels of expertise of application of rules and methods, while in the higher levels of expertise the reflective action of the practitioner is more relevant. Is important to note that Dorst makes the clarification that expertise is not a static thing and that no one is an expert in all situations, so a designer might be expert in some situations and a novice in others (Dorst, 2003).

The final bridge, and perhaps more influential to this thesis, is discussed by Steve Joseph (1996). He examines the problem-solving paradigm and the search strategy proposed by Simon to later relate it to the role of professional designers in navigating this search. Joseph advocates for the treatment of the process of design in terms of the search strategy that was central to Simon's proposal. In his exploration, Joseph points at an efficient way to deal with design problems, may they be more or less well-formulated, involves a search process that produces early "sub-solutions" and give priority to their exploration. He asserts that one of the advantages of the search strategy is that it prioritizes the most "significant uncertainties in the problem" (Joseph, 1996, p. 237). If this 'significant' part of the problems is resolved then a desired outcome can be easily reached and if it is not, then it opens new areas for possible exploration. These affirmations point in the same direction as the ones made before in this thesis, that the design process is not one of linear exploration, but rather one where both solution and problem are explored side by side. To this, Joseph remarks that designers "carry out the design process at the same time [...] as she develops the final design" which for him it means that "There are no problems detached from solutions" (Joseph, 1996, p. 238). 
Now we have taken a detour to briefly present Joseph's view of the design process defined as a search process, which will play a key role in this thesis and will be examined further in the next section, but we have not yet come to see the bridge between paradigms. For this Joseph proposes to observe the 'wickedness' of design not in terms of the problem but rather the "properties of its solutions" (Joseph, 1996, p. 238) and the design professional as an active interactor between the client's situation and the vast space of solutions. And, in the same line as Dorst (2003) and Dreyfus (2003), Joseph elaborates on the capacity that the more experience designers have to interact and reflect between the two. Joseph (1996, p. 238) remarks, "the solution space and its exploration is thus determined by the human interactions and understanding of the designer within the situation." This way Joseph proposes a bridge where we can take Schön's emphasis on the human aspect of the design practice and Simon's emphasis on the search strategy to reconcile in a "search through dialogue". (Joseph, 1996, p. 238)

\subsection{Design Process as a Search Process}

This theoretical model of search forms part of the perspective on organizational studies developed by Herbert Simon, James March and Richard Cyert in their three works, A behavioral theory of the firm (Cyert \& March, 1963) Organizations (March \& Simon, 1993) and Administrative Behavior (Simon \& Short, 1947). From here on a school of thought has then expanded through many researchers in what has come to be known as the Carnegie School of organizational theory. The School committed to studying organizations and decision making by creating a "constellation of closely related ideas" (Gavetti et al., 2007, p. $524)$ considering that decisions are intendedly rational but bounded by the limitations of humans and organizations (Augier \& March, 2008). 


\section{Search Behavior}

During the design process in which individuals or groups attempt to create new solutions for a given problem, they have to embark on the process of looking for possible ideas that could yield the desired results. One of the main characteristics of this exploration is that it is guided in parts by experience, imagination and intuition (Pandza \& Thorpe, 2009). One of the main paradigms that has been used in order to understand this process is the one in which design is regarded as a search process (Dorst, 2003; Newell \& Simon, 1972; Simon, 1969).

Searching is an indispensable part of everyday actions for all humans whether it is done to perform mundane tasks or in the exercise of specialized and professionalized tasks such as the ones found in the many fields of design. In most of these fields, an important element of the design practice is the capability to produce outcomes that are creative and inventive where the professional performs a creative or explorative search. A process in which designers search for possible solutions within a vast problem space and which "involves searching [in a large] maze selectively and reducing it to manageable proportions" (Simon, 1969, p. 54).

Another metaphor that has been commonly used in the search literature to exemplify the search process is the one in which the process is compared to the exploration of a landscape characterized as an unknown, rugged landscape that maps the desired attributes (Figure 3.). This landscape is depicted as a rugged one full of peaks and valleys where each peak represents a combination of possible outcomes, and the searchers job is to explore these peaks in order to identify one that is satisfactory or that represents a desirable outcome (Billinger et al., 2014; Gavetti \& Levinthal, 2000; D. A. Levinthal, 1997). 


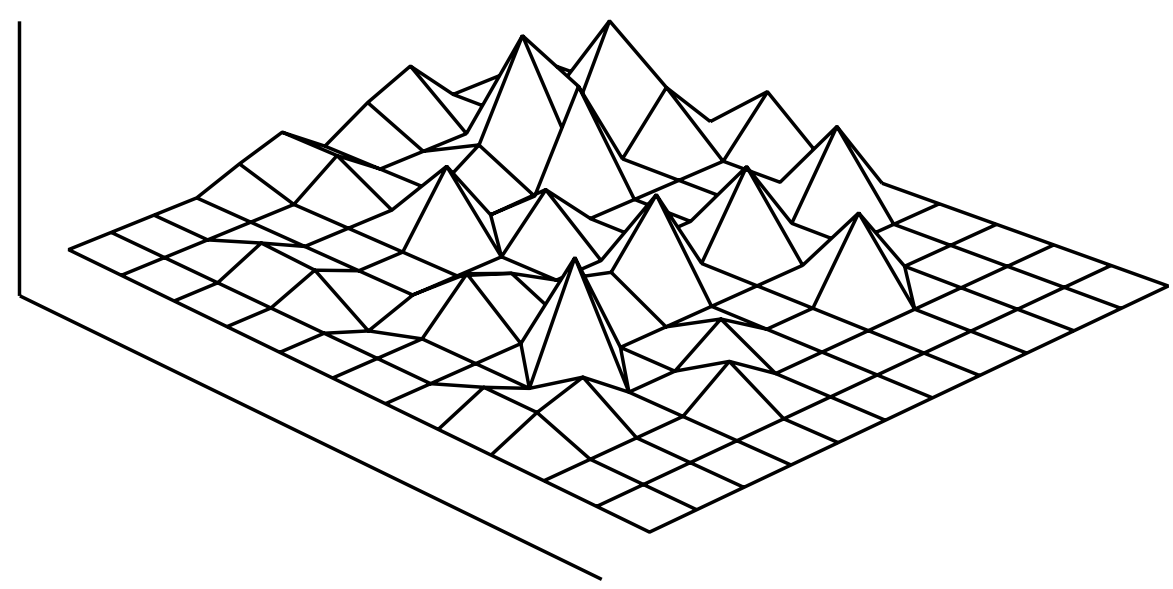

Figure 3. Representation of a rugged landscape. Based on Gavetti \& Levinthal, 2000

This characterization has also been expanded to represent two different spaces, one problem space and one solution space. The problem space can be understood as the area that contains the attributes that describe the problem that is being solved (Remington \& Pollack, 2016). In this landscape each peak can be identified as the combination of attributes that represent the most problematic, or the most significant or the most desirable to be solved. The solution space on the other hand is the area that contains the attributes that make up the desired solution (Remington and Pollack, 2016). Similarly, to the problem space, each peak represents the combination of attributes that in the end represent a more desirable or satisfactory outcome. 
As it has been noted many times in this thesis, in the case of the design process the search behavior can be characterized as one in which the problem space and the solution space are explored simultaneously (Archer, 1979; Cross, 1982; Joseph, 1996; Lawson, 2006). This is done by exploring the significant areas of uncertainty to define problem boundaries and by developing provisional solutions to test and expands those boundaries. The simultaneous and iterative search behavior allows the problem definitions to feed temporary solutions which in turn feed the understanding of the problem to then re-define it to produce new temporary solutions and so on. This emphasis on dual and simultaneous exploration and the emphasis on the production of solutions separates design from scientific process (Cross, 1982). Bringing this back to Simon's metaphor, designers not only search the landscape by selecting and reducing, but by quickly testing possible solutions and learning from those quick tests.

From the theoretical model developed by Simon, March and Cyert and with the inclusion of others such as John Dewey and other researchers from the Carnegie school, we can discern three stages to search within the 'maze' in these exploratory search processes. These three stages of the process could be defined as a pre-search, search and finally adoption stages. In the initial pre-search stage, the desire to look for new goals is established and how to best attempt at looking for said goals. The second stage refers to the actual process of searching for possible solution for reaching said goal. And finally, a stage in which a solution that is satisfactory to the initial goals is selected and adopted as the new behavior. A summary of the rational search process can be seen in figure 4 . 
A Typology of Design Briefs

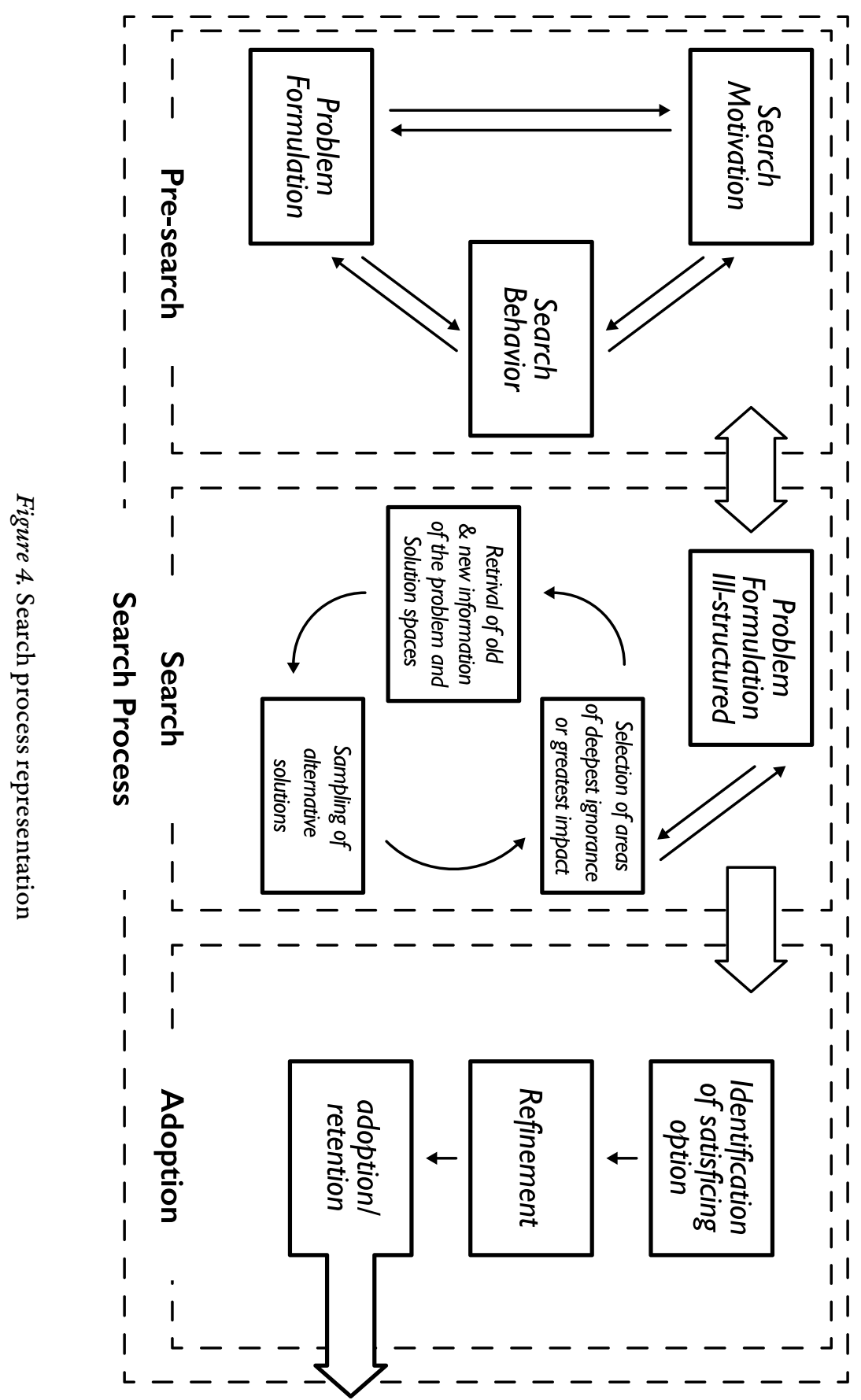

43

A Brief Theoretical Background 


\subsection{Stages of a Search Process}

\subsubsection{Pre-Search Stage}

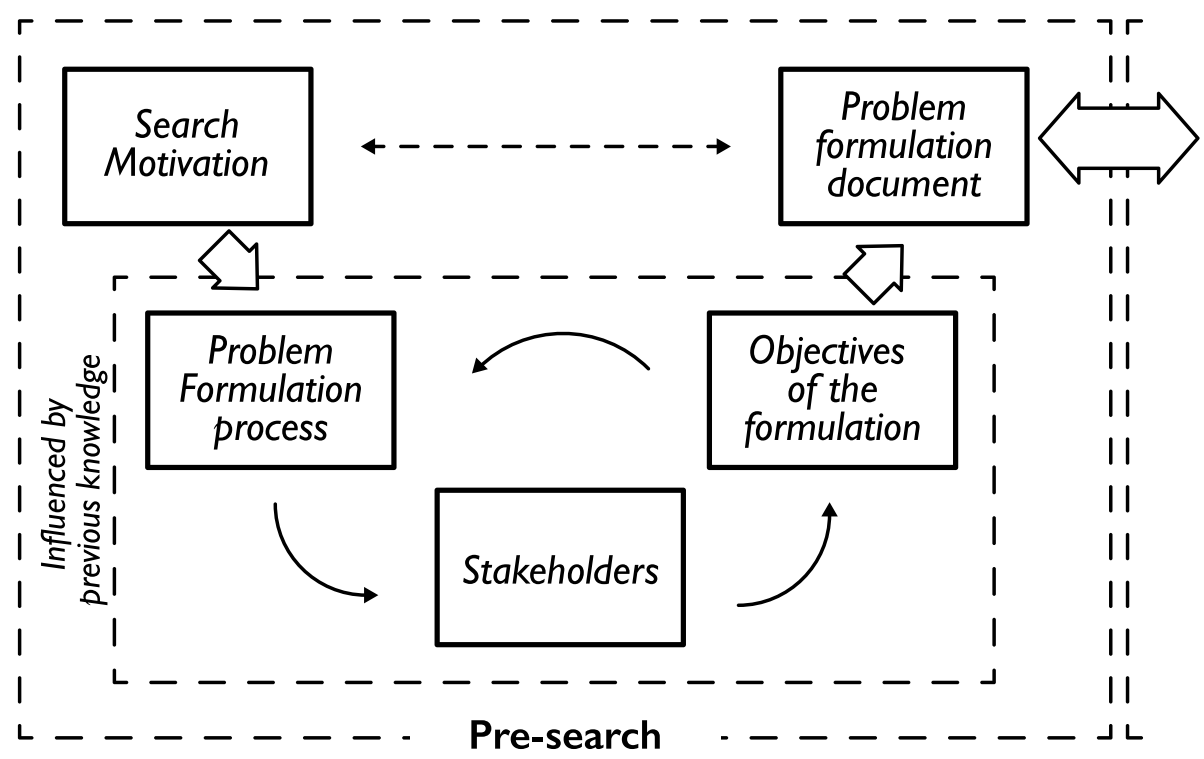

Figure 5. Pre-search stage representation

The first stage of the exploratory search is often referred as the most important stage in the process (Lyles \& Mitroff, 2020; Volkema, 1983) given how problem formulation determines the problem to be solved and consecutively its solution (Hayes \& Simon, 1977; Simon, 1973; Volkema, 1983). During this stage many important things are defined, that in the end will mark what will be searched, how it will happen and where the search will take place. This process of making explicit these questions culminates in an agreement that is known as problem formulation. Within this first pre-search stage we can find three key moments that give birth to the search process. 


\section{Search motivation}

The first of these key moments is the basic inception that marks the beginning of the process. When an organization is dissatisfied based on a mismatch of their performance and the aspirational performance (Chen, 2008) they take the initial step that kickstarts the whole process. This could come from a either desire, need or the recognition that the organization could improve their current state.

Based on what we have learned from the Carnegie school we can then recognize two main motivators that spark an exploratory search, problem-driven search and slack-motivated search (Cyert \& March, 1963). These two types of motivators can determine greatly what type of search is to be conducted. A problem-driven search will tend to be a more reactionary exploration that aims at solving and immediate deficiency while slack-motivated search could produce searches that on a more constricted environment would not have happened (Cyert $\&$ March, 1963). These motivators then trigger the next key moments in which the organization or a more specialized design team define the problem to be tackled, this can be seen as the first step to starting the actual search.

\section{Problem formulation}

This next step in the exploratory search process marks the moment in which the stakeholders involved in the search, specify the identified problem to be solved. This involves setting the goals of the search that will ultimately culminate in a desired or satisfactory solution. Problem formulation plays a key role during the actual search. A better understanding of the task at hand will in the end produce a 
more intelligent identification of the alternatives to sample (Nelson \& Winter, 1982) and that ultimately will be adopted as the satisfactory new behavior.

We learned from Cyert and March that there are two motivators that kickstart a search process, problemistic and slack. These motivators can also be initial building blocks of a problem formulation and can ultimately be the formulation itself. Problemistic searches come from a specific problem and focuses on trying to find a specific solution for said problem (Cyert \& March, 1963). This immediately translates into a formulation that focuses on a specific goal that needs to be achieved, leaving less spaces to explore more distant alternatives. Slack motivated exploratory searches, on the other hand, come from an excess or underutilization of resources, such as labor, capacity, capital among others (Cyert \& March, 1963; D. Levinthal \& March, 1981). In contrast to the way in which problemistic search frames problems to a specific goal, slack motivated searches could motivate a more open and experimental framing that allows for more risk taking in the later stages of the search process.

\section{Adoption of a search behavior and strategy}

Once the problem has been formulated, the next step in the pre-search process is the adoption of a search behavior. Here the distinction of which comes first, problem formulation or the adoption of the behavior, could be debated with validity for both sides. In some cases, we might know what behavior we want to adopt and thus we shape the problem formulation to facilitate the search, while in other cases we might decide which behavior would suit better the type of problem that we have at hand. For the data projects that are used in 
this research the type of behavior was established long before the specific problems were formulated.

The reasons that motivate an organization to conduct an exploratory search and the way in which the problem formulation happens play an essential role in the search process. Much of what happens during the search is influenced by the formulation of the problem. The strategies that an organization might engage on or use to find possible solutions could be traced back to the initial motivation and/ or formulation. Strategies can be understood as rules or biases that humans use to better their chances of being successful (Reader, 2015) and these strategies stem from our own experiences and learnings. From the studies on human behavior we can learn that humans may use different strategies, that could be accumulated though experience, to guide the search process. These strategies are deeply related to the type of problem being tackled. For problemistic searches a strategy with a defined goal could be utilized as well as other strategies such as more controlled ones, that are guided by information acquired from the environment (Reader, 2015). On the other hand, slack searches utilize strategies that are uncertain about what is being searched more like an aimless exploration or blind variation (Campbell, 1960) or other such strategies as sampling thought the environment (Reader, 2015).

In 2000, Gavetti and Levinthal from the same Carnegie School, defined two type of behavior that can be adopted when trying to conduct an exploratory search. One is a backward-looking behavior that is based on experiential learning with trial and error as a basis for exploring different alternatives and later these trials serve as a way to select and retain the most promising alternatives. The second behavior 
is a forward-looking one which in contrast to experiential learning is based on the 'cognitive representations' of the environment (Gavetti \& Levinthal, 2000). Forward-looking used the mental models created by an actor that represent his understanding and evaluation of future and its outcomes. From what we learned from Gavetti and Levinthal these two search behaviors differentiate themselves on the location, regarding current behavior (distant vs local), the mode of evaluation and the extensiveness of the alternatives considered. The adoption of a behavior also marks the point in which the pre-search ends and the search process begins.

\subsubsection{Search Stage}

The second stage on the exploratory search process is where the actual activity of searching is performed. During this stage the objective is

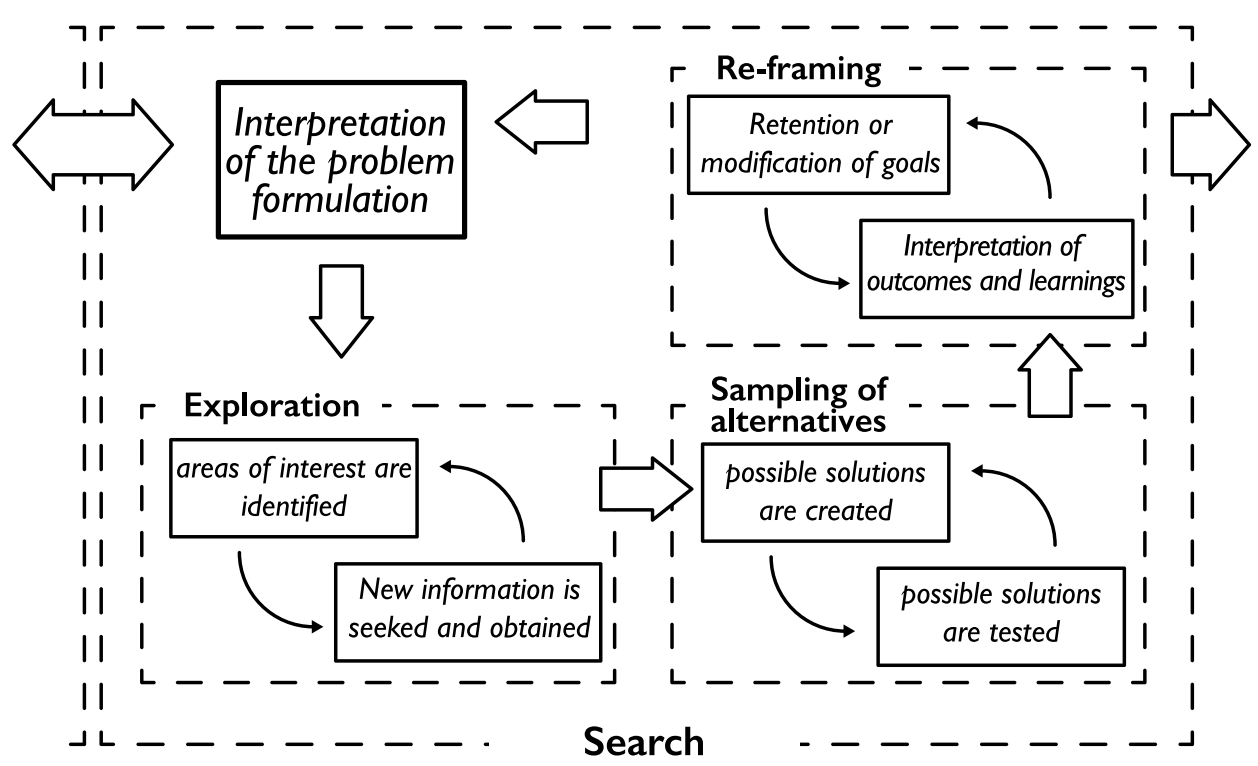

Figure 6. Search stage representation 
to discover and examine alternatives. This process of searching or discovering ideas is one that is very much future oriented (Pandza \& Thorpe, 2009) it involves the creation of possible new alternative behaviors that reimagine what is currently being done. These new alternatives are not just laid out perfectly ready to be applied to the problem at hand, but we must work to find them (Knudsen $\&$ Levinthal, 2007).

\section{Search/Discovery of alternatives}

Given that the exercise of searching for new alternatives is one that involves thinking about the future, imagination and creativity are very heavily involved as primary tools to the search for novel behaviors (Pandza \& Thorpe, 2009). March (2010, p. 75) explains novelty as “a deviation from established knowledge" and creativity as novelty that has been accepted as successful. He notes that, even though is not the only ingredient, novelty is necessary for creativity. Furthermore, Lumsden (1999) refers to creativity as the event in which an individual will go beyond their previous experience to a novel outcome. In order to achieve this, we must rely on a recombination of concepts that deviate from what has already been established as knowledge (March, 2010; Schumpeter, 1934). A recombination of existing knowledge which requires an exploration of ideas seemingly unrelated to the problem space and connect distant knowledge domains.

There are several processes at play that takes an individual or team from their prior knowledge or experience to new ones. New outcomes are not born of the same experiences, that is why other methods to help generate them are needed. Methods or tools such as recombination of seemingly unrelated knowledge, randomness, searches in fields 
different from the problem space (analogies), associations with other individuals, among other are needed to inspire the new unconceived alternatives. And thus, the space of possible alternatives is sampled which leads the next step in the process of the creative search, which relates to evaluating and choosing one of the explored alternatives as a desired one that will be then adopted.

\subsubsection{Selection and Adoption Stage}

The last stage of the process marks the end of the search for alternatives but the beginning of a completely different organizational process. This process is the one in which the organization recognizes or identifies from a set of possible choices the one that seems to best satisfy the criteria established before the search began. Once an alternative is selected in the final step of adoption the organization bring alternative selected as the new behavior. However, once again we encounter that neither the beginning not the rest of this step is as clear and simple as just choosing the best of a set of options. The first problem that we encounter in this step of the search process relates to the previous step and it come in the form of a question, when do we stop searching or sampling more alternatives?

The odds that we are against dictate that only a small fraction of the ideas conceived will turn to be good since at first most new ideas are bad ideas so we must generate as many as possible to better the possibilities of finding one turns to be successful (March, 2010; Osborne, 1957). For this reason, March (2010) reflects on the importance of the process for refinement and retention within the novelty generation process. Because of the impossibility to test or consider every possible alternative or their outcome, Simon (1955) 
suggests that individuals search until they identify one that satisfies the minimum performance desired. By stopping the search process, we can identify a solution that fulfills the minimum criteria but might not be the best. However, it must be considered that we might never be able to identify an alternative as the best but rather what Simon (1947) refers to as a satisficing one. Given the limitations of individuals in terms of the amount of knowledge that can be store and the number of alternatives that can be considered that comes with bounded rationality a mechanism of choice needs to be adopted. With these limitations in mind the selection of alternatives cannot be thought of as a "optimization of a well specified set of choices" (Gavetti et al., 2007, p. 526). For this Simon proposed that during a search process the individual or organizations stop when an alternative meets a threshold of acceptability based on goals or aspiration that motivated the search rather than one than seeking an ideal or perfect solution.

Finally, we arrive at the adoption of the satisficing alternative step as the new behavior desired by the organization. From the previously mentioned Carnegie school and more specifically from Cyert and March's Behavioral theory of the firm we can conclude that the process of search should end once the satisficing solution has been identified, and largely this research adheres to that believe. However, it is also important to note that for other authors such as Crossan, Lane and White (1999) the identification of the desired alternative is only the starting point for the organization to learn from what was found in the search process (Knudsen \& Levinthal, 2007)). This step is truly an important one, because without learning from the process or the adoption of the alternative as the new behavior, then the search process is just an exercise in futility. 


\section{A Brief}

Explanation

of the Method

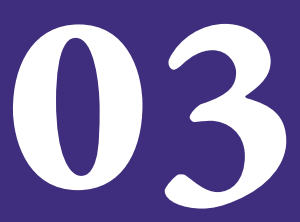


Chapter 3

\section{A Brief Explanation of the Method}

\subsection{Introduction}

Before I begin my methodology chapter, I would like to introduce you to the structure that I will follow. The idea behind this chapter is to go beyond simply presenting what my ontological and epistemological stance is, the design paradigm that I have chosen or the research method that I used. Don't get me wrong, I believe those things to be very important, however the main focus of this chapter is to take the reader behind the curtain of how the process of making this thesis happened.

As a trained and somewhat still practicing designer, my process of creating things follows the same process that I explained previously on my theoretical chapter. That means that the creation of this thesis was not one of straight forward question or problem formulation and then a linear process to find a solution. It was a constant iterative search to define what the problem was while attempting to produce a solution. This led to several versions of research questions and aims, that got tweaked as I understood more of the problem space. And on the other hand, it also led to several versions and iterations of the codex to characterize the briefs that changed as I understood more of 
the theoretical underpinnings of problem formulation but also as I confronted the codex to the data set.

Because the process that I followed in the creation of this thesis was not straight forward and linear, I would like this methodology chapter to reflect that journey that I took. This means that it will not have the normal structure that I have found in other theses but rather a more narrative form that takes you chronologically to the same places that I went. I would like to clarify that this structure is not of my own making. Rather, as google scholar always likes to remind us, I will try to stand on the shoulder of giants and emulate, in a smaller scale, a great methodology chapter done by a former Ph.D. student from Linköping University, Linnea Wahlstedt (2013). In her methodology chapter, she presents her process in a manner that takes the reader behind the scenes of making her thesis to understand her process and reasoning beyond only the methods that she used.

\subsection{Science and Research}

Before I start to explain the process that I used in my research and that culminates in this thesis, it is important to mention what my stance is in regard to science and research and how knowledge is constructed. Previously in the theoretical chapter, I started to outline the two most prominent paradigms of design research and to indicate what I use in this thesis as the view of the design process in the light of said paradigms

As indicated in section 2.2 in the theoretical chapter of this thesis, two of the most prominent paradigms in design research are rational 
problem-solving and reflection-in-action. Both classical paradigms differ in their fundamental view of science and knowledge. On the one hand the rational problem-solving paradigm observes design from the positivistic perspective while on the other side reflectionin-action, is rooted in the constructivist perspective. However, in that same section, I also presented a perspective that researchers in the field have taken in order to reconcile or connect them which very much represent my own view of the study of the design process.

Through these bridges Dorst (2003), Dreyfus (2003) and Joseph (1996) propose that the exercise of design can be reconciled in the two different paradigms. Firstly, by conceiving the possibility that the design practitioner can both behave as an objective and subjective interpreter in the process of gaining knowledge of the world that surrounds them. Furthermore, the decision falls on to them to decide whether a specific part of the design process involves objective or subjective interpretation. Secondly, that it is in the different levels of design expertise that the designer learns to shift from these two interpretations of the problem.

In terms of my own stance on philosophy of science I must say that the subject is one that to this day eludes me. Not to say that I do not know, or I do not care, but rather is still in development as I learn more through my exploration in the world of research. However, for the realization of this thesis I do have a stance rooted in my design education. By this I mean that I hold a very practical view of the world which in turn connects to the pragmatic research paradigm where as a research, and with this thesis, I aim to solve practical problems of the real world (Hothersall, 2019; Kaushik \& Walsh, 2019; Maxcy, 2003; Meissner et al., 2011; Rorty, 2000). Furthermore, I also share the same 
perspective of pragmatism that our own interpretation of reality is linked to our own experiences and is dependent on the context in which we inhabit (Dillon et al., 2000) and it can never be determined once and for all (Pansiri, 2005). My own pragmatic view of science reflects my desire and intention to find theoretical bridges between the paradigms of design. Finally, in terms of the methodology used in this thesis, pragmatism remains at the forefront of my own research behavior. To start with as expressed by Kaushik and Walsh (2019), Goldkuhl (2012), and Morgan (2007) a pragmatic approach is mostly related to abductive methods as the one used in this thesis.

\subsection{Inspiration}

To begin the story of how I made this thesis, I must start with how I got interested and then inspired to do this study. For the past 10 years I have been involved with design projects that are part of a large international network of universities that collaborate with industry partners in the development of product design and innovation projects. I have been part of this projects in many different capacities. Starting as a student in the projects at Javeriana University Cali to currently being part of the teaching team that runs the projects at Linköping University and in between being a teaching assistant and also working in industry replicating the concepts and set up learned in the projects.

Through the many years of both doing the projects myself and teaching and coaching my students, I have been able to experience firsthand what the design teams goes through. This includes the great breakthroughs they make, the gaining of insights into the human behavior, the creation and production of solutions and of course 
the challenges and difficulties faced along the way. As a researcher in training, I was of course attracted to studying and understanding the design process and why they face the difficulties they do. This is where the story of this thesis begins.

At the beginning of my Ph.D. studies me and my supervisors worked on a paper that explored design fixation (Ruiz et al., 2018). Design fixation can be explained as a 'designers' tendency to become consciously or unconsciously influenced by precedents they come across while generating new solution ideas" (Cardoso \& BadkeSchaub, 2011, p. 77). The paper explored the negative effects that fixation has on the design process and explored the role that the introduction of randomness could have in snapping the design teams from their state of fixation. The interest in studying design fixation came from an observation that we had on one of our student teams that was struggling to create new ways of using UAVs ${ }^{1}$ that differed from the current use they have.

That paper is not present in this thesis; however, it inspired and provided an interesting new question. In most studies on design fixation what was being studied deals more with identifying what design fixation is and measure its manifestation in the end solutions. The introduction of the fixating element was a given and a part of the study. This led to the question of how design fixation is being introduced? and what role does the way we frame the task plays in fixation being introduced? In other words, what role had the initial brief on our students being stuck and fixated. However, as I expressed before, the process of this thesis involved many rounds of questioning

1 UAV stands for Unmaned Aerial Vehicle which are also call drones in other contexts 
my own assumptions and research questions and eventually that question also changed. The new evolution of my initial question then morphed in order to understand problem formulation beyond fixation. The question that follow then was: what influence the framing of the task has in the design process? And was the initial seed to the research questions of this thesis.

\subsection{The Data Set}

As the popular expression goes, hindsight is $20 / 20$, and in the case of this thesis it would be fairly easy to linearly describe a process in which the methodology was crafted and then the data set was collected. However, the reality of the process of this thesis, is that the type of data to which we would have access, in connection to the design innovation projects previously mentioned, drove a lot of the decisions made in terms of the methodology used. So, in order to understand the methodology that was used it is important to first introduce the design projects and the setting in which they happen and secondly what data came out of them that was used in this thesis.

\subsubsection{Design Projects}

For the past five years to the date of this thesis, Linköping University has collaborated in the development of design projects based on the Design Thinking methodology with Stanford University in the frame of the ME310 Design Innovation projects course. These design projects bring together corporate sponsors and universities around education in innovation and human-centered design through real challenges. 
Each of these projects, typically, consists of a corporate sponsor that finances the project working with two universities. In this set up the corporate sponsors brings forth a real challenge or problem from their organization and the universities provide teams of students that constitute the design team and a group of teachers from each university, with knowledge and previous experience in design thinking and human-centered design, that teach and coach the teams (figure 7.).

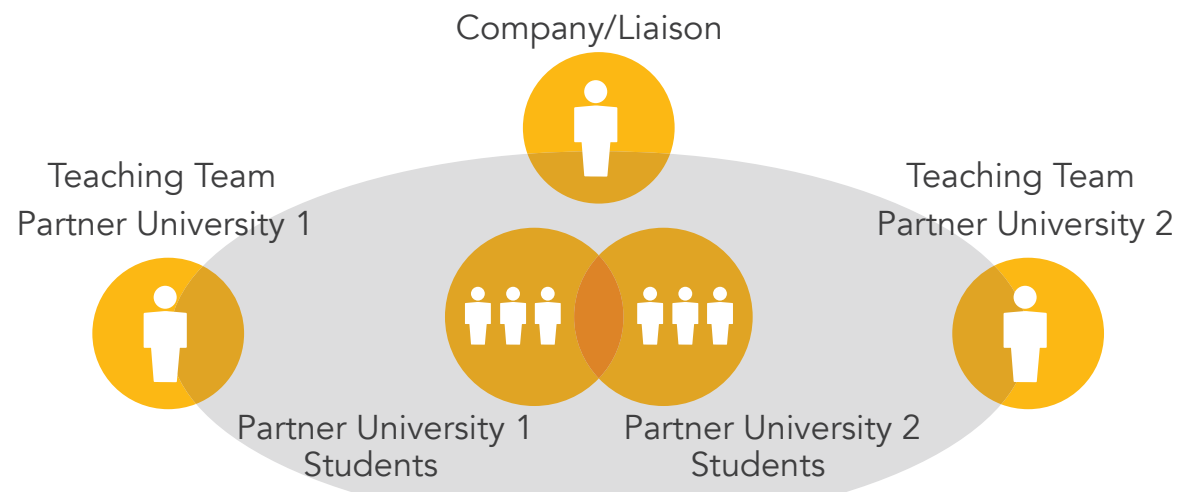

Figure 7. Stanford ME310 teams setup

At the beginning of the projects, each design team is given a design brief that presents the challenge or problem that the sponsor company has put together either by themselves or with input from the teaching teams. Throughout the course of the projects the different teams receive missions based on the design thinking methodology (Figure 8.) along with different variations such created by the Stanford ME310 program that require them to research their problem, re-frame their 
challenge, prototype design concepts and test them with real users. During the development of the projects, there are several points in which the team present and document their progress and at the end of the project a final solution is presented by the teams at the Stanford EXPE fair.

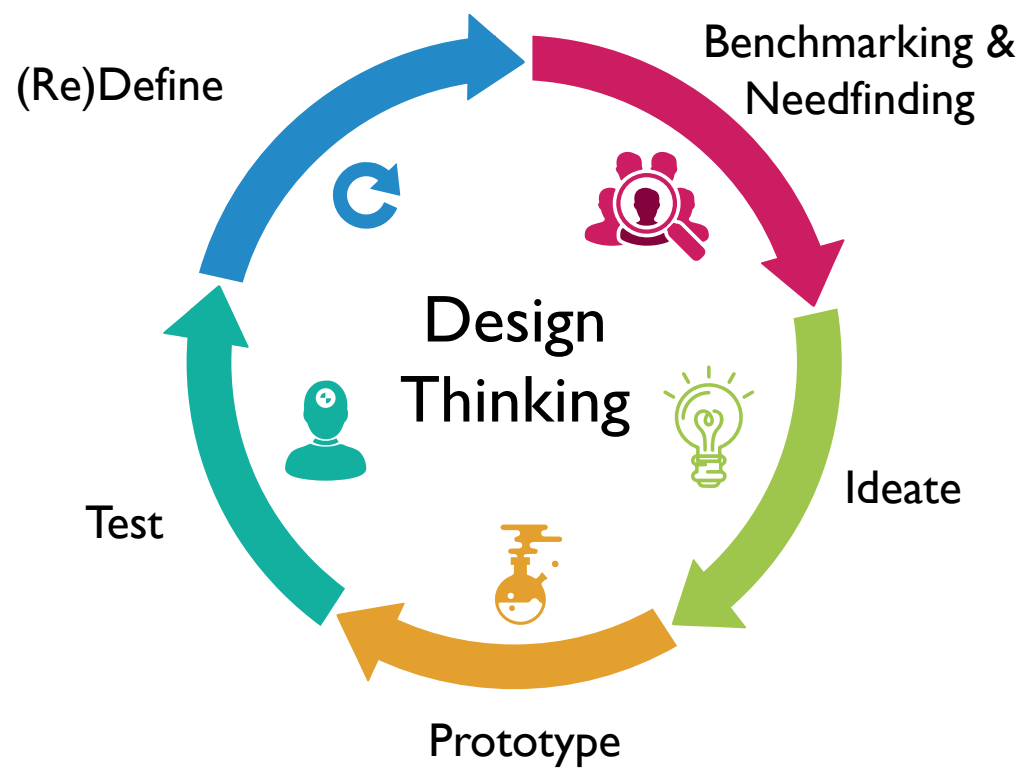

Figure 8. Design Thinking process

Though the 50 plus years of existence the ME310 course, it has partnered with companies from a wide variety of sectors. Among them we can find companies in the healthcare, food, financial services, technology and aerospace just to name a few. Each one of the participating corporate sponsors come to the projects with very

60 
different types of motivations to pursue such projects and in very different states of development of problem formulation and the design brief document.

This diversity of organizations also provides a rather wide range of challenges and problems that are brought forward for the design teams to tackle. Each year during the final presentation and product fair in the EXPE event it is not uncommon to see, alongside, projects that have explored vastly different problems. Among this we can find projects that deal with the car driving experience, reinventing photography sharing, redesigning the constructions site of the future, all the way to the application of eye make-up. Given that their individual challenge is very different, each team explores different industries, problems, needs and users and in the end produce different functional prototypes that can be digital, physical or hybrids.

Having this diversity of industries that can all coexist under the same program and explore different problems throughout the same design methodology is an advantage of the program. However, having challenges that span from such a wide range of industries, also means that each design team will be provided with a completely different starting point and design brief than the rest of the projects.

\subsubsection{The ME310 Intended Design Process}

The frame of the ME310 course at Stanford University the design process in which the students work is a purposeful process that combines Design thinking and specific missions and prototypes designed to guide the students through a divergence and convergence exploration of problem and solution. The global teams of students, 
prototype, test and iterate in order to develop a solution and at the end of the 9 months process final prototypes are created and featured at a Design Fair where all the projects are presented.

During the development of the projects, there are several points in which the team, present and document their progress. The projects are time divided into 3 quarters, Fall, winter and spring quarters. Each quarter is divided into 2 to 4 mission and each mission has a duration of 2 to 4 weeks. During the mission the design team has informal meetings with their teaching/coaching teams to discuss advances and receive feedback. At the end of each mission, the design teams present deliverables which include, prototypes, learnings and other findings which is typically documented through hand outs and presentation slides.

At the end of each quarter the design group have a formal presentation in which they present their advance and also submit a documentation that encapsulates their progress and process to the date. And finally, at the end of the project the design teams present the final results of the projects in a design fair. This includes physical prototypes of their solutions to the challenge, a short presentation of their process and solution and different graphic materials such as brochures and posters. The groups also submit a final documentation that documents both the final result and the process.

The methodology that the students follow is summarized in the following figure 9 , which demonstrates the placement of each mission in the divergence and convergence cycle. 


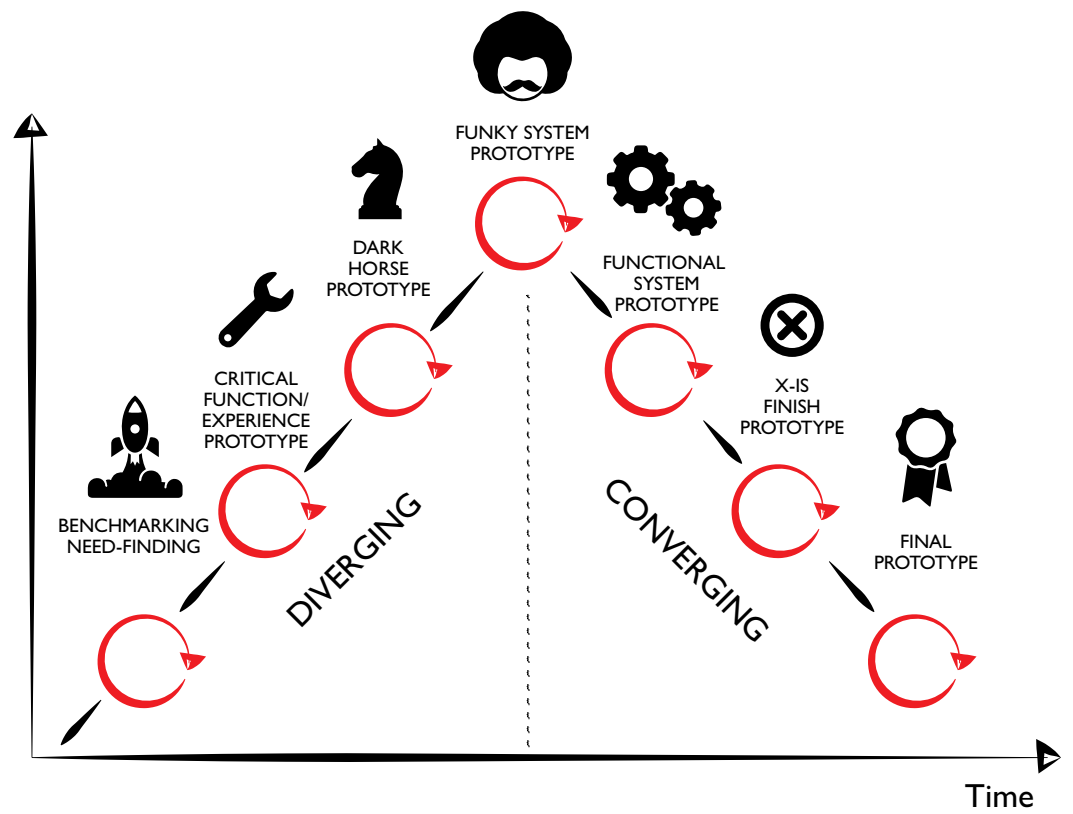

Figure 9. ME310 course missions in terms of timeline of the project and the divergence and convergence stages

\section{The Missions}

\section{Benchmarking and Needfinding:}

The first mission of the ME310 methodology is aimed towards making a first exploration of the problem space and what makes it up. The mission is divided into two complementary actions, one that looks outward into the world and what already exists and another that looks inward into the problem and more specifically to the users and their needs. The first action, Benchmarking, is intended to explore what is the current state of the field, and to do so the students explore existing technologies, market trends, existing solutions to similar or analogous situations and key industry (Domingo et al., 2020). The main intention of this mission is to "avoid reinventing the wheel" 
(Domingo et al., 2020, p. 1690). The second action, Needfinding, is intended to identify and explore the users in the specific project and their needs. This is done through the use of ethnography tools such as interviews and observations in order to uncover "people's explicit and implicit needs" (Sirking \& Currano, 2020, slide 4).

For teaching purposes this mission is the initial one of the student projects. However, the ME310 methodology indicates that during each mission the students must perform benchmarking and needfinding based on the new learning from the previous mission (Domingo et al., 2020).

\section{Critical Function/Experience Prototype (CFP \& CEP):}

After the first mission the group of students are expected to have as a result an initial understanding of the who their user might be, and their needs and pains related to the problem. This information serves as the basis for the CFP and CEP prototypes. For the preparation of each prototype, students must first identify a question non-obvious or a lack of knowledge from the design space that the prototype aims to answer, consequently the result of the prototype is to provide an answer or to deepen the team's knowledge (ME310 Intranet, 2020). The final aim of the prototype is to provide a base line understanding of critical functionalities and experiences on the problem space.

Critical function Prototype: The purpose of this prototype is to first identify which are the most challenging elements of the problem space and then to build and test a prototype that addresses said element (Domingo et al., 2020). The functional aspect of this prototype also indicates that the prototype relates to a function of the system that should perform as a credible solution idea (Domingo et al., 2020). 
Critical Experience Prototype: The purpose of this prototype is to identify a challenging element of the problem space that relates to the user's response to an experience or an interaction with a functionality (ME310 Intranet, 2020). In contrast to CFP, the purpose of this prototype is to simulate an experience and elicit the expected/intended reaction from the user.

\section{Dark Horse Prototype (DHP):}

As the projects move forward in the timeline, students start to move deeper into the divergent stage of the project. The Dark Horse Prototype serves as the mission that forces the design teams to explore riskier ideas that stretch the limits of what is possible or feasible. The DHP concept come from the term used to refer to a contender (such as a racehorse) of which not a lot is known and that is not expected to perform well but unexpectedly does. The main intention of the DHP is to "keep the design space from shrinking too fast" (ME310 Intranet, 2020, Missions Dark Horse Section). This purposeful stretching of what is possible serves to both challenge the already existing assumptions and fixations and to provide experiments on high risk ideas that could provide high returns and learnings for the team in their final solutions (Domingo et al., 2020).

\section{Funky System Prototype (FKSP):}

The focus of the previous prototypes has been to explore individual elements of the overall system (CFP \& CEP) and to expand the possibilities of what those elements could be (DHP). However, to this point very little has been explored in terms of the overall system and how different subcomponents or elements come together into the full system. The funky element of this prototype indicates however, that the coming together of the elements into the full system are done in 
'low-resolution' or even 'hacked' together in a quick and inexpensive matter in order to explore what the system could be (Domingo et al., 2020). This prototype marks the middle point in between divergence and converge as in the beginning the mission is in the exploration stage of what a system could be, and which elements might comprise it and at the end of the mission the team start to set and consider that possible system.

\section{Functional System Prototype (FSP):}

After the Funky prototype the teams of students have started to consider what the overall system could be and in this Functional System Prototype that consideration is taken further into a more define one. The FSP marks the definite beginning of the convergence stage towards a final solution. The expectation for the FSP is that it should provide a medium-high fidelity prototype that even if not fully integrated it should perform as much as possible the intended functionality (Domingo et al., 2020). The purpose of this is to force the team to consider elements of technical implementation such as performance of the system and production of the different elements (Domingo et al., 2020).

\section{$X$-is-Finished Prototype (XFP):}

The $\mathrm{X}$-is-Finished Prototype mission get the student teams closer to the final solution as it moves deeper into the convergence stage. In the XFP the students select and build a high-fidelity or finalized prototype of a critical or non-trivial element of the final system (ME310 Intranet, 2020; Domingo et al, 2020). The purpose of the $\mathrm{XFP}$ is to help the team reduce the number of elements that need to be built in the final mission but also to force them to consider final dimension and final materials that would be used (Stanford ME310). 


\section{Final Prototype:}

The last mission of the project is to produce a finalized high-fidelity solution that "integrates fully functional prototyped and refined systems" (Domingo et al., 2020, p. 1965). As part of the final mission, the teams also produce a number of deliverables of the project such as documentation of the prototype and process, a business case for the solution and a narrative of how the product answer the needs of the users (Domingo et al., 2020).

\subsubsection{The Briefs}

As it is expected the diversity previously mentioned is very much reflected on the design brief document that serves as starting point to each project. Some organization come to the project with more problemistic-driven motivation (Cyert \& March, 1963), seeking answers to a rather particular problem that has been identified and formulated. Others may have a more slack-driven motivation with a more open to experimentation and consecutively with a less clearly developed formulation. These differences are also reflected in the different levels of prior knowledge that the organization may have in regard to the challenge. An organization that has identified a clear problem has a higher chance to put forth a larger amount of preexisting information than an organization wanting to openly explore new possibilities. And so, the design briefs come in all shapes and sizes.

For this thesis I was granted access to briefs of 118 design projects across 14 years. It is very important to note that for this study the data used was the initial brief which could be understood as the state of the problem in $t=0$. As it was expressed in the theoretical chapter, a rather important part of the design process is the iterative and 
mutual exploration of the problem and the solution through the use of experimental solutions or prototypes that expand the knowledge of the practitioner as the process progresses. This means that after an initial exploration of the brief each design team should, theoretically, have re-framed the problem to include newly found information.

One of the most interesting aspects of these design projects, as mentioned before, is their uniqueness. No project is exactly the same as another and no brief is exactly the same both in the physical characteristics of the brief and the intrinsic characteristics of the problem. Among the 118 briefs that where obtained for this thesis we can find all manner of formulations. They vary in size, with some briefs including several pages of text and information to briefs that are but a single paragraph. The briefs contained large explanations regarding the why's and the who's of the projects while others contained no mentions of reasons or stakeholders. Regarding the problem, some briefs had different types of goals, information of problem or solution space and where oriented to different timelines with some where the problem might be located 10 or 20 years into the future, while others deal with current problems.

Despite the many differences mentioned before, the constant of the projects is that there is always a brief that initiates the design process and that communicates in one way or another pertinent information about the projects that ignites the process.

\subsection{Building the Codex}

Once I got access to the 118 briefs that constitute the data, the next step that followed was to establish what would be the desired outcome of analyzing the data. It was very much emphasized from 
the beginning that the study of this briefs was not going to be a quantitative study that would allow me to reach through deductive reasoning a logical conclusion that generalized all design briefs into a taxonomy of briefs. This would rather negate the uniqueness of each project. The idea was rather to use a qualitative approach to analyze the design briefs coupled with abductive reasoning. The journey started in theoretical articles about problem-solving, design processes and problem formulation and from those I picked up a first set of dimensions and characteristics that could be used to understand the ingredients that made up the briefs. I then coded some of the briefs and found that there were aspects in there that my dimensions and characteristics did not cover. I then went back to the literature to see if I could find concepts that would describe what I had noted in the briefs, and iterated back and forth this way until a codex started to take form. With the final version of the codex I coded all briefs to see if certain dimensions and characteristics seemed to cluster and belong together when people write briefs. I then extrapolated those clusters into a typology of briefs and connected it to dimensions and characteristics of search processes and known cause-effect relationships from that literature. This was done to help us understand better the consequences that initial problem formulations can have in the rest of the design search process.

\subsubsection{Typology vs Taxonomy}

It is important to note that the main desire of this thesis was to provide a typology of design briefs and not taxonomy of briefs. However, this requires a quick clarification of what a typology is and why it differs from a classification scheme. To do so, I would use the clarification provided by Doty and Glick (Doty \& Glick, 1994). Firstly, Doty 
and Glick provide a definition of taxonomy and other classification schemes which "refer to classification systems that categorize phenomena into mutually exclusive and exhaustive sets with a series of discrete decision rules" (Doty \& Glick, 1994, p. 232). While a typology "refers to conceptually derived interrelated sets of ideal types" (Doty \& Glick, 1994, p. 232). This distinction is important in order to establish that this typology aims at providing ideal types of briefs that share a combination of attributes that present relevant information regarding the possible implications in the design process of each type.

\subsubsection{Characteristics of a Brief}

In the process of the creating the clusters that led to a typology, the initial step was to identify which were the characteristics of a brief that allowed us to recognize the patterns that formed the cluster. Here is where I pick back up the story of how this research happened after the first question was identified from the initial study on design fixation.

The identification of the characteristics came from both the theoretical foundation laid by previous researchers and showed in the theoretical chapter but also through contrast with more practical characteristics that were identified through interaction with the briefs. This process of identification of the characteristics led to three different prototypes or versions of the codex that evolved to better represent the characteristics found in the briefs and the ones found in the design and problem formulation theory. 
As discuss previously in chapter 3. we can identify and characterize problems based on a group of variables or characteristics that the problem poses. Through Simon (1973) and then expanded by other researches (Hoppe, 2002; Smy et al., 2016), we have already learned about problem structure and the characteristics that make it so. The characteristics being the ones previously mentioned: goal definition, knowledge of problem domain, criterion for solution, possible solution paths, and limitations or constrains. However, some of these characteristics remain open and allow for further definition.

\subsubsection{First Codex Prototype}

As stated in the theoretical chapter, in order to build a codex of characteristics of problem formulation we must combine knowledge found in the design and problem formulation literature of the different aspects of problems and their formulation. This combination led to a first prototype of a codex (table 1.) that I built as a first attempt to encapsulate the characteristics that make up a design brief.

For the development of the first prototype of codex some categories need further development in order to allow a practical sorting of the briefs. These categories were type of goals and objectives of the formulation. For types of goals, the categories I used came from Volkema's (2009) study of the linguistic structure in problem formulations. For the objectives of the formulation, the categories that I used had its foundation on the categories created by Volkema (1986) in the separation of different purposes of a formulation based on the problem statements. 
Table 1.

First codex prototype

Theoretically obtained characteristics

1. Type of problem structure

a. Well-structured

b. Ill-structured

2. Type of goals

a. Open goals

i. To solve an Issue

ii. Unqualified goal

b. Specific goals

i. Quantified goal

ii. Hierarchical goal

iii. Conjunctive goal

iv. Disjunctive goal

3. Objectives of the formulation
a. serve as a starting point
b. suggest a procedure
c. put the problem in a form that can be passed on to others
d. rearrange priorities
e. narrow the problem to make it more manageable
f. generate solutions
g. generate other problem statements that are rich in solutions
h. indicate who will be affected by the solution
i. circumscribe the situation
j. As a means of measurement,
k. ensure that a desired solution is considered
1. obscure or eliminate certain solutions
m. hide certain aspects of the problem

Practical characteristics

(Pre established from empirical experience)

1. Type of timeframe
a. Present oriented
b. Future oriented 
2. Semantics and syntaxis

a. Problem space description

i. Detailed description

ii. Vague description

b. Solution space description

i. Detailed description

ii. Vague description

3. Other relevant information
a. Empirical support
b. Inclusion of examples
c. Benchmarking
d. Competitors
e. Users
f. Visual aids

This attempt to create a sorting tool or codex was done knowingly that it was going to be a first attempt at trying to identify all the relevant characteristics and that it might fall short once it was applied to the design briefs. However, the intention of this first prototype was to establish grey zones where further theoretical knowledge was needed, and which practical characteristics were prominent.

After this prototype was created, I used it in order to characterize a number of the briefs in order to determine its validity and completeness. From this initial prototype I gathered several important lessons that informed the creation of the next prototype. Firstly, it became obvious that the two overarching categories were not truly descriptive of the briefs. It became more relevant to look at problem formulation structure from two overarching categories, 
Characteristics of the Problem presented by the corporate sponsor and Characteristics of the problem formulation. This change meant that characteristics where no longer distinguished as theoretical or practical but rather if they describe the problem the design team will tackle or if they describe how it was formulated.

Furthermore, for some of the categories of this first prototype it became obvious that a clear criterion needed to be established in order to consistently characterize the briefs in the same category. One such category was problem structure. The immediate question became, what constitutes a well-structured problem and what is an ill-structured problem. In the case of these specific category, the original text by Simon was used in conjunction with Smy et al. (2016) and Hoppe (2002) was used to establish that:

Well-structured problems:

- Steps to solve are identifiable

- Problem solver is aware of constrains and limitations

- Any solution is testable

- Knowledge to solve the problem is accessible.

Ill structured:

- No specific goal can be found

- No clear end state is defined

- There is no clear path to solve it.

Furthermore, with the inclusion of this definitions and these articles it was also established that some problems inhabit in a structure state that is neither ill nor well defined but rather is semi or moderately 
defined where there might be clear or unclear goal, Clear or unclear end state, some possible paths to solve.

\subsubsection{Second Codex Prototype}

Based on the lessons learned a new prototype was created, where the options were either enhanced in order to define the sorting criterion, others were broadened to contain more options or in some cased re organized in a more suitable structure.

In order to better explained this second version, I would divide them in two, based on the overarching categories.

\section{Characteristics of the problem:}

In this section several of the characteristics received further development (Table. 2). The first category, type of structure, received both an expansion in order to include moderately structured problems and also a criterion definition in order to make classification clearer.

Second, the category of types of goal received very little change. First, the undefined goal category was added to the open goals to account for briefs that have no indication of a goal. Secondly, examples from the original types from Volkema (2009) where included to improve the sorting of the categories.

Finally, the type of goal timeframe category was also expanded in order to account for a larger spectrum of projects with different types of timelines. 
Table 2.

Characteristics of the problem:

1. Type of structure

a. Ill-structured (no specific goal, no clear end state, no clear path to solve)

b. Moderately structured (Clear or unclear goal, Clear or unclear end state, some possible paths to solve)

c. Well-structured (specific goal, clear end state, clear path to solve)

2. Type of goals

a. Open:

- Undefined

- To solve an Issue (vague) (ex. pollution)

- Unqualified goal (ex. To decrease pollution)

b. Specific:

- Quantified goal (ex. To decrease pollution by 10\%)

- Hierarchical goal (ex. Increase efficiency to decrease pollution)

- Conjunctive goal (ex. Decrease pollution and reduce oil dependency)

- Disjunctive goal (ex. To decrease pollution or reduce deforestation)

3. Type of goal timeframe
a. Distant Future oriented (10 or more years into the future)
b. Near Future oriented ( 2 to 9 years into the future)
c. Present oriented (for current market to 2 years)
d. Unspecified (No timeframe given)

\section{Characteristics of the formulation:}

This section (Table 3.) received a bigger overhaul compared to the characteristics of the problem. The first category that was changed was the one previously named semantics and syntaxis and was changed to types of description. The idea of this change was to be able to characterize how much information was provided in regard to both the problem and the solution spaces. This proved to be a rather important change given that based on how much information is provided from each space would indicate if a brief leaned more to being problem focused or solution focused. 
The next category, types of objectives, remained from the previous version but received some changes. This category was based on the list presented by Volkema (1986) when referring to purposes served by the problem statements. However, in order to make the classification clearer the purposes were clustered based on the different purposes they served. Furthermore, in between version 2 and version 3 it was also further divided into generative purposes and constrictive purposes.

Finally, a new category of supportive material was added. This category served to classify briefs that added extra information which in some cases could constitute sources of fixation or inspiration and could be material for further exploration in future research.

Table 3.

Characteristics of the formulation:

1. Types of description

a. Problem space:

- Detailed description (provided and clearly stated)

- Vague description (somewhat provided but not clearly stated)

- No description (not provided)

b. Solution space:

- Detailed description (provided and clearly stated)

- Vague description (somewhat provided but not clearly stated)

- No description (not provided)

2. Type of Objectives (the objective of the formulation is to...)

Generative formulations

a. Generate:

- generate solutions

- generate other problem statements 
Table 3. Continuation

b. Set up:

- serve as a starting point

- circumscribe the situation (i.e. outline boundaries)

c. Question:

- Question assumptions of current state

- Confronts the current solutions that exist

Constrictive formulations

d. Limit:

- obscure or eliminate certain solutions

- hide certain aspects of the problem

- a desired solution is considered (i.e. to target the solution-set)

e. Define:

- put the problem in a form that can be passed on to others

- narrow the problem to make it more manageable

f. Indicate:

- suggest a procedure

- rearrange priorities

- indicate who will be affected by the solution

- As a means of measurement, to know when and if the problem is solved

3. Types of supportive material
a. Problem space representations (ex. Images, charts, diagrams, descriptions)
b. Solution space representations (ex. Images, charts, of existing or possible/desired solutions)
c. Users (example of existing or possible/desired users)
d. Research material (Empirical or Theoretical information on both solution and problem space)
e. Benchmarking (ex. solutions or projects done by others)
f. Industry background (Industry and company background information) 


\section{Lessons from the second prototype:}

This second prototype proved to be a much better tool in order to characterize the different briefs. When the codex was applied to the design briefs it already proved to be more complete. However, in the final round of testing the codex against the briefs a couple of elements of the brief seemed unaccounted for.

In the category of characteristics of the formulation it became evident through observation that different briefs exhibited different types of expected outcomes that were being made explicit. This expected outcome did not refer to specific desired solutions, but rather to the character of the outcome. This character of the outcome manifested in two characteristics. One is the form that the outcome might take either by explicit request or by the intrinsic characteristics of the organization: It was dived in Physical, digital, hybrid outcome or undefined. And the second referred to the type of outcome divided into product, service, process, subcomponent or no indication of a desired form of the outcome.

In the category of characteristics of the problem it also became evident that, independent of the degree of information provided in both the problem and the solution space, there was evidence that different briefs dealt with completely different sizes of space to explore. As an example of this, one brief would ask a design team to explore a problem space such as solution the steering wheel of a vehicle while in the next brief a team was asked to explore the space of the complete industry of UAVs. This for the design process means that a bigger problem space would require a more time in order to explore and understand such a vast space compared to exploring a small component of a product. 
The problem space is a metaphorical way of describing the space where the problem is located which in term means that there is no definition of what constitutes or does not constitute a problem space and there is no current denomination of different sizes of problem spaces. Because of this I was forced to divide this metaphorical space into different sizes to account for teams having to inherently survey a bigger or smaller space (Figure 10.). Given that the projects that serve as data are embedded in a corporate setting where the intention is to create a product for an organization, the definition given to problem space as levels of openness and closeness are based on the Global Industry Classification Standards. The levels are as follow:
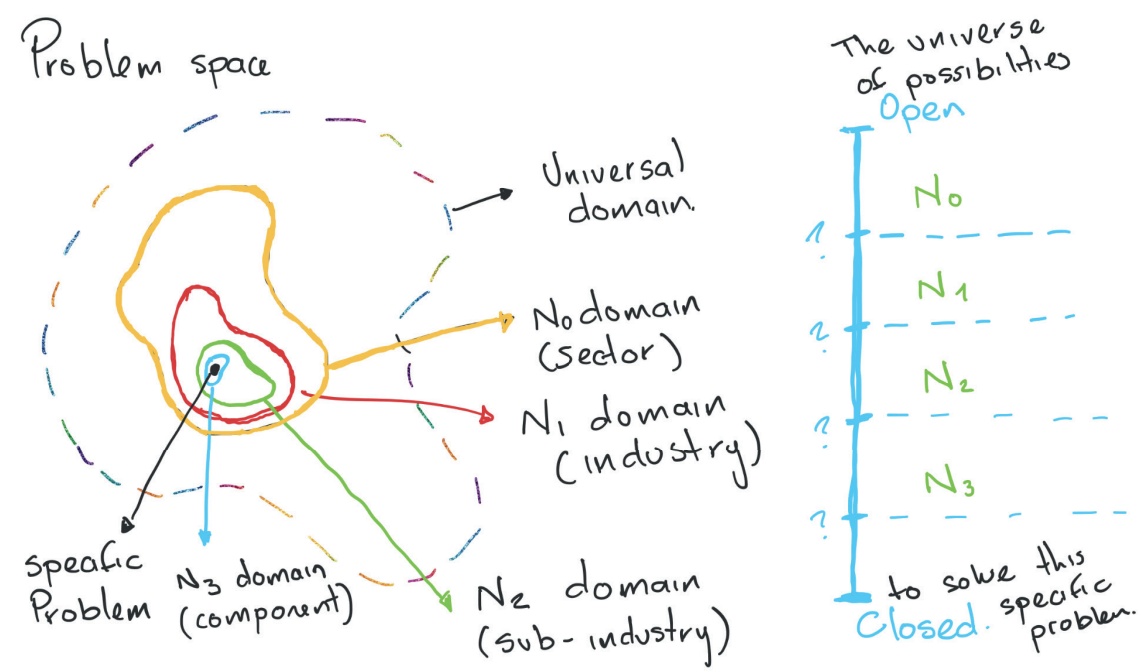

Figure 10. Initial definition of problem space sizes from my research notes 
- N0: No domain, the problem space extends to a search within all sectors (Universal domain)

- N1: Industry groups domain, the problem space extends to a search within one specific 'Industrial group' (Telecoms, Health care, Software services, automobiles, transportation)

- N2: Industry domain, the problem space extends to a search within one specific industry (Ex. within automobiles: autos, components)

- N3: Subindustry domain, the problem space extends to a search within 'one specific subindustry' (Ex. within Health Care providers: facilities, services, distributers)

- N4: Product domain, the problem space extends to a search within one specific product (specific company or product within any of the mentioned subindustries)

These are the spaces where the design teams are supposed to search. That being said it goes without saying that as part of the design thinking process, stretching the limits of what constitutes the problem is very much encouraged. This means that even though they can stretch what the problem space in which the solution might be, this is the space in which this first picture of the brief in $t=0$ is indicating where they need to search.

\subsubsection{Final Codex Prototype}

With the implementation of the last categories added, the final codex (Table 4a. and 4b.) was finished and with the use of the qualitative research software Nvivo and Microsoft Excel, the process of sorting the 118 briefs into these categories began. 
Table 4a.

Characteristics of the problem:

1. Type of structure

a. Ill-structured (no specific goal, no clear end state, no clear path to solve)

b. Moderately structured (Clear or unclear goal, Clear or unclear end state, some possible paths to solve)

c. Well-structured (specific goal, clear end state, clear path to solve)

2. Type of goals

a. Open:

- Undefined

- To solve an Issue (vague) (ex. pollution)

- Unqualified goal (ex. To decrease pollution)

b. Specific:

- Quantified goal (ex. To decrease pollution by 10\%)

- Hierarchical goal (ex. Increase efficiency to decrease pollution)

- Conjunctive goal (ex. Decrease pollution and reduce oil dependency)

- Disjunctive goal (ex. To decrease pollution or reduce deforestation)

3. Type of goal timeframe

a. Distant Future oriented (10 or more years into the future)

b. Near Future oriented ( 2 to 9 years into the future)

c. Present oriented (for current market to 2 years)

d. Unspecified (No timeframe given)

4. Type of problem space size

No No domain or multi-industry domain (Universal domain)

N1 Industry groups domain (Telecoms, Healthcare, Software services, automobiles, transportation)

N2 Industry domain (ex. within health care: providers, equipment, HC tech)

N3 Subindustry domain (Ex. within HC providers: facilities, services, distributers)

N4 Company/Product domain (specific company or product within any of the mentioned subindustries 
Characteristics of the formulation:

1. Types of character of the outcomes
a. Form of the outcome:
b. Physical
c. Digital
d. Both/Hybrid
e. Unspecified

2. Type of Outcome:
a. Physical product
b. Service
c. Subcomponent of a larger product
d. Strategy or new business model
e. System of products or services
f. Unspecified

3. Types of description

a. Problem space:

- Detailed description (provided and clearly stated)

- Vague description (somewhat provided but not clearly stated)

- No description (not provided)

b. Solution space:

- Detailed description (provided and clearly stated)

- Vague description (somewhat provided but not clearly stated)

- No description (not provided)

2. Type of Objectives (the objective of the formulation is to...)

Generative formulations

a. Generate:

- generate solutions

- generate other problem statements

b. Set up:

- serve as a starting point

- circumscribe the situation (i.e. outline boundaries) 
The Problem of Formulating Design Problems

Table 4b. Continuation

c. Question:

- Question assumptions of current state

- Confronts the current solutions that exist

Constrictive formulations

d. Limit:

- obscure or eliminate certain solutions

- hide certain aspects of the problem

- a desired solution is considered (i.e. to target the solution-set)

e. Define:

- put the problem in a form that can be passed on to others

- narrow the problem to make it more manageable

3. Types of supportive material

a. Problem space representations (ex. Images, charts, diagrams, descriptions)

b. Solution space representations (ex. Images, charts, of existing or possible/desired solutions)

c. Users (example of existing or possible/desired users)

d. Research material (Empirical or Theoretical information on both solution and problem space)

e. Benchmarking (ex. solutions or projects done by others)

f. Industry background (Industry and company background information) 
A Typology of Design Briefs 


$$
\text { A Brief }
$$

Explanation of the Use of the Codex

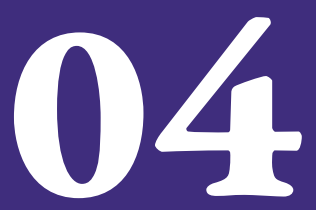


Chapter 4

\section{A Brief Explanation of the Use of the Codex}

This next chapter of this thesis will serve as a continuation of the presiding methodological chapter and its narrative structure. Consecutively, the data and results produced by the application of the codex will be presented and will finally lead to the creation of the typology which represents the outcome of this thesis.

In order to achieve this the structure that will be followed is to divide the delivery of the results into two separate sections. First, this chapter will follow how the codex was applied to the design briefs and what further data and results came out of doing so. Secondly, in the next chapter, based on the findings of the data from the design briefs coupled with the theoretical concepts of problem solving that were presented in the theoretical frame, the typology will be introduced.

\subsection{Applying the Codex to the Briefs}

\section{Considerations}

Before the results of applying the codex to the design briefs are presented there are two important consideration that have to be made. The first consideration concerns with the replicability of the 
study and the need to maintain consistency in the application of the codex. First and foremost, as this study was a qualitative analysis of these documents some basic criteria had to be established in each of the characteristics in order to define what made a brief possess one characteristic or the other. Some of these characteristics were very much self-explanatory and in its own definition laid the criteria for selection. While in other cases further definition was needed.

In order to create a reliable codex that could be applied consistently to all the briefs a small guide of the codex was designed and used. The guide aimed at defining a criterion for selection in some categories where the characteristic was not readily found in the text and where interpretation of the text was needed. Nonetheless, given that these documents were not written with this research in mind, some judgement calls and decisions had to be made in order to define some of the less evident briefs.

The second consideration to the application of the codex relates to the interpretation of the information obtained when the codex is applied. This study is not meant to be a quantifiable and statistical analysis of the results of assigning these values to the briefs. Rather, as it has been explained before, an identification of patterns and clusters of types of briefs to inform the constructions of a typology based on the observation of the coding and the theoretical underpinnings of problem formulation and design briefs literature. However, some numerical results will be presented here, not with the intention of using said numerical results as demonstration of behavior but rather indications of behavior that leads to identification of patterns. 


\section{The procedure of applying the codex}

The process of applying the codex to the design briefs was done with the aid of two different software. First, I used the qualitative data analysis software Nvivo which was used to organize the data and to aggregate markers in the form of nodes on top of each design brief. In this software the codex was translated into the previously mentioned nodes that helped to denotate where, specifically, in the text the information can be found that indicates the existence of one of the characteristics. This process helped to identify the different characteristics but also as a tool for traceability for future studies.

The second software that I used was a simple spreadsheet that helped to organize and categorize each document. The use of a secondary software became apparent when I identified that not all characteristics can be pinpointed in the text as they need to be interpreted from context and the language used in the document rather than to a specific paragraph or line. In the spreadsheet a table that contained all of the characteristics and attributes of the codex was created and each document was assigned placed in the table and the characteristics denoted in Nvivo were marked in the spreadsheet as follows in the example in figure 11.

\subsection{Information Obtained From the Design Briefs}

\section{Initial data exploration}

After all the 118 design briefs were assigned the different characteristics the next step was to do a simple sum in each of the categories in order to try to identify immediate tendencies or common behaviors in this 


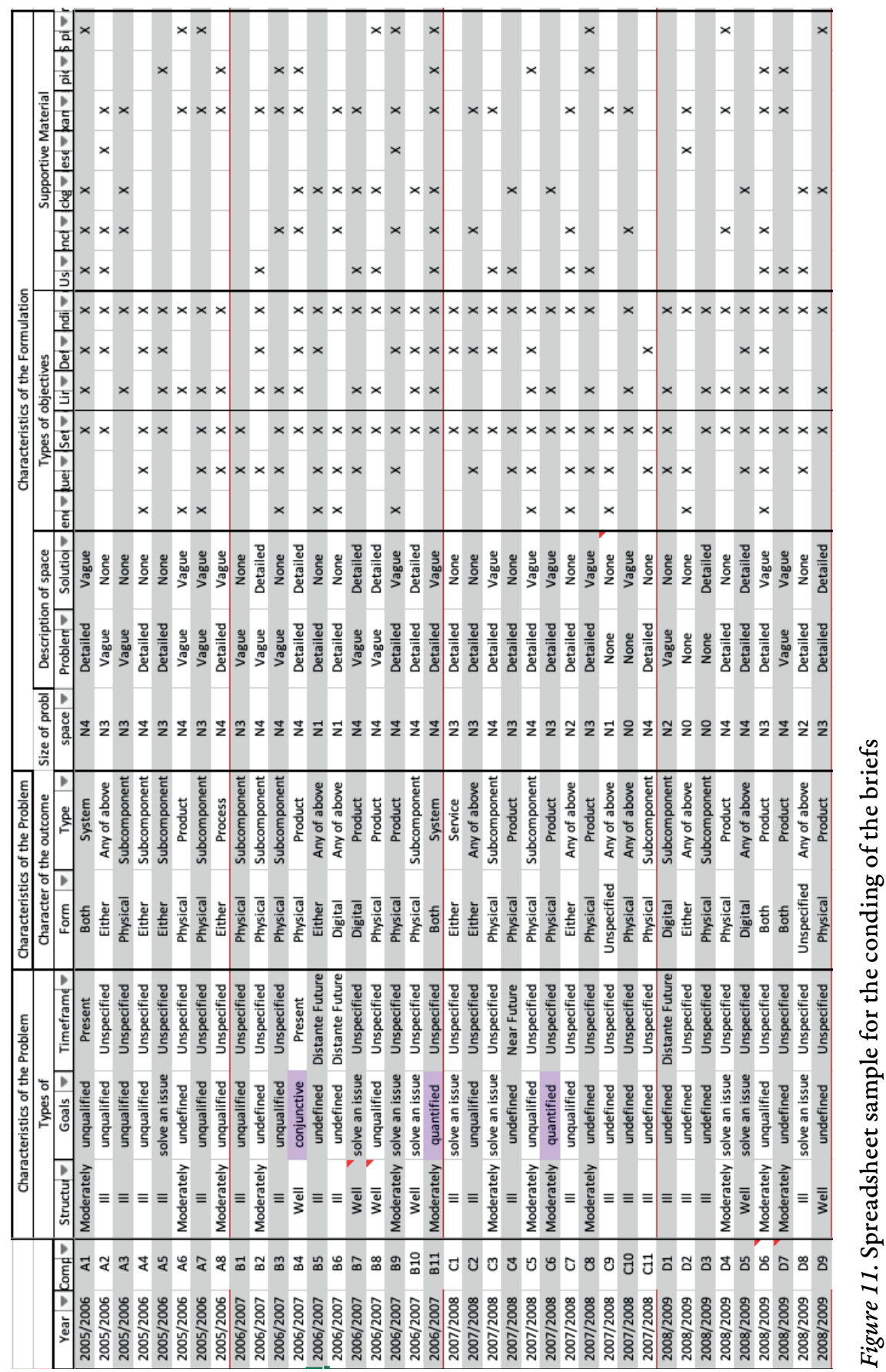


group of design briefs. In this first counting some initial tendencies started to appear that were indicative of the nature of design projects that also concurred with the theoretical understanding of design problems presented in the theoretical framing. Among this I observed that a majority of the problems where of the ill-structure kind, however very closely followed the moderately structure (figure 12a). This in turn showed that the vast majority of projects had open type goals (figure 12b) which is very closely related to the structure presented by the problem.

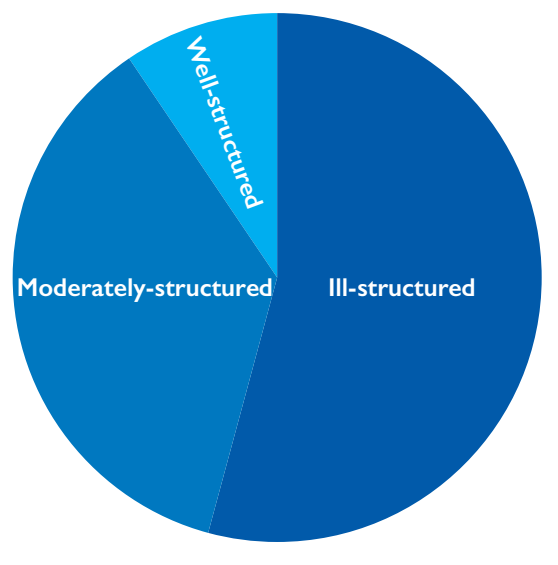

Type of Problem Structure

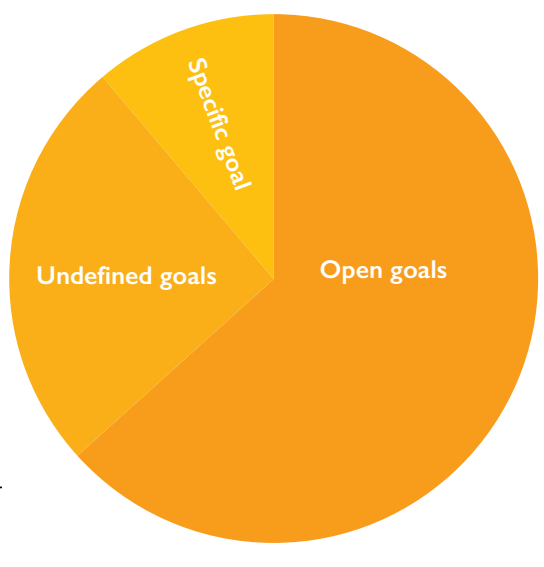

Type of Goal

Figure 12a. Proportion of briefs based on type of problem structure Figure 12b. Proportion of briefs based on type of goal

However, a group of characteristics showed to be less consequential and very much connected with ill to moderately structure problems with open or undefined goals. These were the characteristics that pertained to the character of the outcome as it seemed that by a large margin the design briefs either mentioned openness to any kind of character or failed to mention the desire for any specific character of 
outcome required in the solution. Nevertheless, the few briefs that do specify a desire for a specific character fall within the physical products which could be related to the nature of the setting in which the projects are embedded which is product design.

\section{Problem and solution spaces}

During the process of the coding, and prior to finalizing the marking and classification of all the briefs, I observed that three categories seemed to have the most relevance in the text of the briefs. These categories were the ones connected to the spaces in which the project is located, the problem space, the solution space and their sizes. The initial observation from coding the briefs was the identification of two very specifical types of briefs that were located in opposite extremes.

On the one hand side there were briefs that contained very specific explanations of what the problem was and what the solution ought to be and how it ought to perform. This first extreme of problem formulation contained very specific problem and solutions spaces and in the majority of the cases the size of the problem fell within very specific products or components of a product. This in turn reduced the size of these spaces to the size of the product itself, or according to the codex, type $\mathrm{N} 4$ of problem space. These kinds of briefs were dubbed 'a problem waiting for a solution to be assembled', and later on directed search briefs, as their intention was to produce a viable solution that fulfil the requirements rather than inventing or discovering an unforeseen solution.

On the opposite side of the spectrum where the briefs that provided very little to no information regarding the problem space or the 
solution space. The main characteristic that could be found in this type of briefs was that it lacked concrete information regarding any of the spaces and only provided a general area of interest. These kinds of briefs were dubbed 'a project looking for both a problem and a solution', and later on discovery search briefs. In some of the more extreme cases we could find briefs of a single paragraph or a couple of lines providing very little information. As an additional characteristic this type of briefs would contain a very open area of exploration such as exploring an industry or even multiple industries to try to find a problem to address and a solution within that problem space. An example of such a brief would contain a problem formulation like: "New product or service that takes advantage of emerging portable MRI technology. What if MRI machines were small enough to wheel out onto a football field or the site of an accident".

Within the boundaries of these two extremes we could then find design briefs in very different states of definition of problem spaces and solution spaces within the coding scheme of the codex. This observation led to the creation of an early hypothesis of clustering the design briefs based on the amount of information provided in terms of problem and solution spaces. The hypothesis was based on the codex definition that all briefs contain either detailed, vague or no information regarding the problem space and the solution space (figure 13) and that based in this pairing of attributes we might observe some commonalities.

\subsection{Grouping and Clustering}

Upon completion of the coding of all briefs the next step to examine, in order to identify the patterns in which briefs could be clustered, 


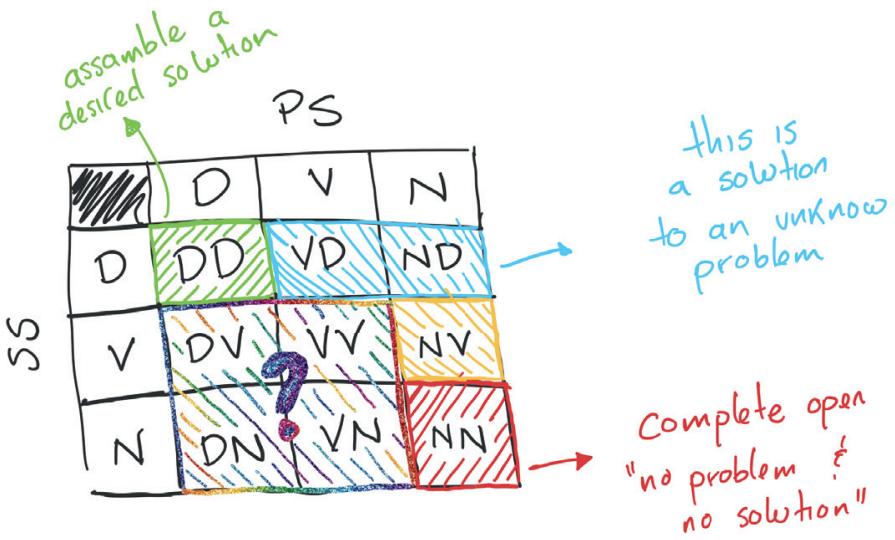

Figure 13. Initial clustering based on problem space and solution space definition from my research notes

was the grouping and analyzing of briefs based on the information provided in regard to the problem and the solution space. In this step, with the use of filters in the spreadsheet that helped to group the briefs based on the richness of information presented on the problem space and the solution space, the briefs were divided into 9 distinct categories. The 9 categories can be identified as the 9 different quadrants on table 14, where PS is Problem Space and SS is Solution space.

\begin{tabular}{l|l|l|l|}
\multicolumn{2}{c}{ PS DEFINED } & PS VAGUE & NO PS \\
\hline \multirow{2}{*}{ SS DEFINED } & $\begin{array}{l}\text { PS Defined } \\
\text { SS Defined }\end{array}$ & $\begin{array}{l}\text { PS Vague } \\
\text { SS Defined }\end{array}$ & $\begin{array}{l}\text { No PS } \\
\text { SS Defined }\end{array}$ \\
\cline { 2 - 4 } SS VAGUE & $\begin{array}{l}\text { PS Defined } \\
\text { SS Vague }\end{array}$ & $\begin{array}{l}\text { PS Vague } \\
\text { SS Vague }\end{array}$ & $\begin{array}{l}\text { No PS } \\
\text { SS Vague }\end{array}$ \\
\cline { 2 - 4 } NO SS & $\begin{array}{l}\text { PS Defined } \\
\text { No SS }\end{array}$ & $\begin{array}{l}\text { PS Vague } \\
\text { No SS }\end{array}$ & $\begin{array}{l}\text { No PS } \\
\text { No SS }\end{array}$ \\
\cline { 2 - 4 }
\end{tabular}

Figure 14. Categories selected for clustering 
However, this new grouping did not last long as a new process of filtering and organizing the data in accordance to this table showed similar behavior among some of the quadrants that could be combined and rearrange to include these similarities. The first combination showed that briefs that had PS Vague + SS Vague had similar characteristics that those with No PS + SS Vague and PS Vague + no SS (Figure 15).

\begin{tabular}{l|l|l|l|}
\multicolumn{2}{c}{ PS DEFINED } & PS VAGUE & \multicolumn{1}{c}{ NO PS } \\
\hline \multirow{2}{*}{ SS DEFINED } & $\begin{array}{l}\text { PS Defined } \\
\text { SS Defined }\end{array}$ & $\begin{array}{l}\text { PS Vague } \\
\text { SS Defined }\end{array}$ & $\begin{array}{l}\text { No PS } \\
\text { SS Defined }\end{array}$ \\
\cline { 2 - 4 } SS VAGUE & $\begin{array}{l}\text { PS Defined } \\
\text { SS Vague }\end{array}$ & $\begin{array}{l}\text { PS Vague } \\
\text { SS Vague }\end{array}$ & $\begin{array}{l}\text { No PS } \\
\text { SS Vague }\end{array}$ \\
\cline { 2 - 4 } & $\begin{array}{l}\text { PS Defined } \\
\text { No SS }\end{array}$ & $\begin{array}{l}\text { PS Vague } \\
\text { No SS }\end{array}$ & $\begin{array}{l}\text { No PS } \\
\text { No SS }\end{array}$ \\
\cline { 2 - 4 } & & \multicolumn{2}{c}{}
\end{tabular}

Figure 15. First grouping of briefs based on similar characteristics based on PS + SS definition

Subsequently, the second combination showed that briefs that had a PS define had similar characteristics when the solution spaces was either vague or non-given (Figure 16).

\begin{tabular}{l|l|l|l|}
\multicolumn{2}{c}{ PS DEFINED } & \multicolumn{1}{c}{ PS VAGUE } & \multicolumn{1}{c}{ NO PS } \\
\hline \multirow{2}{*}{ SS DEFINED } & $\begin{array}{l}\text { PS Defined } \\
\text { SS Defined }\end{array}$ & $\begin{array}{l}\text { PS Vague } \\
\text { SS Defined }\end{array}$ & $\begin{array}{l}\text { No PS } \\
\text { SS Defined }\end{array}$ \\
\cline { 2 - 4 } SS VAGUE & $\begin{array}{l}\text { PS Defined } \\
\text { SS Vague }\end{array}$ & $\begin{array}{l}\text { PS Vague } \\
\text { SS Vague }\end{array}$ & $\begin{array}{l}\text { No PS } \\
\text { SS Vague }\end{array}$ \\
\cline { 2 - 4 } & $\begin{array}{l}\text { PS Defined } \\
\text { No SS }\end{array}$ & $\begin{array}{l}\text { PS Vague } \\
\text { No SS }\end{array}$ & $\begin{array}{l}\text { No PS } \\
\text { No SS }\end{array}$ \\
\cline { 2 - 4 }
\end{tabular}

Figure 16. Second grouping of briefs based on similar characteristics based on PS + SS definition 
Finally, briefs that contained SS define but had either vague or nongiven PS also contained similar characteristics and could be combined into one (Figure 17).

\begin{tabular}{l|l|l|l|}
\multicolumn{2}{c}{ PS DEFINED } & \multicolumn{1}{c}{ PS VAGUE } & \multicolumn{1}{c}{ NO PS } \\
\hline \multirow{2}{*}{ SS DEFINED } & $\begin{array}{l}\text { PS Defined } \\
\text { SS Defined }\end{array}$ & $\begin{array}{l}\text { PS Vague } \\
\text { SS Defined }\end{array}$ & $\begin{array}{l}\text { No PS } \\
\text { SS Defined }\end{array}$ \\
\cline { 2 - 4 } SS VAGUE & $\begin{array}{l}\text { PS Defined } \\
\text { SS Vague }\end{array}$ & $\begin{array}{l}\text { PS Vague } \\
\text { SS Vague }\end{array}$ & $\begin{array}{l}\text { No PS } \\
\text { SS Vague }\end{array}$ \\
\cline { 2 - 4 } & $\begin{array}{l}\text { PS Defined } \\
\text { No SS }\end{array}$ & $\begin{array}{l}\text { PS Vague } \\
\text { No SS }\end{array}$ & $\begin{array}{l}\text { No PS } \\
\text { No SS }\end{array}$ \\
\cline { 2 - 4 }
\end{tabular}

Figure 17. Third grouping of briefs based on similar characteristics based on PS + SS definition

The new combination of categories of provided a better clustering of the briefs in accordance to the characteristics they possess. These new categories had similar orientation in terms of the initial framing of the projects. As some briefs tend to be more problem oriented and others more solution oriented as previously presented in other studies (Sosa et al., 2018). However, here it is also presented that beyond problem and solution oriented we might find more categories that separate themselves from these two categories established by Sosa et al. (Figure 18). First, there are those that where both the problem space and the solution space are well defined and are one step closer to an engineering project that a design one. At the other extreme of these types we may find the design briefs which have no orientation. In this cluster briefs provide a vague idea of what the problem or solution might be and orient the design team towards a discovery of what those vague ideas might be. Furthermore, within the discoveryoriented briefs, I identified a more extreme version, the open ended 
design briefs. These design briefs share similarities with the discoveryoriented one, however, the definition of the spaces were of the kind that had no indications of what the problem or the solution might be. This represented for the design team a white canvas to define both spaces which could allow for a wider but more risky exploration.

\begin{tabular}{l|l|ll|}
\multicolumn{2}{c}{ PS DEFINED } & PS VAGUE & NO PS \\
\hline SS DEFINED & Directed search & Solution Oriented \\
\cline { 2 - 2 } SS VAGUE & Problem Oriented & \multicolumn{2}{|l|}{ Discovery oriented } \\
\cline { 2 - 4 } NO SS & & & Open end \\
\cline { 2 - 4 } & &
\end{tabular}

Figure 18. Final grouping of briefs based on similar characteristics based on PS + SS definition

This new combination of cluster of briefs provided the building blocks for the typology that was then constructed building upon the types obtained from the exploration of the briefs with the theoretical underpinnings from the design field and problem solving.

\section{Typology and ideal types}

The next step in the process of construction of a typology of design briefs was to select the constructs that will ultimately make up the ideal types. However, before I explain which constructs were select it is necessary to insert a small clarification of what an ideal type is within the frame of a typology. As the main foundation of an understanding of what a typology is, I took Doty and Glick's (1994) article which discusses typologies as forms of theory building and the makings of 
typologies. In this article the authors not only differentiate typologies from taxonomies but also denotate ideal types as a central piece. These ideal types are then explained as "complex constructs that can be used to represent integrated configurations of unidimensional constructs" (Doty \& Glick, 1994, p. 233). Having ideal types as representations have three important implications: 1) Ideal types represent things that might exist rather than existing ones. 2) They describe complex multidimensional "phenomena" (Doty \& Glick, 1994, p. 233).3) They are not categories that can be used to sort things such as organizations, or in this case briefs, but rather they represent a "unique combination of the dimensions" (Doty \& Glick, 1994, p. 233).

Based on what I learned from analyzing the design briefs, the next step was to define the different constructions that would represent the ideal types on my typology from the perspective of the problems' characteristics. The first constructs that play the central part as the main dependent dimensions are the ones identified in the previous clustering of design briefs. The constructs are the amount of information provided of each space, or better yet level of definition of each space. This left me with two constructs, definition of problem space and definition of the solution space, and both their dimension are from undefined to defined (figure 19).

The final step on the process before the creation of the typology was to identify the other constructs and the dimensions that they have within the ideal types. These constructs were selected, from what I observed from the analysis of the design briefs, as the elements connected to the definition of problem spaces and the ones having theoretical influence over the search process. The first construct that was selected as being part of the ideal types and linked to the definition of the 


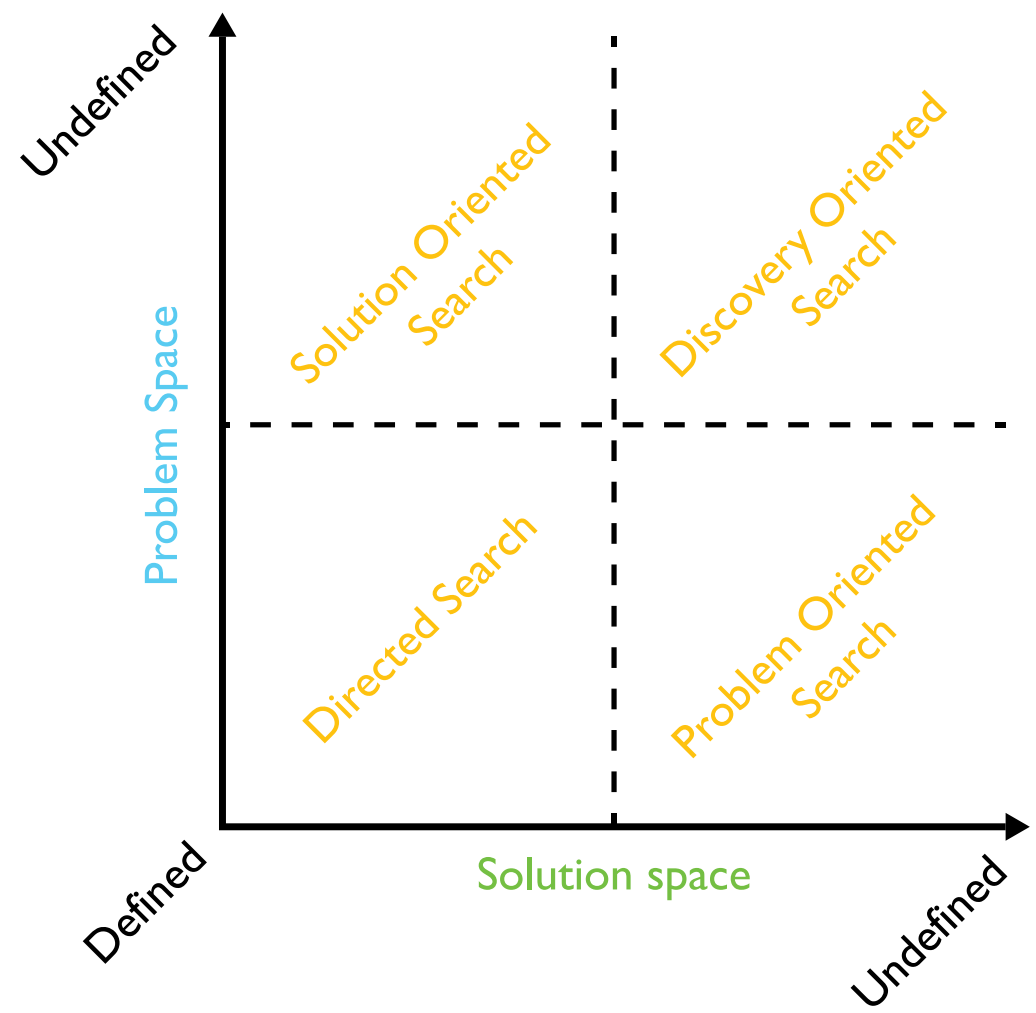

Figure 19. Typology quadrants based on the problem space and solution space constructs

problem was the proposed goal in the design brief. The dimensions of the goal construct are from determined to undetermined. The second construct was size of the spaces and boundaries. The dimensions for this construct was, small to large for size and fenced-off boundaries to open boundaries. Once these constructs were determined a graphic representation of them was created (Figure 20) that helped to visualize the constructs of each ideal type (Figure 21). 


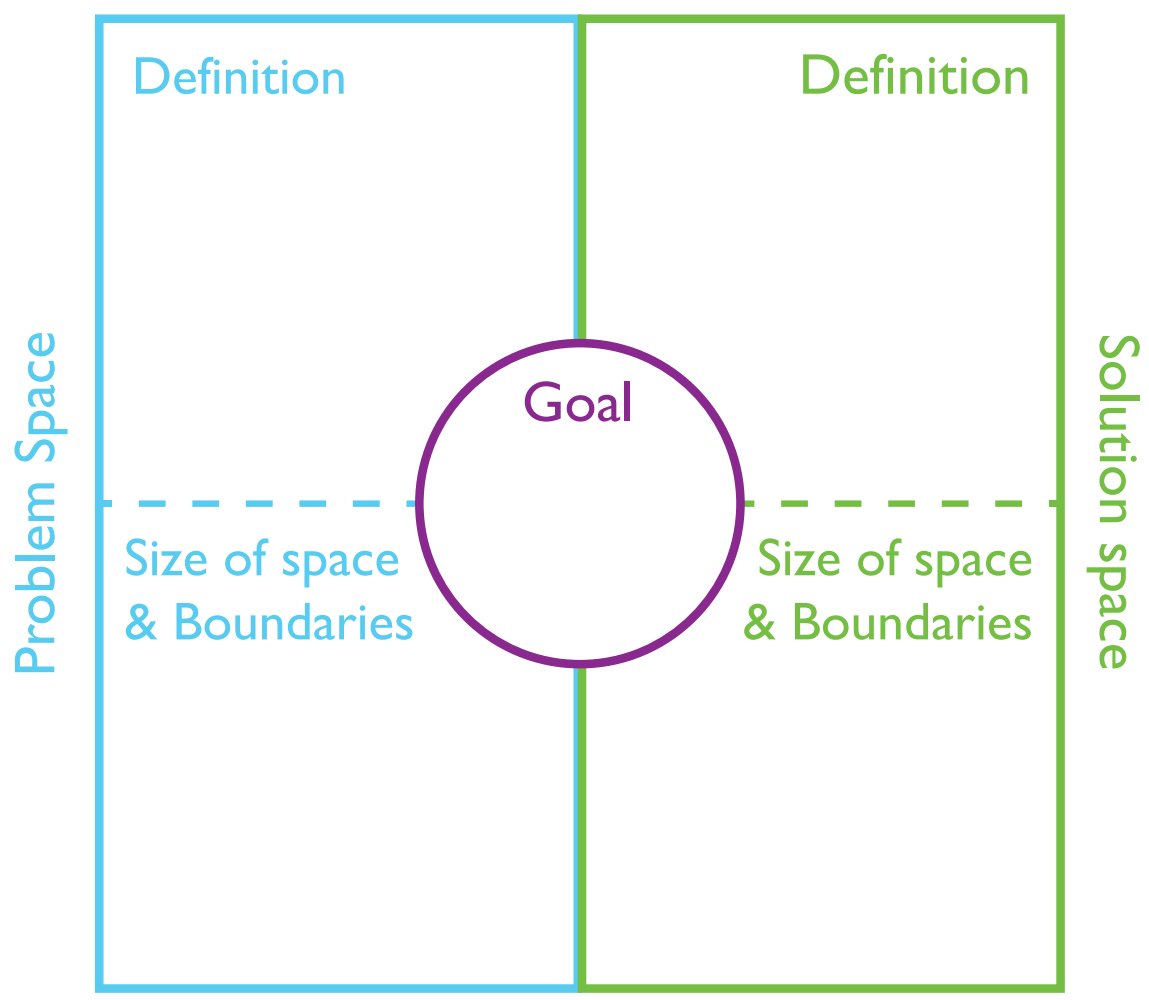

Figure 20. Represetations of the constructs selected for the typology 


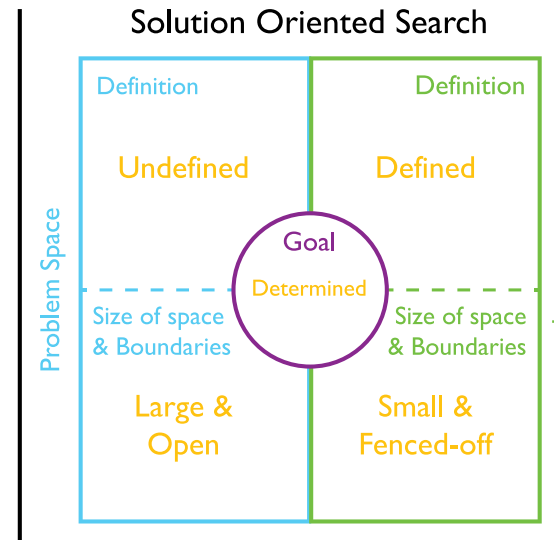

\section{Discovery Oriented Search}

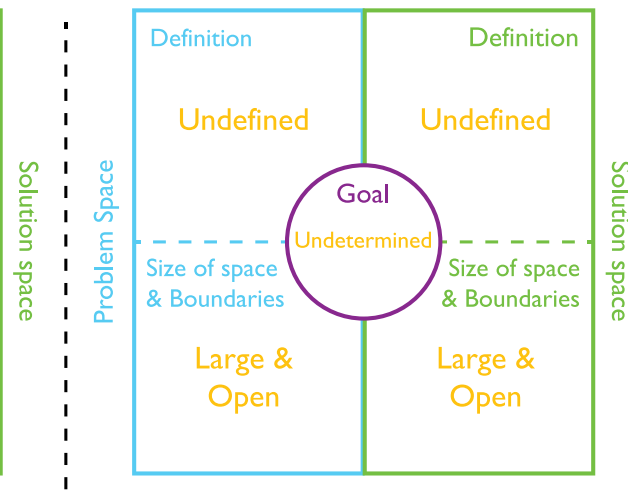

Directed Search

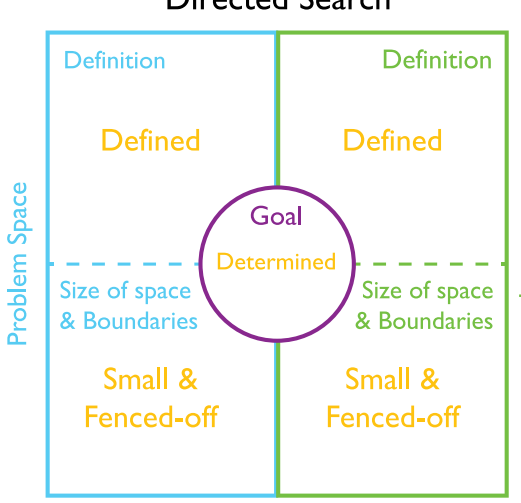

Problem Oriented Search

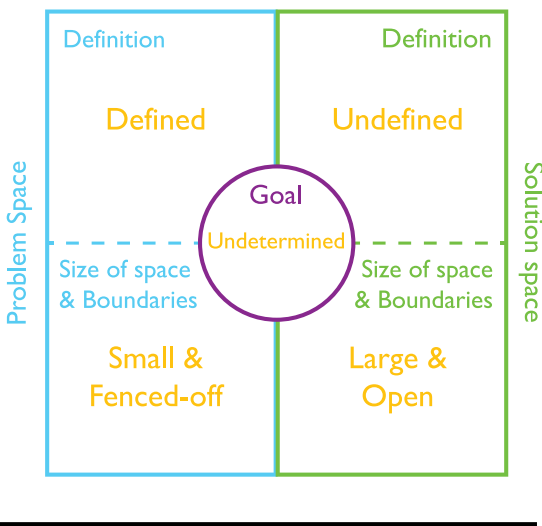

Figure 21. Represetations of the constructs selected for the typology plus the four ideal types 


$$
\begin{array}{r}
\text { A Brief } \\
\text { Typology }
\end{array}
$$

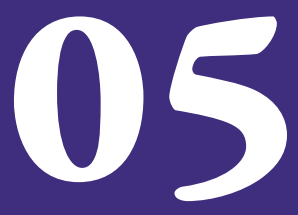




\section{Chapter 5}

\section{A Brief Typology}

\subsection{Grand Theoretical Assertion}

The underlying theoretical background of this typology is design problem solving where designers search for a satisfactory solution. Said search is viewed as an exploration of an unknown landscape that contains peaks, which represent potential solutions of varying quality. In the simulation settings of researchers such as Gavetti \& Levinthal (2000) some peaks may be locally optimal in the already searched space, but there may still be more globally optimal peaks out there in the yet to be searched landscape.

These simulations and ways of understanding the design problem solving process are simplified compared to the richness of a design process 'in the wild' (Crilly \& Cardoso, 2017), but the simplicity gives us indicators of cause and effect relationships that can be expected. By using the typology to understand the initial state of a project's knowledge of the problem and solution spaces we can then create hypotheses of the types of search behaviors that logically may be triggered and expected in the search process that follows. 


\section{Problem Characteristics}

The first set of these characteristics are the ones that allows us to create the ideal types and refer to the initial state of the problem formulation in the brief that precedes the exploration.

The first of these characteristics is the structure of the problem as defined by Simon (Simon, 1973) which connects to the goal of the exploration, given that the definition of goals plays a central role in giving structure to a problem. This characteristic refers mainly to the level of specificity or openness and measurability of said goals. In the codex used in the exploration and classification of the briefs these were operationalized by incorporating the work of Volkema (2009).

The other construct is an amalgamation of different characteristics, that put together, gives a picture of the Problem and Solution Spaces and how they are defined. To begin with, it must be clarified that the problem space is understood as the area in the landscape where the final problem to be addressed can be found, and then separately the solution space is the area of the landscape where the solution can be found. These two spaces interact with each other and the change, expansion, or definition of the problem space will have consequences for the solution space but at the same time exploration and expansion in the solution space might clarify and expand the problem space.

The first characteristic on these spaces refers to the richness of the description of space as stated in the brief. These characteristic serves to identify the amount of information presented before the exploration in terms of information about the space in which the problem is located and the space in which the solution is located. The second one refers to the Boundaries of the space. This characteristic represents 
how well delimited the spaces are by having soft or hard boundaries of what constitutes the space. A problem space with a defined boundary will make clear what constitutes or not the space, while an undefined one will not. And the third one refers to the size of the spaces to be explored. In an exploratory search it is not only important to know how richly the spaces have been described but also the size of them. A Search on a bigger space such as surveying a whole industry to define a problem differs greatly from a search in a smaller space such as a specific type of product.

\section{Consequences for the search processes}

The second set of characteristics refer to the implications and consequences that can then be derived from having a formulation of any of the types here presented.

The first of this implication is Search behavior and it refers to which type of process are likely to follow based on the characteristics of the problem. The type of process that might follow relate to patterns of search, types of expansion of search domains (Baumann \& Siggelkow, 2013), the tradeoffs between width and depth that arise from the qualities of the space presented in the brief and the probability of encouraging a search near (local) or far (distant) from current solutions (Gavetti \& Levinthal, 2000). The second characteristic refers to time as a constraint for the search process. The amount of time available, and the different characteristics of the spaces that need to be explored, can play a significant part in the strategy adopted for the allocation of time in the different stages. Here, the time allocation patterns of front-loading, fixed times and back-loading as presented by Baumann and Siggelkow (2013) serve to describe likely behaviors for each type of brief. 


\section{Examples}

An important part of the representation of each type is the use of examples in order to envision how each type may look like in a real context. The examples that are used are taken from the briefs in the data set for this thesis. This allows us to identify the different characteristics of each brief based on a real formulation of a problem. Permission to use these briefs as examples in this text has been granted. However, permission has not been granted to disclose details of the sponsoring company(s) or to provide access to the full documents. For this reason, here will only be presented excerpts that demonstrate the formulation of the problems in the design brief document as the design team received it. 


\subsection{Typology}

\section{Design Brief Type I: Directed Search}

A problem waiting for a solution to be assembled and tweaked

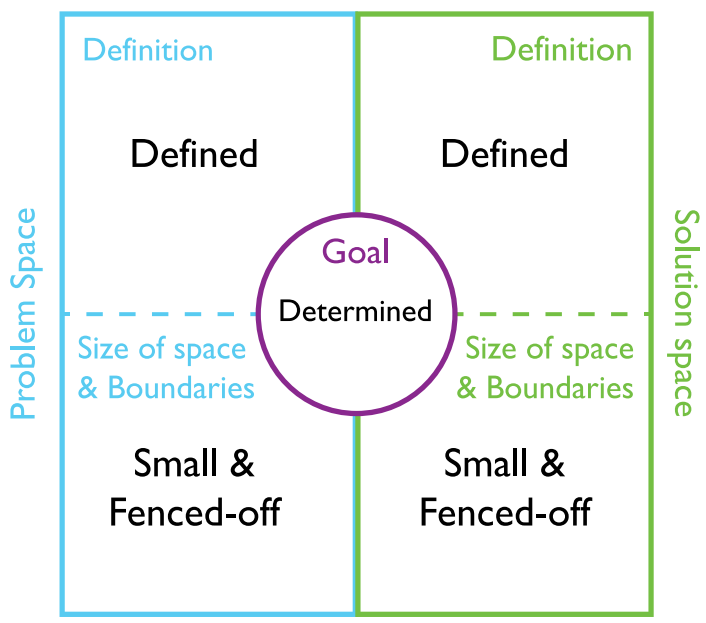

\section{Problem Characteristics:}

This type of brief has a clear beginning state where the problem is well-identified and fenced off, and where the knowledge to solve the problem is more or less available. Moreover, this type also has a defined solution space and a determined goal (in terms of character of the solution or a list of requirements rather than the actual embodiment of the solution will need). In this type, the desired goal is determined in a quantifiable manner that can be measured and indicates when a satisfactory outcome has been reached. This means that the proposed solutions are testable. Consequently, this type of brief has a close resemblance to a 'determinate problem' (Buchanan, 
1992) were the conditions of the problem have already been defined, making it a more trivial design problem (although the engineering of the solution may still be untrivial). Based on the characteristics mentioned above we can then say that this type of brief is of the WellStructured Problems kind as defined by Simon (1973). Finally, this type of brief typically gives the design team a rather small space to be survey both in terms of the problem and the solutions.

\section{Example:}

"The backbone of dental offices is the movement of air. Compressed air is utilized to run tools and dry working surfaces, while vacuum is used to keep the oral cavity clean. This requires a large investment from dentists to purchase and locate within their offices two separate pieces of machinery and the associated piping infrastructure, each specialized to a single task. This investment is much more a burden for small offices on a tight budget that have no alternative to the high price separate units. Finally, mobile dental teams have no equivalent options that are either light weight or inexpensive.

The goal of this project is to deliver a new air management system to the dental community that meets the following criteria: Single unit that provides compressed air and vacuum. Significant cost savings for smaller dental offices. Able to coexist within the operatory (noise control, size constraint). Meet the full air and vacuum requirements for one operatory. Smaller than conventional equipment but scalable and Easily transportable" 
In this problem formulation we can observe that both the problem and solution space are well defined. The area where the problem is located is rather defined and knowledge of where to search for solutions to the problem can be found. At the same time the desired goal is clear and non-ambiguous, where possible outcomes can be tested to ensure the requirements have been met.

\section{Search Behavior:}

Based on the characteristics mentioned above a Directed Type brief will tend to encourage the following search behaviors.

\section{Space exploration:}

Width

Depth

Width

Depth

The implication of having a small space to survey to get an overview means that in this type of process the teams can focus rather intensively to the exploration of the specific problem and the specific characteristics of the solutions gaining deeper understanding of a very small space. Additionally, this type of exploration prioritizes a narrow search with depth and high resolution of the outcome, rather than broad exploration of the landscape and more varied possibilities. 


\section{Search location:}

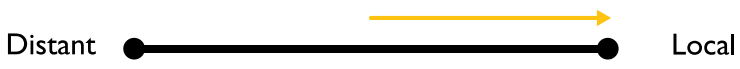

In this type of brief the combination of having a limited and richly described problem and solutions space and a specific goal that can be measured, encourages a search in the vicinity of the desired outcome making a wider and more distant search less likely. This in terms of types of innovation (Norman \& Verganti, 2014) indicates that an incremental improvement within a frame of known solutions is more likely than a radical innovation being achieved.

\section{Time allocation:}

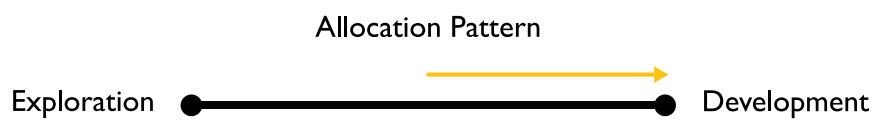

Pattern: Given the more manageable problem space and solution space size, for a Directed Type brief, a pattern of search that is integrated where the whole system is taken into account is likely to occur. This type of exploration requires that less time is allocated in the surveying of the problem space in order to better define it, since it has already been richly defined. Consequently, this means that more time can be spent in the development of the desired outcome which falls into a back-loading time allocation pattern (Baumann \& Siggelkow, 2013) where the majority of the time is allocated to the configuration of the final solution rather than in the early stages of the search process. 
Time of execution: The brief that follow the Directed Type structure starts with a rather small space to be surveyed both in terms of the problem and the solutions which in accordance with Bauman and Siggelkow is more desirable for searches with limited time.

Resolution of the outcome:

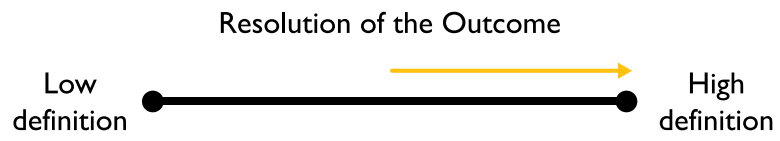

In this type of brief as explained before, the bulk of the exploration falls on the development of the outcome. This makes the Directed Type brief more suitable for projects where the motivation for the search is problemistic and the need to reach a high-resolution solution that meets the desired goal is the priority. 


\section{Design Brief Type II: Problem Oriented Search A problem waiting for a solution to be developed}

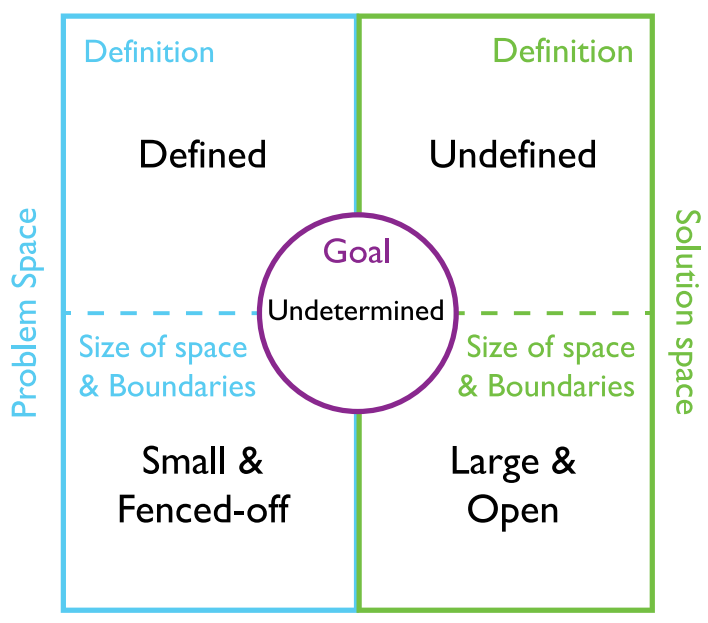

\section{Problem Characteristics:}

This type of brief has a clear beginning state where there is a rich description of what the problem space is and the border between what constitutes the problem and what does not is somewhat defined. However, the solution space is undefined and consequently no border of what might constitute a solution has been given, and an important part of the search is to define it and fence it off. This consequently means that the solution space is wide and there is an undetermined goal that is desired. In this type of brief the desired goal is established in terms that indicate an end state or value (Dorst, 2015), such as solving an issue. The goal is not necessarily measurable 
and optimizable, but something indicates that a satisfactory outcome has been reached. However, in this type of goals other mechanisms of acceptance of the solution, such as 'satisficing', need to be used. Based on the characteristics mentioned above we can then say that this type of brief is of the moderately-Structured Problems kind. Finally, this type of brief typically starts with a small or limited problem space to be survey and a large solution space that has no boundaries to be defined and surveyed.

\section{Example:}

"Open-top motoring is a lifestyle for many people. In California it is not uncommon for a person's primary vehicle to be a convertible-top car. For many, however, it is simply not practical for the primary vehicle to be a convertible due to either interior space requirements or climate restrictions. Hardtop convertibles provide a compromise between a fixed-top vehicle and a soft-top convertible. This solution, however, has drawbacks due to the requirements of a complex mechanical system, the reduced cargo area due to additional packaging, and the additional cost of the system.

The goal of this project is to design and build a concept that virtually recreates the feeling of a convertible vehicle. In addition to finding a solution through such means as displays, sounds, and lighting, what other features could such a system include? How could the vehicle occupants be able to customize such an experience?" 
In this problem formulation we can observe that the problem space is well defined. At the same time the desired goal is undetermined and open. The area where the solution might be located is rather undefined and it is unclear what it could be. Questions such as "What other features could such a system include?" or "How could the vehicle occupants be able to customize such an experience?" point to vague things to consider in the solution space without proposing or demanding a solution. A project of this type has identified problems and possible stake holders in the problem space; however, it leaves the window of the solution wide open to explore.

\section{Search Behavior:}

Based on the characteristics mentioned above, a Problem oriented brief would encourage the following search behaviors.

\section{Space exploration:}

Exploration of Problem

Width

Depth Width

Exploration of Solution

Depth

The type of search process that this type of brief encourages is one where the exploration prioritizes an initial phase of deep exploration on a well fenced off problem space that aims at gaining deep understanding of the different variables of the problem. Consecutively, the phase of solution exploration fosters a wider and more distant exploration. 


\section{Search location:}

In this type of brief the combination of having a small and richly described problem and open and undefined solutions space with an undetermined goal encourages a distant search or in terms of Norman and Verganti, a radical innovation that aims at exploring new and unforeseen possibilities. This given the openness of what the outcome could be. However, this distance of the search can also be affected by time allocation and resolution of the outcome as less time and higher definition can push for more local searches.

\section{Time allocation:}

Pattern: Problem oriented briefs that have a defined starting point and an open-end state favors searches that do a broad exploration of possible solutions. This means that the balance in between how much exploration and how much development is performed would depend on the requirements of the resolution of the end result, how distant the search would be and how much time is allocated to the project and to each stage. In terms of chunking pattern, a first pattern of less incremental steps and rather bigger chunks or even integrated search in the problem space might be more beneficial to consider more of 
the overall problem system. As for the exploration of the solution space, a pattern of small chunks and incremental expansion stages. As shown by Baumann and Siggelkow (2013), teams that follow this pattern are more likely to reach global peaks.

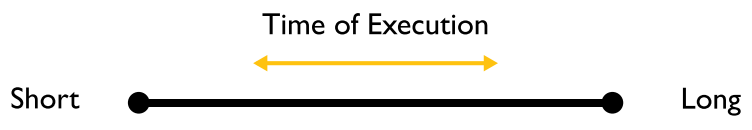

Time of execution: This consequently means that time needs to be allocated in both the deep exploration of problem space first and then in surveying many possible solutions to determine one that is preferable for later development. In terms of time distribution, a backloading pattern that ensures enough time for the final configuration of the desired solution and that allow a uniform expansion of the space might prove is likely. This in practical terms means that this type of briefs could operate under both short and long times of execution. However, the depth of exploration, the distance of the search and the resolution of the outcome will be affected by the amount of time assigned to the project's execution.

Resolution of the outcome:

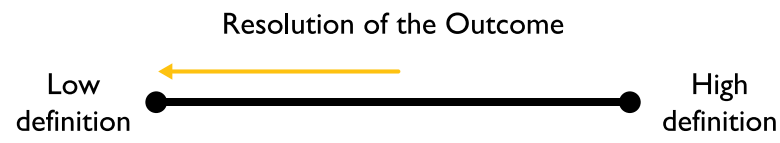

In this type of brief given the openness of the solution space and the possibilities of what it could be, can create a predisposition to a broad 
search for solution. This makes Problem oriented briefs more suitable for projects where the motivation for the search is more slack-focused or where the need for a solution that is ready to be integrated is not high. Rather this type of brief a would be more suited for encouraging exploratory searches. 


\section{Design Brief Type III: Solution Oriented Search}

A solution waiting for a problem to appear so that it can be tweaked

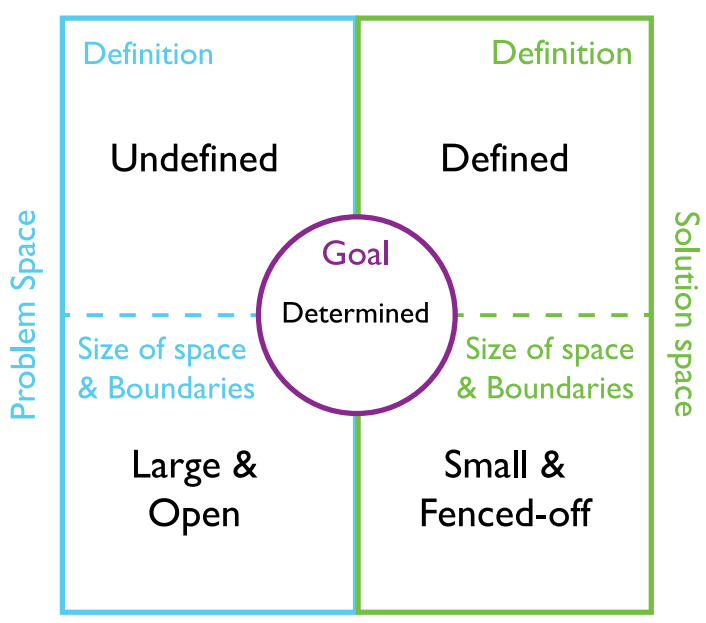

\section{Problem Characteristics:}

This type of brief has a clear end state and includes a description of what the desired outcome might be and the border between what needs to be included in the solution space and what does not is defined. However, the problem space is undefined and an important part of the search is to initially find it, define it and explore it. This type of brief refers more to projects where either a technology or a product needs to be situated in a position to generate value in an unknown problem space. This consequently means that the solution space is well fenced and there is a specific determined goal desired. In this type the desired goal is specified in a quantifiable way but not 
necessarily measurable, which still might indicate that a satisfactory outcome has been reached by fulfilling a set of condition. Based on the characteristics mentioned above we can then say that this type of brief is of the moderately-Structured Problems kind. Finally, this type of brief typically starts with a large problem space with no boundaries to be surveyed and a small solution space that includes some requirements.

\section{Example:}

“Traditional sensor systems for robotics and 3D reconstruction applications involve expensive laser scanners, stereo sensors or other 3D cameras. Sensor systems based on optical triangulation are widely used in profilometry and quality control. Phase shifting triangulation (PST) in particular is interesting for reasons of lower hardware cost potential, lower computational requirements and high near-range accuracy. PST involves projecting a coded light-pattern onto the environment and then measuring the phase shifts in the reflected light to decipher the $3 \mathrm{D}$ surfaces in the environment.

Develop a camera-projector prototype sensor system utilizing PST techniques and addressing the following points:

1. Comparison and evaluation of different encoding schemes (time series encoding, color encoding and spatial encoding).

2. Selection of an adequate camera/projector combination addressing technical, design and cost criteria. 
3. Synchronization of camera and projector to maximize the systems acquisition performance.

4. Design and implementation of an integrated sensor head containing projector and camera that is suitable for mobile robotics.

5. Demonstration of the capability of designed sensor system for mobile robotics and 3D measurement applications. For this purpose, the sensor head can be mounted on a mobile cart or on a mobile robot."

In this problem formulation we can observe that the solution space is well defined. At the same time the desired goal is very clear and nonambiguous. "Develop a camera-projector prototype sensor system utilizing PST techniques". However, the area where the problem is located is undefined and it is unclear what problems this solution might be addressing. A project of this type might have added value to offer, but at this point it is unclear under which circumstances the required solution generates that value.

\section{Search Behavior:}

Based on the characteristics mentioned above, a Solution oriented brief would encourage the following search behaviors.

\section{Space exploration:}

$$
\text { Exploration of Problem Exploration of Solution }
$$

Width

Depth Width

Depth 
The type of search process that this type of brief encourages is one where the exploration prioritizes an initial phase of broad exploration in the problem space in order to find a space that fits and generates value for the desired solution space. Once this wide exploration has provided a desirable problem space, depth can be gained in the matching solution space.

\section{Search location:}

In this type of brief the combination of having a large and undefined problem space and defined solution space with a specific goal, fosters a search in the vicinity of the known solutions and outcome making a broader and more distant search less likely This in terms of types of innovation (Norman and Verganti, 2014) indicates that an incremental improvement within a frame of known solutions is more likely than a radical innovation. However, a more distant search can be achieved based on a less specific and detailed set of requirements in the solution space and a search process that proposes the use of the existing solution in areas or markets where said solution might prove a radical change to the existing solutions.

\section{Time allocation:}

Allocation Pattern

Exploration

Development 
Pattern: Solution oriented briefs that have a defined desired end state and an open starting point encourages both searches that explore the possible problems, but also look to properly develop solutions. The type of search that would follow this type of brief, would benefit from adopting a chunky search in the problem space (Bauman and Siggelkow, 2013) where the type of chunking pattern benefits from a small chunks and incremental expansion of the problem space, in order to avoid focusing on a local area. However, for the solution space, a pattern of integrated search that takes into consideration the overall solution system and all of its requirements or a chunky pattern with larger chunks with less incremental expansion could be more beneficial as it considers more elements of the overall system together.

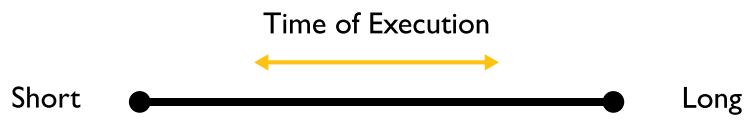

Time of execution: For this type of brief the solution space provides an initial fence around the desired outcome, which in turn could provide a hint of what a relevant problem space might be. However, a large amount time must spent finding and surveying the problem space in order to gain a better understanding of where the defined solution space and the desired goal would be a better fit. The team would need to explore the problem spaces in a small chunks and incremental patterns meaning that time needs to be allocated in a fixed time pattern to allow a uniform expansion of the space in a front-loaded pattern that prioritizes exploration of the problem. This in practical terms means that this type of briefs could operate under both short and long times of execution. However, the extensiveness 
of the number of problem spaces that are taken into account and the resolution of the outcome might be affected by the time assigned, where a high resolution and distant search would need a longer time of execution.

\section{Resolution of the outcome:}

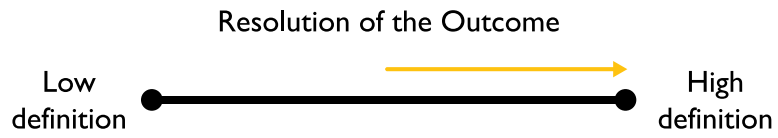

In this type of brief, given the openness of the problem space and the possibilities of where a set solution could be placed can create a disposition to a broad search for a problem and an in-depth development of the solution. This makes Solution oriented brief more suitable for projects where the motivation for the search is more problemistic-focused or where the need for a solution that is ready to be integrated into an unknown problem space is high. This means that this type of search could yield a higher definition outcome. 


\section{Design Brief Type IV: Discovery Oriented Search}

A project looking for both a problem and a solution

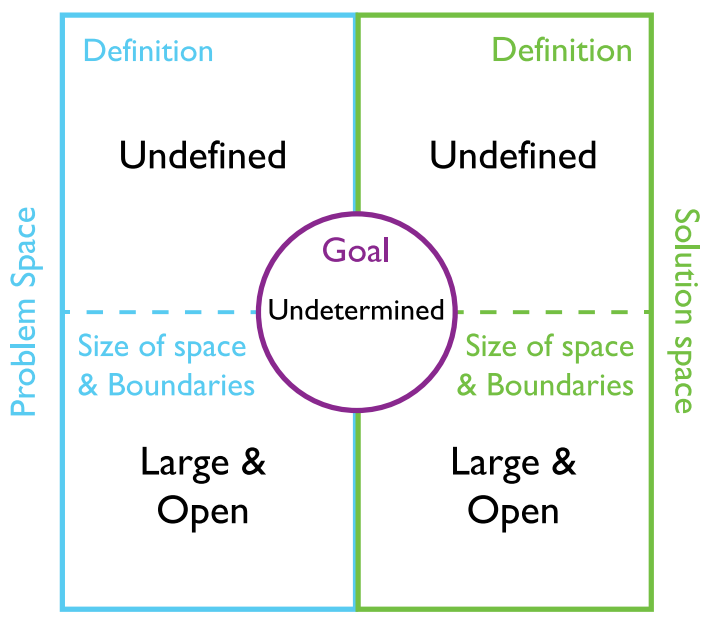

\section{Problem Characteristics:}

This type of brief does not have a clear beginning or end state as a consequence of both the problem and solution space being undefined. However, some indication of either or both needs to exist which provides rather wide spaces to define, fence and search. The desired goal in this type of brief is undetermined and does not indicate a clear end state. However, some indication of possible goal interest in solving an issue, or simply the unguided exploration of the solution space might indicate that a satisfactory outcome has been reached. However, other mechanisms of acceptance of the solution need to be used in order to determine that a 'good enough' solution has been 
reached and the search can be stopped. Based on the characteristics mentioned above we can then say that this type of brief is of the Ill-Structured kind as less of definition of the spaces is presented. Given that a large exploration for problems and solutions need to be performed, there are multiple activities and tasks that need to take place. Hence, this type of brief typically starts with large problem space to be survey and a large solution space to be defined and surveyed.

\section{Example:}

"Invent the 'assisted driving experience' of the 60/80 years old population in $2020-2025$

Challenges: Tackling physical and cognitive impairments, acceptation of new technologies, and transgenerational relationship

Key questions identified so far: How to redesign the humanmachine interface for the assisted driving experience? How to forecast the evolution of needs from today with social devices (phone, tablets) that will have an influence on the cockpit for seniors? What are the differences between age groups?"

In the more extreme cases of discovery-oriented search briefs, it is not strange to find even more undefined challenges as the one in this second example:

"How can nature inspire the next generation of water treatment, transport, or analysis technologies?” 
In this problem formulations we can observe that none of the spaces is defined and the desired goal is very open and undetermined. The area where the problem is located is undefined and it is unclear what problems this solution might be addressing, even if we can use intuition or our own experience, the brief does not provide it. Furthermore, the area where the solution might be located is undefined and it will greatly depend on what problem space is found and defined.

\section{Search Behavior:}

Based on the characteristics mention above a Discovery Oriented briefs will encourage the following search behaviors.

\section{Space exploration:}

Exploration of Problem

Width

Depth Width

Exploration of Solution

Depth

A project of this type is very open, and it would benefit projects that have a more slack-driven motivation, where the idea is to explore as much of the problem space or even spaces as we can and then, within those, explore as many solutions as possible. This means that this type of exploration prioritizes a wide exploration of the problem space and solution spaces which then limits the amount of depth that can be gained within a given time period. 


\section{Search location:}

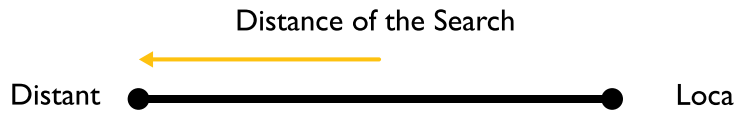

The combination of having big and undefined spaces and an open and undefined goal, encourages a wider search for more distant solutions where more radical innovations could be found (Norman and Verganti, 2014). However, a more distant search that provides a wider exploration and that varies greatly from existing solutions represents a greater risk associated with experimenting with unknown and new outcomes (Gavetti \& Levinthal, 2000).

\section{Time allocation:}

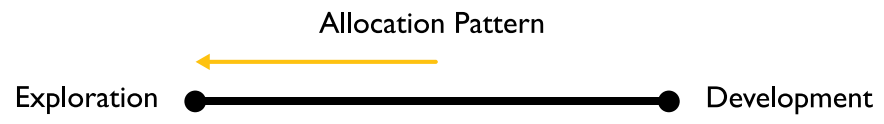

Pattern: Based on the openness of Discovery Oriented briefs in both the starting point and the end point, this type would favor exploratory searches rather than solution development ones. The type of search that this type of brief encourages, is one that adopts a chunky search both in the problem space and the solution space (Bauman and Siggelkow, 2013) rather than an integrated search. Given the amount of unknown information that needs to be uncovered, the possibility of considering the complete system at once is limited, so it needs to be chunked both the problem and solution space. The chunking pattern that might provide a better fit for this type of process would be one of 
smaller chunks and incremental expansion. However, of those smaller chunks the largest chunk might be consider in the beginning and incremental expansion of several stages of smaller chunks throughout the whole search process as suggested by Baumann and Siggelkow in their findings.

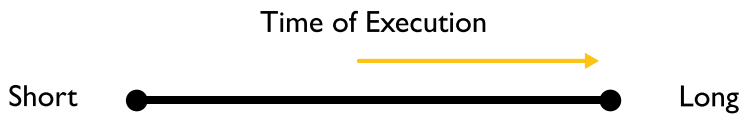

Time of execution: For a Discovery oriented brief the kind of search process where both spaces need to be defined, fenced and explored more time must be spent in both spaces which consequently means that time needs to be equally allocated in both in order to not run the risk of not exploring the problem space enough or not developing the solution space enough. This represent a higher amount of time be used in the completion of the project in comparison to any of the types before this one. This in practical terms means that this type of briefs is more appropriate for projects with long times of execution.

Resolution of the outcome:

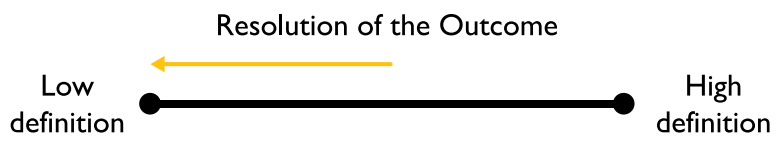

A project that uses a brief of Discovery oriented is as open as they come, and suits the slack-driven exploration where a wide exploration of the problem is just as desirable, or even more desirable, than a definite outcome The production of a bank of problems and ideas is 
more attractive. The need to spend large amounts of time defining the problem and searching for solutions means that the kind of outcome would be low-resolution or even 'raw' ideas to further develop at a later time. 


\section{A Brief}

\section{Discussion}

of Outcomes

and Future

Possibilities 
Chapter 6

\section{A Brief Discussion of Outcomes and Future Possibilities}

\subsection{Thinking/Talking Tool}

One of the main objectives of this thesis from the beginning has been to better understand what makes a good brief and the role that problem formulations in the design brief play for the design process and the outcome. Part of this objective was to somehow generate a tool for practitioners to better understand and consider the different elements of a formulation for their intended goal. In the process of doing this research, the codex that I used to discern the different elements of the briefs I studied transformed into a tool that can be used to start a conversation about their project before it starts and aid reasoning. The objective would be to both be mindful of what is known about the problem to be tackled and the desired goal to be achieved but also about what possible design process might follow based on how we present that information. The ultimate goal would be to reduce the potential mismatch of expectations and misunderstandings in between the problem formulators and the design team charged with solving said problem.

The Thinking/Talking Tool is then here presented and with this discussion my aim is to provide clarity on how this tool in combination 
with the typology of four well described ideal types, can provide a better understanding of a design project at the outset. The function that it aims to provide is not that of a contract but rather as a common ground for discussion and sharing of points of views. The reasoning and the give and take that it generates will probably be more important than the neatly filled in boxes themselves.

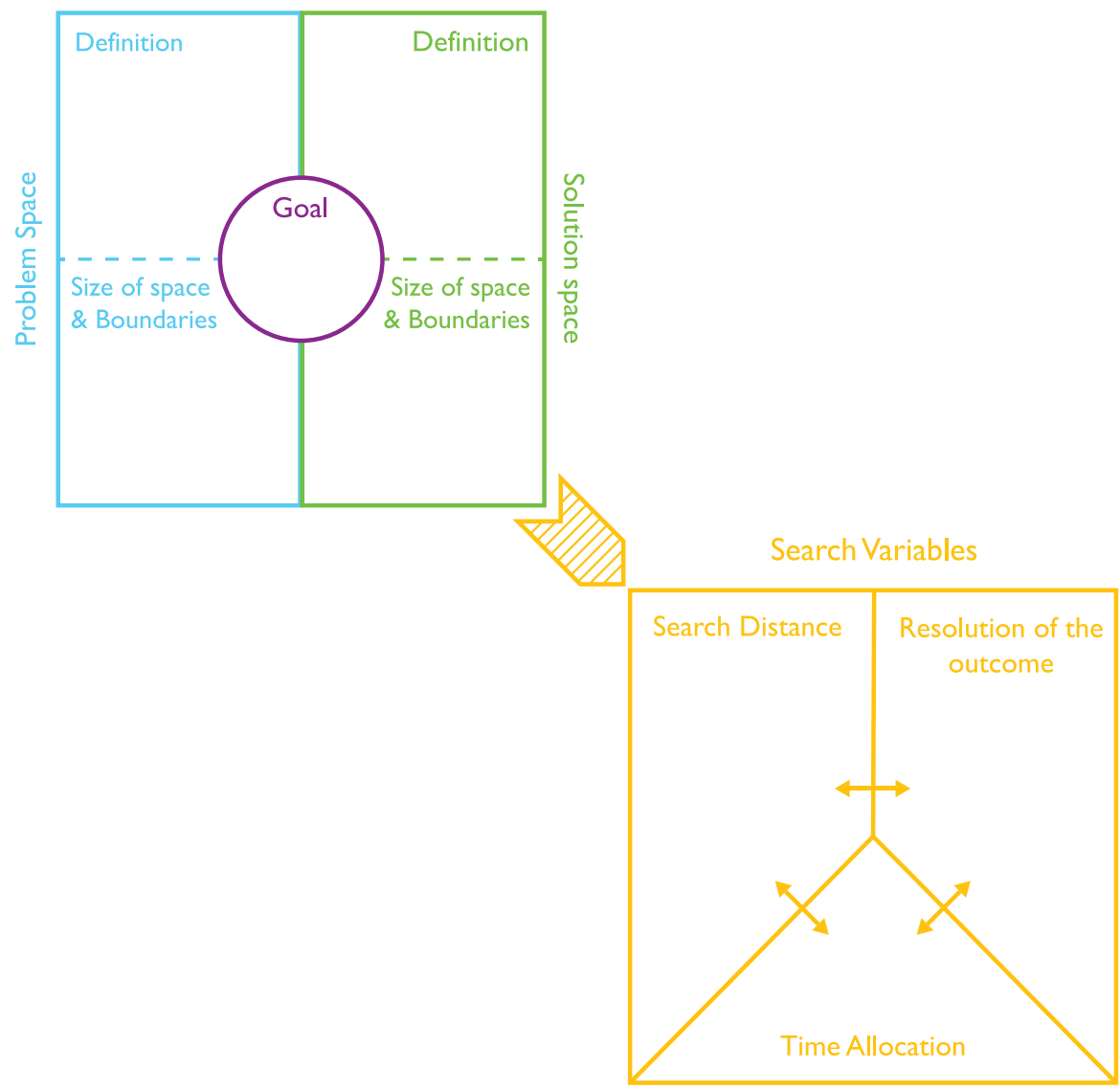

Figure 22. Thinking/Talking Tool 
The tool as can be seen in figure 22, consists of a canvas-like shape that relates on one side to the knowledge about the design space, which contains the problem space, the desired goal to be achieved, and the solution space. In the other side it contains three variables that relate to the search process and the conditions under which the search for solutions should take place.

\section{Design space}

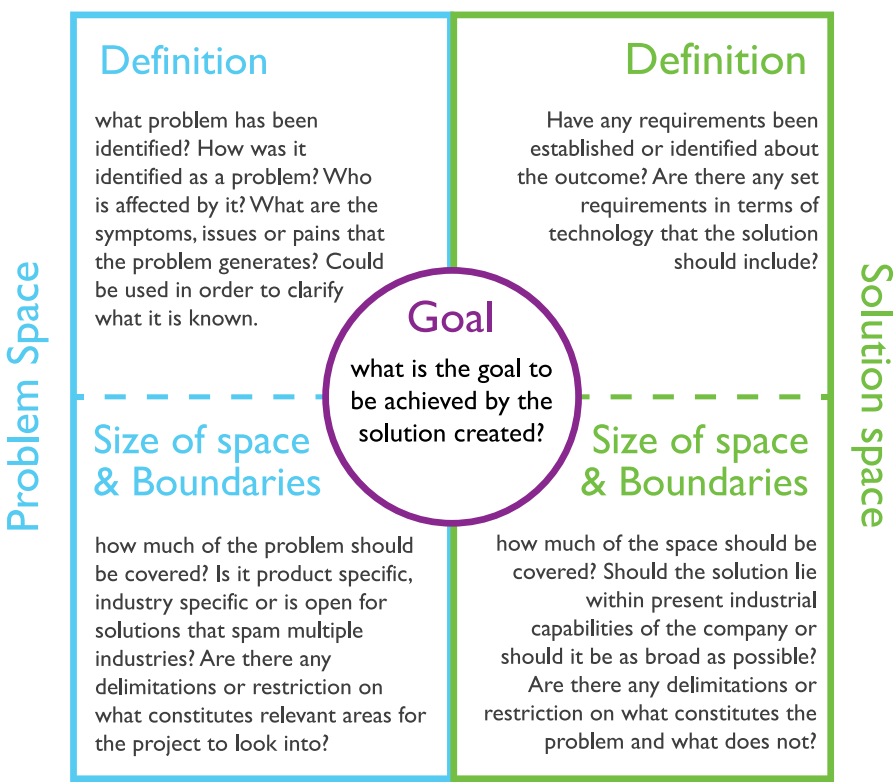

Figure 23. Design Space Tool

This part of the thinking/talking tool provides the problem formulators a space to reflect and record what is known about the problem that is to be formulated. The idea in this area is to also question how much information is known beforehand but it does not necessarily mean that said information has to be known. It is possible 
that part of the design process of the specific project is to investigate and uncover this information, but it is important to stipulate that as part of the objective of the process.

Goal: At the center of the design space knowledge is the goal to be achieved and what has been defined about it. The central question in this subsection is: what is the goal to be achieved by the solution created? The goals can be presented in the brief as a guiding question or statement that could help the design team to detect or established a satisfactory outcome. Goal definitions span from open and unmeasurable such as "improve quality of life" to specific and measurable such as "reduce time in X process by $20 \%$ ".

Problem space: On the left side, comes the information that is known about the problem that the project would be addressing and is divided into two subsections. The first subsection, which is located on the top left corner, involves the amount of knowledge of the problem that has already been uncovered. Questions such as what has been identified? How was it identified as a problem? Who is affected by it? What are the symptoms, issues or pains that the problem generates? Could be used in order to clarify what it is known. The second subsection, on the bottom left corner, incorporates limitations that can be added to the problem space. In this section, questions such as, how much of the space should be covered? Is it product specific, industry specific or is open for solutions that spam multiple industries? Are there any delimitations or restriction on what constitutes relevant areas for the project to look into?

Solution space: On the right side comes the information that is known about the character of the desired solution and it is also divided into 
two subsections. The first subsection, which is located on the top right corner, involves the amount of knowledge that has been identified about desired elements of the possible solution. In this section the main guiding question would be: Have any requirements been established or identified about the outcome? The second subsection, on the bottom right corner, incorporates limitations that can be added to the solution space. Similar to the limitations of the problem space in the previous bottom left section, the main guiding questions relate to how delimited the solution space is. In practical terms this question would be how much of the space should be covered? Should the solution lie within present industrial capabilities of the company or should it be as broad as possible? Are there any delimitations or restriction on what constitutes the problem and what does not? Are there any set requirements in terms of technology that the solution should include?

\section{Search Variables}

\section{Search Variables}

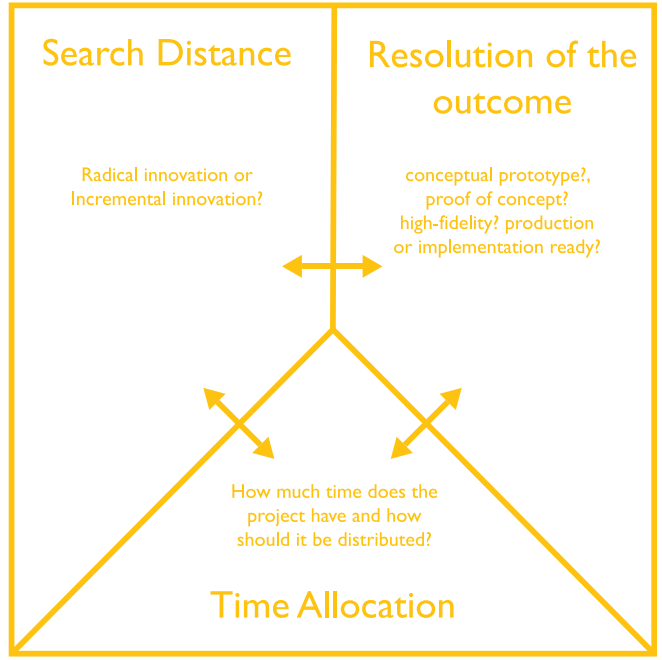

Figure 24. Search Varaibles Tool 
The part of the thinking/talking tool provides a space to reflect and record what is known, desirable or advisable regarding three different variables of the search process. In this section there is the possibility that these variables have been established before the brief has been decided, such as the case of the projects analyzed in this thesis, which means that the brief should accommodate to them. The other possibility is that after the problem has been identified then these three variables are stipulated based on what is defined in the previous design space section.

Search Distance: On this subsection the central point of discussion is the desirable level of distance from the solutions that already exist or level of innovation from the outcome. The discussion that follows here should revolve around the aspirational level of innovation that the project aims to pursue. It should be taken into account that pursuing a radical innovation that is distant from what exists has different effects on the design process than an incremental or local innovation might have.

Resolution of theoutcome: On this subsection the point in consideration is the level of resolution that the final solution presented at the end of the project should have. A final solution might be presented in a conceptual way, as a proof of concept or in very high-fidelity ones that are production or implementation ready.

Time Allocation: The final subsection refers to the amount of time allocated for the completion of the process. This is a straightforward section as it considers the length of the project, however, a second variable of how the time is distributed, might be left for the design team to establish or in case of a controlled design processes such as 
education programs or corporate guiding methodologies this might be pre-established.

Considerations and interrelations: In the case of the last three variables, it has to be considered that there is an interrelation among them and the change of one will affect the other and the deciders must balance which factor are more desired or important. A distant search for a radical innovative solution would be more likely to need more time of development as more options need to be considered, tested and elaborate. A search for distant solutions that culminate in radical innovation that is also high-fidelity ready for implementation would need more time of development and will incur a higher risk than a local search that ends in a proof of concept. A project that has a short and set time limit would be less ideal for a distant search or for a high-fidelity outcome.

\subsection{An Example of How This Can Be Used}

\subsubsection{The Typology In A Known Search Process}

Part of the motivation for this thesis, as explained in Chapter 3., came from my observations and experiences in design processes such as the ones in the ME310 projects. Part of those observations were about the relation that a design brief has to the process that follows, and the different roads that different teams might have within the same pre-established design process. This observation leads me to the discussion of what might be expected in said established process if we have an idea of what the starting point might be. In this thesis I did not look into the process of problem re-definition and follow up on what happened in each project that my briefs started. That will 
be a next step in future research. However, the projects all follow the same rhythm of missions and prototypes that aim to steer the process in certain directions and encourage certain search behaviors. This is the intended design process of all projects in my brief database and I would like to put the typology to use in relation to this process to show how it can be used. This is hence a situation where time is a set and non-negotiable factor, level of outcome is also set, as well as the required prototyping steps. This means that either the briefs need to be tweaked to the process, or the non-set parts of the process have to be actively managed and the teams 'herded' to make sure that each project arrives at each prototype mission with the right input and output despite varying starting points.

In order to discuss this, I would first like to describe the type of design process that the ME310 projects have in the same theoretical terms as the ones used in the typology. In terms of the thinking/talking tool, these projects have a defined search variables section and from this we can then observe and discuss the possible consequences for the design spaces definition.

The first variable that is known about the projects is Time Allocation both in terms of the amount of time allocated and the pattern used. The projects have a pre-established duration of 9 months from October to June, and this is for many students done in parallel to other courses. Time is distributed in a uniform chunking pattern that in the first half prioritizes exploration and the second half prioritizes development. Each prototype mission further represents a given chunk of two to four weeks. The second set variable is the Search Location. The aim of the projects is to have radically innovative solutions. They should produce a "Wow!" rather than a "Thank you." 
from the corporate sponsors (Leifer, personal communication, May 10, 2018). This requires distant search that pushes for divergence in missions such as Dark Horse Prototype and Funky System Prototype and the encouragement of novelty is important. The projects emphasize 'on-line' evaluation mode (Gavetti \& Levinthal, 2000) through the strong reliance on prototyping and testing. Finally, the last aspect that is set is the Resolution of the outcome that the teams produce. As part of the final results of the project the design teams present a final high-fidelity solution along with a 'business case' that relates to the adoption of the solution by the commissioning industry partner.

Given these known conditions, we can then argue that in this type of search process a certain type of design brief might thrive more than others. According to the intended design process and the expected resolution and distance of the final outcome we can argue that there needs to be a balance in between how much information or knowledge of the spaces can be provided.

If we consider the first half of the process which is the divergent phase, the teams receive a limited amount of time of space exploration in the Benchmarking and need-finding mission, to establish a baseline of critical elements before the CFP/CEP mission. This means that in a very open or undefined problem and solution space with an open and undefined goal, which fosters wide exploration, the teams might not be able to gain enough depth into the problem space to establish a proper baseline. However, a constrained and defined problem and solution space can limit the amount of distance of exploration and deviancy of elements that a team can consider. 
On the other hand, if we consider the second half of the project where the solution takes shape, a too constrained solution space with a clear and measurable goal might restrain or fixate (Cardoso \& BadkeSchaub, 2011) the team into considering only a limited amount of possibilities that can be produced. This then goes against one of the intended outcomes of the process in the distance of the search and how radically different it is from what exists. However, an open and undefined solution space that produces a distant solution needs longer periods of exploration, limiting the amount of resolution that can be gained.

A team that gets a Directed Search type of brief, where the problem they should solve is fairly well-known and fenced off and a solution indicated, the Space Exploration mission will be quite comfortable and can be focused on adding depth to the already defined problem area. The first stab at a solution in the CEP/CFP prototype where they need to identify a critical function or experience will follow naturally. The challenge for the team with this type of brief will be to push the solution far enough in terms of distance from current solutions and to avoid fixation on the available solution description, which may or may not be a good one.

A team that gets a Problem Oriented Search brief, with a decently fenced off problem space to be searched, which gives the possibility of depth within a short timeframe, and a large and open solution space where there is opportunity to find the unexpected will probably have the brief that is most adapted for the ME310 journey. This brief will also make the Space Exploration mission comfortable. They can 
gain depth in the problem space which should help direct the search in the solution space and temporarily take on only a critical chunk of it to be further explored in the CEP/CFP. The Dark Horse will then push the team to push the fences around the problem space before starting to converge.

A team that gets a Solution Oriented Search brief, where they have a solution (or an element of a solution) without a problem have a slightly more challenging start. The problem space to be explored in the Space Exploration first need to be discovered, and unless they are lucky this will take some time. The more fenced off solution space can however give some direction to the discovery process. If the problem space cannot be identified within the Space Exploration mission, the CEP/CFP may risk turning into a 'prototype for the sake of prototyping' and the Dark Horse, if still wrongly timed, may expand something that may already look 'infinite' to the team. The challenge here will be to find methods to more quickly navigate the problem space discovery process. However, once the fenced off problem space has been discovered, the team should be able to follow the design process.

Finally, a team that gets a Discovery Oriented Search brief, where both problem space and solution space are undefined will initially have very little to guide them. Here too, Space Exploration will be challenging since the problem space first needs to be discovered but this time the solution space will not be of much help. A challenge here will therefore be to quickly find a place to start, something that perhaps needs to be based on a quick but rather uninformed decision. 


\subsubsection{The Typology in a Setting With Multiple Goals and Differing Levels of Expertise}

An important element of the data used in this thesis has to do with the fact that the design process in the frame of the projects serves a dual purpose. On the one hand, the projects are real design projects that follow the same rigor and the same considerations of quality and high expectations that a professional design project might have. On the other hand, the projects are part of an educational platform that aims to educate students in the use of the design thinking methodology and user centered design and to do so in a high complexity, collaborative and ambiguous real-life project setting. In the services of these dual goals the design brief can also be an important part to consider.

As part of the definition of the ME310 course Domingo et al., (2020) explain the educational purpose of each of the two phases and of each of the missions. The structure of the course is one that has been predefined and follows a set number of mission and assignments that all groups should accomplish and complete. The times of deliverables, the requirements of each mission and the outcomes in which they are coached and evaluated remain the same for all. With this in mind it is also important to understand that the different projects, depending on their starting point, will experience different difficulties that might be attached to their particular project. A design team that is provided a broad, undefined design space, the same time of exploration might not reach the same level of depth of exploration of the problem as one that has a more defined design space. On the other hand, a team that has been provided a very delimited and specific solution space might struggle to generate more deviant ideas in the divergent part of the process given the constrained requirements that must be meet. 
Another aspect to take into consideration might be the aspirational goals of the industry partner versus the intended process that the team must follow. As explained before a design exploration might have different motivations attached to it. Some searches are problemdriven, and they aim to obtain a solution to a given problem, others are more slack-driven, and the aim might be to explore as many scenarios as possible. The level of resolution of both types might be different as one needs a solution that is more defined and addresses the problem while the other might benefit from a wide but unrefined exploration that provides a 'bank of ideas'. From the perspective of the design teams and their outcomes this becomes irrelevant as they should all present a complete and high-resolution prototype at the end of the process which limits the amount of time that can be used to do a wide exploration of solutions. This does not mean that the projects are not useful for a slack-driven search but rather to understand the limitations of the set-up and that the search processes of different projects may need to be managed differently. The processes within the different prototyping missions and for example coaching sessions, workshops and exercises aimed at reframing, could very well change the path and this is something that I want to look into in future work. These projects are also carried out by students who sometimes have little design experience when they begin. A project team of experienced designers either in terms of method or project content would be an interesting contrast.

\subsection{Future Work}

In the work done in this thesis several things have been taken into account regarding the design process from a theoretical perspective and the problem formulation and design briefs from both the 
theoretical and the practical perspective. One of the variables that played a key role in this was the understanding that the design brief, as a document, represents the starting point of the design process. In it, one party transfers the knowledge and information that they have gained about a problem that has been identified to another party. This, as I have mentioned before can represent the point of $t=0$ for the start of the project, and the brief is the first snapshot that the design team receives. This led to the creation of a typology of briefs to help identify the structure of how this first picture looks. Consecutively, I explored and hypothesized how, from a theoretical perspective, this initial picture of the problem can play an important role on the following search process for solutions. From here there are other things that can be explored to further understand the relation of the design brief to the design process and the consequences that this can have on the outcome.

As mentioned before this typology of briefs represent a first snapshot of how the problem has been framed (or not) by the commissioning party. One of the future works that can follow this thesis would be to use the design brief typology to define the starting points and the logic of the ensuing search process as a steppingstone for studying the actual projects that followed these briefs. This could be done retrospectively, while at the same time also following a few new projects live. The possibility to follow ongoing projects could allow to better understand the different dynamics and elements at play in the process of using the design brief and to enrich our understanding of the rather clean simulated search behaviors with behaviors from a real design setting. One of the important elements of this would be to understand the role that the re-framing activity has in the search process. 
Another important element that can be part of future work and future studies, especially in the relation to the activity of reframing, could be to study the design practitioner with different levels of design expertice and the relation they have to the initial design brief.

Finally, yet another possible area of future work can relate to the initial brief as a source of fixation. So far in the studies of design fixation, the empirical studies have been focused on controlled laboratory experiments where the participants are presented outside stimuli in which, good and bad examples of existing solutions are presented to them. Later in the studies the researchers analyzed the number of elements in the final solution that can be traced back to the introduced stimuli. If we think of the design briefs as the initial stimuli, what is the influence as an element of fixation that it can have on the final solution? The framing of both the problem space and the solution space can become elements that are hard to displace from the designer's mind. 


\section{A Not so}

\section{Brief List of}

References 
Chapter 7

\section{A Not So Brief List of References}

Archer, B. (1979). Design as a discipline. Design Studies, 1(1), 17-20.

Augier, M., \& March, J. G. (2008). A retrospective look at A Behavioral Theory of the Firm. Journal of Economic Behavior and Organization, 66(1), 1-6.

Baer, M., Dirks, K. T., \& Nickerson, J. A. (2013). Microfoundations of strategic problem formulation. Strategic Management Journal.

Baumann, O., \& Siggelkow, N. (2013). Dealing with complexity: Integrated vs. chunky search processes. Organization Science, 24(1), 116-132.

Billinger, S., Stieglitz, N., \& Schumacher, T. R. (2014). Search on rugged landscapes: An experimental study. Organization Science, 25(1), 93-108.

Blyth, A., \& Worthington, J. (2010). Managing the Brief for Better Design. In Managing the Brief for Better Design.

Bogers, T., Van Meel, J. J., \& Van Der Voordt, T. J. m. (2008). Architects about briefing: Recommendations to improve communication between clients and architects. Facilities, 26(3-4), 109-116.

Buchanan, R. (1992). Wicked Problems in Design Thinking Author ( $s$ ): Richard Buchanan Published by : The MIT Press. Design Issues, 8(2), 5-21.

Campbell, D. T. (1960). Blind variation and selective retentions in creative thought as in other knowledge processes. Psychological Review, 67(6), 
380-400.

Cardoso, C., \& Badke-Schaub, P. (2011a). Editorial: Fixation or inspiration: Creative problem solving in design. Journal of Creative Behavior, 45(2), 77-82.

Cardoso, C., \& Badke-Schaub, P. (2011b). The influence of different pictorial representations during idea generation. Journal of Creative Behavior, 45(2), 130-146.

Chen, W. R. (2008). Determinants of firms' backward- and forward-looking R\&D search behavior. Organization Science, 19(4), 609-622.

Conklin, J. (2006). Wicked Problems and Social Complexity. Dialogue Mapping: Building Shared Understanding of Wicked Problems.

Cox, G. (2005). COX Review of Creativity in Business. UK Treasure.

Crilly, N., \& Cardoso, C. (2017). Where next for research on fixation, inspiration and creativity in design? In Design Studies (Vol. 50, pp. 1-38).

Cross, N. (1982). Designerly ways of knowing. Design Studies, 3(4), 221227.

Cross, N. (1999). Design Research: A Disciplined Conversation. Design Issues.

Crossan, M. M., Lane, H. W., \& White, R. E. (1999). An organizational learning framework: From intuition to institution. Academy of Management Review, 24(3), 522-537.

Cyert, R. M., \& March, J. G. (1963). A behavioral theory of the firm. Englewood Cliffs, NJ, 2(4), 169-187.

Dell'Era, C., Buganza, T., Fecchio, C., \& Verganti, R. (2011). Language Brokering: Stimulating Creativity During the Concept Development Phase. Creativity and Innovation Management, 20(1), 36-48.

Dillon, D. R., O’Brien, D. G., \& Heilman, E. E. (2000). Literacy Research in the Next Millennium: From Paradigms to Pragmatism and Practicality. Reading Research Quarterly.

Domingo, L., Moore, D., Sirkin, D., Toye, G., Leifer, L., \& Cutkosky, M. 
(2020). . Proceedings of the Design Society: DESIGN Conference.

Dorst, K. (1997). Describing design. A comparison of paradigms. In Industrial Design.

Dorst, K. (2003). The Problem of Design Problems. Design Thinking Research Symposium 6, 4(Creativity and Cognition Studio Press), 135-147.

Dorst, K. (2015). Frame Innovation: Create new thinking by design. In The MIT Press.

Dorst, K., \& Dijkhuis, J. (1995). Comparing paradigms for describing design activity. Design Studies, 16(2), 261-274.

Doty, D. H., \& Glick, W. (1994). Typologies as a Unique Form of Theory Building : Toward Improved Understanding and Modeling. Academy of Management Review, 19(2), 230-251.

Dreyfus, H. L. (2003). The Spinoza lecturesTitle.

Ekströmer, P., Nåbo, M., Pavlasevic, V., Eklöf, D., \& Wever, R. (2017). Challenging briefs; learning through client and designer roles in freshmen design education. Proceedings of the 19th International Conference on Engineering and Product Design Education: Building Community: Design Education for a Sustainable Future, E and PDE 2017, September, 400-404.

Gadamer, H.-G., Bernstein, R. J., Walker, N., \& Bernasconi, R. (1988). The Relevance of the Beautiful and Other Essays. The Journal of Aesthetics and Art Criticism.

Gavetti, G., \& Levinthal, D. (2000). Looking forward and looking backward: Cognitive and experiential search. Administrative Science Quarterly, 45(1), 113-137.

Gavetti, G., Levinthal, D., \& Ocasio, W. (2007). Neo-Carnegie: The Carnegie School's past, present, and reconstructing for the future. Organization Science, 18(3), 523-536.

Goldkuhl, G. (2012). Pragmatism vs interpretivism in qualitative informa- 
tion systems research. European Journal of Information Systems.

Gregory, S. A. (1966). Design Science. In The Design Method.

Hatchuel, A. (2001). Towards design theory and expandable rationality: The unfinished program of Herbert Simon. Journal of Management and Governance, 5(3-4), 260-273.

Hatchuel, A., \& Weil, B. (2009). C-K design theory: An advanced formulation. Research in Engineering Design, 19(4), 181-192.

Hayes, J. R., \& Simon, H. A. (1977). Psychological Differences am Problem Isomorphs. Cognitive Theory.

Hey, J. H. G., Joyce, C. K., \& Beckman, S. L. (2007). Framing innovation: negotiating shared frames during early design phases. Journal of Design Research.

Hobday, M., Boddington, A., \& Grantham, A. (2011). An innovation perspective on design: Part 1. Design Issues.

Hoppe, R. (2002). Cultures of public policy problems. Journal of Comparative Policy Analysis: Research and Practice, 4(3), 305-326.

Hothersall, S. J. (2019). Epistemology and social work: enhancing the integration of theory, practice and research through philosophical pragmatism. European Journal of Social Work, 22(5), 860-870.

Joseph, S. (1996). Design systems and paradigms. Design Studies.

Ill-structured problems (n.d.). In oxfordreference.com. Retrieved from https://www.oxfordreference.com/view/10.1093/oi/authority.20110803095957654

Kaushik, V., \& Walsh, C. A. (2019). Pragmatism as a research paradigm and its implications for Social Work research. Social Sciences, 8(9).

Knudsen, T., \& Levinthal, D. A. (2007). Two faces of search: Alternative generation and alternative evaluation. Organization Science, 18(1), 39-54.

Koronis, G., Chia, P. Z., Siang, J. K. K., Silva, A., Yogiaman, C., \& Raghunath, N. (2019). An Empirical Study on the Impact of Design Brief 
Information on the Creativity of Design Outcomes with Consideration of Gender and Gender Diversity. Journal of Mechanical Design, Transactions of the ASME, 141(7), 1-14.

Lawson, B. (2006). How designers think. In How Designers Think.

Leifer, L. (May 10, 2018) Personal communication [Email].

Levinthal, D. A. (1997). Adaptation on rugged landscapes. Management Science, 43(7), 934-950.

Levinthal, D., \& March, J. G. (1981). A model of adaptive organizational search. Journal of Economic Behavior \& Organization, 2(4), 307-333.

Lumsden, C. J. (1999). Evolving creative minds: Stories and mechanisms. Handbook of Creativity, 1(1), 153-168.

Lyles, M. A., \& Mitroff, I. (2020). Organizational Problem Formulation: An Empirical Study Author ( s ): Marjorie A . Lyles and Ian I . Mitroff Source: , Vol. 25, No . 1 ( Mar ., 1980 ), pp . 102-119 Published by: Sage Publications, Inc . on behalf of the Johnson Graduate School of Ma. 25(1), 102-119.

March, J. G. (2010). The ambiguities of experience. Cornell University Press. March, J. G., \& Simon, H. A. (1993). Organizations. 1958. NY: Wiley, New York.

Maxcy, S. J. (2003). Pragmatic threads in mixed methods research in the social sciences: The search for multiple modes of inquiry and the end of the philosophy of formalism. In Handbook of mixed methods in social and behavioral research.

Meissner, H., Creswell, J., Klassen, A. C., Plano, V., \& Smith, K. C. (2011). Best Practices for Mixed Methods Research in the Health Sciences. Methods.

Mintzberg, H., Raisinghani, D., \& Theoret, A. (1976). The structure of" unstructured" decision processes. Administrative Science Quarterly, 246-275.

Morgan, D. L. (2007). Paradigms Lost and Pragmatism Regained. Journal of 
Mixed Methods Research.

Nadler, G. (1980). A timeline theory of planning and design. Design Studies, 1(5), 299-307.

Nelson, R. R., \& Winter, S. G. (1982). An evolutionnary theory of economic change. Cambridge, Mass. and London, Belknap Harvard.

Newell, A., \& Simon, H. A. (1972). Human problem solving. Prentice-Hall.

Norman, D. A., \& Verganti, R. (2014). Incremental and radical innovation: Design research vs. technology and meaning change. Design Issues.

Osborne, A. F. (1957). Applied imagination. New York, NY: Scribner.

Pandza, K., \& Thorpe, R. (2009). Creative search and strategic sense-making: Missing dimensions in the concept of dynamic capabilities. British Journal of Management, 20(SUPP. 1), 118-131.

Pansiri, J. (2005). Pragmatism: A methodological approach to researching strategic alliances in tourism. Tourism and Hospitality, Planning and Development.

Paton, B., \& Dorst, K. (2011). Briefing and reframing: A situated practice. Design Studies, 32(6), 573-587.

Ralph, P. (2010). Comparing two software design process theories. Lecture Notes in Computer Science (Including Subseries Lecture Notes in Artificial Intelligence and Lecture Notes in Bioinformatics), 6105 LNCS, 139-153.

Reader, S. M. (2015). Causes of Individual Differences in Animal Exploration and Search. Topics in Cognitive Science, 7(3), 451-468.

Remington, K., \& Pollack, J. (2016). Tools for Complex Projects. In Tools for Complex Projects.

Rorty, R. (2000). Pragmatism. International Journal of Psycho-Analysis, 81(4), 819-823.

Ruiz, J., Bengtsson, M., \& Wever, R. (2018). This is how we roll; a play on creative thought and the generation of novelty. Proceedings of Meaningful Play 2018, 380-387. 
Ryd, N. (2004). The design brief as carrier of client information during the construction process. Design Studies.

Schön, D. (1983). The reflective practitioner: How professionals think in action. In The Reflective Practitioner: How Professionals Think in Action.

Schön, D. (1987). Teaching artistry through reflection in action. In Educating the reflective practitioner.

Schön, D. (1992). Designing as reflective conversation with the materials of a design situation. Knowledge-Based Systems.

Schumpeter, J. (1934). The theory of economic development Harvard University Press. Cambridge, MA.

Simon, H. A. (1955). A behavioral model of rational choice. Quarterly Journal of Economics, 69(1), 99-118.

Simon, H. A. (1969). The sciences of the artificial.

Simon, H. A. (1973). The structure of ill structured problems. Artificial Intelligence, 4(3-4), 181-201.

Simon, H. A. (1980). Models of Thought. The American Journal of Psychology.

Simon, H. A., \& Short, L. M. (1947). Administrative Behavior. The American Political Science Review.

Sirkin, D. \& Currano, R. (2020). Needfinding 1 Introducing Observation and Frames [PowerPoint presentation]. Retrieved from Stanford University ME310 course Website: http://our310.stanford.edu/

Smy, V., Cahillane, M., \& MacLean, P. (2016). Sensemaking and metacognitive prompting in ill-structured problems. International Journal of Information and Learning Technology, 33(3), 186-199.

Sosa, R., Vasconcelos, L. A., \& Cardoso, C. C. (2018). Design briefs in creativity studies. The Fifth International Conference on Design Creativity, 1-8.

Stanford ME310 course (2020). ME310 Intranet. Retrieved October 2020, 
The Problem of Formulating Design Problems

from our310.stanford.edu

Tether, B. (2006). The Role of Design in Business Performance. ESRC Centre for Research on Innovation and Competition (CRIC), 1-26.

Volkema, R. (2009). Natural language and the art and science of problem/ opportunity formulation: A transportation planning case analysis. Journal of the Operational Research Society, 60(10), 1360-1372.

Volkema, R. J. (1983). Problem Formulation in Planning and Design. Management Science, 29(6), 639-652.

Volkema, R. J. (1986). Problem formulation as a purposive activity. Strategic Management Journal, 7(3), 267-279.

Wahlstedt, L. (2013). Dynamic Knowledge Integration : A field study of an Information Systems Development Project. In Dynamic Knowledge Integration: A field study of an Information Systems Development Project.

Wever, R., Ruiz, J., \& Bengtsson, M. (2019). Structure versus Meaning: Client-Designer Dynamics around Sustainability Ambitions. EcoDesign 2019 Internation Symposium, 217-222. 
"There is no real ending. It's just the place where you stop the story." Frank Herbert 


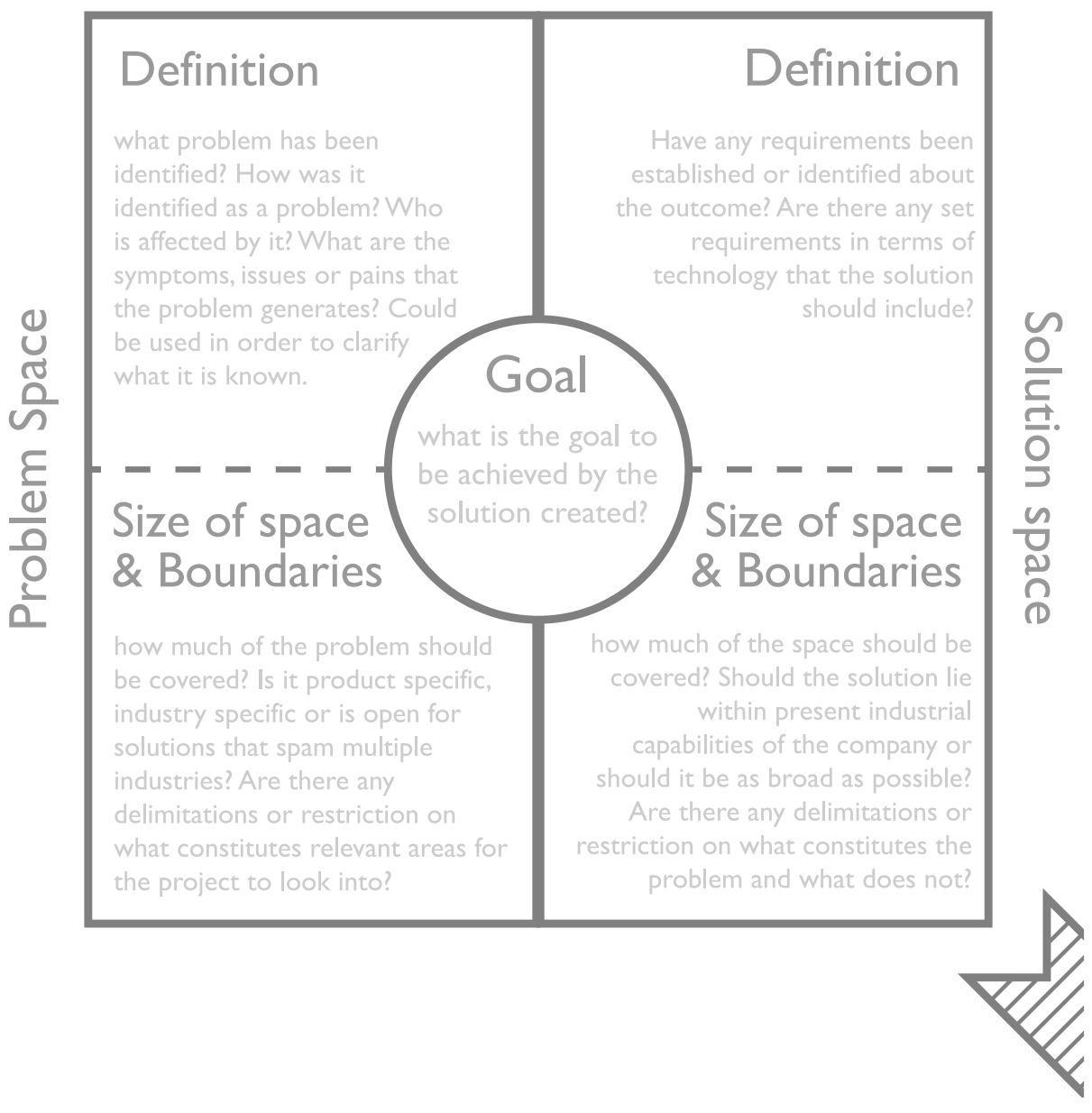

\section{You may use this space to Think \& Talk about your project's brief}


You may use this space to Think \& $x$ Talk about your project's brief

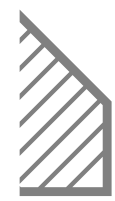

Search Variables

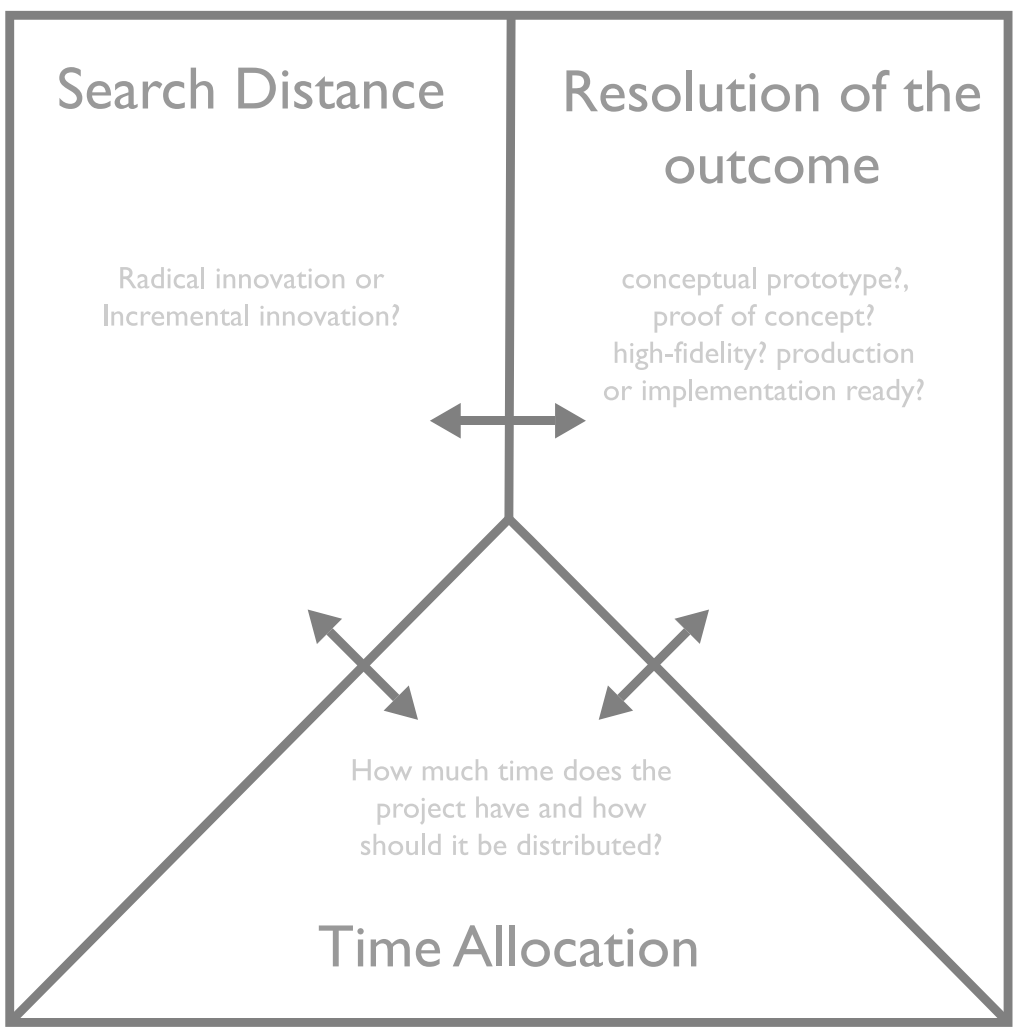


Notes 
Notes 
Notes 
Notes 


\section{FACULTY OF SCIENCE AND ENGINEERING}

Linköping Studies In Science And Technology. Licentiate Thesis No. 1895, 2020 Division of Product Realization

Department of Managment and Engineering

Linköping University

SE-581 83 Linköping,

Sweden

www.liu.se
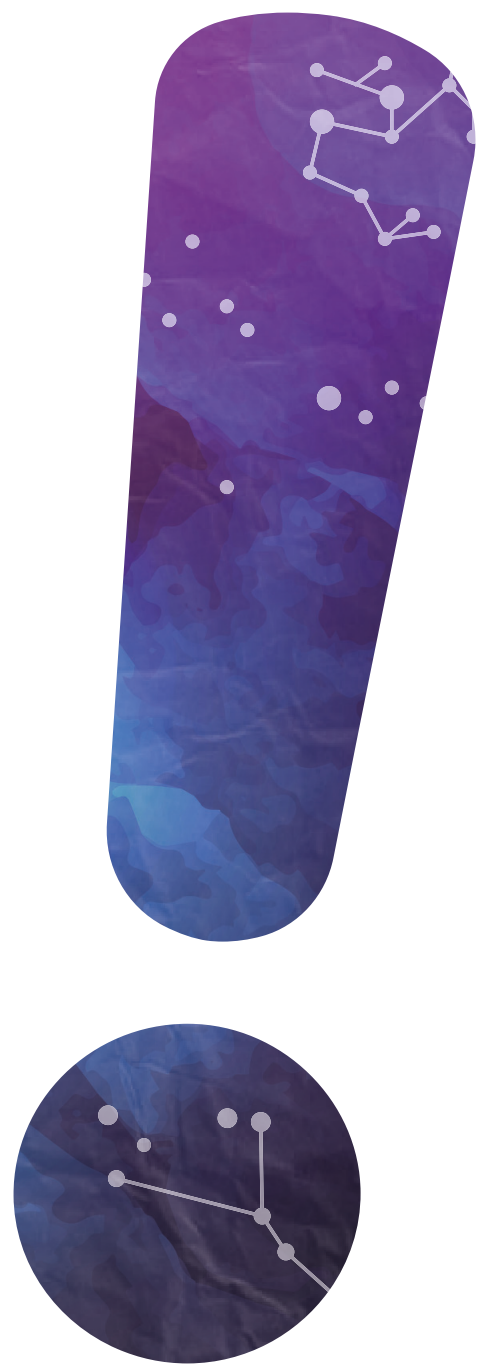